GAO Report to Congressional Requesters

August 2008

\title{
MILITARY PERSONNEL
}

DOD's and the Coast Guard's Sexual Assault Prevention and

Response Programs

Face Implementation

and Oversight

Challenges

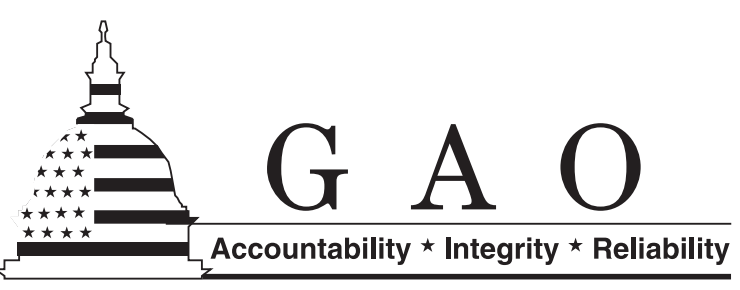




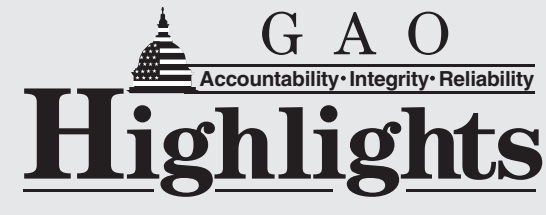

Highlights of GAO-08-924, a report to congressional requesters

\section{Why GAO Did This Study}

In 2004, Congress directed the Department of Defense (DOD) to establish a comprehensive policy to prevent and respond to sexual assaults involving servicemembers. Though not required to do so, the Coast Guard has established a similar policy. In response to congressional requests and Senate Report No. 110-77, GAO evaluated the extent to which DOD and the Coast Guard (1) have developed and implemented policies and programs to prevent, respond to, and resolve sexual assault incidents involving servicemembers; (2) have visibility over reports of sexual assault involving servicemembers; and (3) exercise oversight over reports of sexual assault involving servicemembers. To conduct this review, GAO reviewed legislative requirements and DOD and Coast Guard guidance; analyzed sexual assault incident data; and obtained through surveys and interviews the perspective on sexual assault matters of more than 3,900 servicemembers.

\section{What GAO Recommends}

GAO is suggesting that Congress consider requiring the Coast Guard to submit data to Congress on reported sexual assaults involving its members. GAO is also making a total of 11 recommendations to improve implementation of DOD's and the Coast Guard's programs, such as by reviewing and evaluating guidance and training, and to improve oversight of the programs. DOD and the Coast Guard concurred with our recommendations.

To view the full product, including the scope and methodology, click on GAO-08-924.

For more information, contact Brenda S.

Farrell at (202) 512-3604 or farrellb @ gao.gov.
MILITARY PERSONNEL

\section{DOD's and the Coast Guard's Sexual Assault Prevention and Response Programs Face Implementation and Oversight Challenges}

\section{What GAO Found}

DOD and the Coast Guard have established polices and programs to prevent, respond to, and resolve reported sexual assault incidents involving servicemembers; however, implementation of the programs is hindered by several factors. GAO found that (1) DOD's guidance may not adequately address some important issues, such as how to implement its program in deployed and joint environments; (2) most, but not all, commanders support the programs; (3) required sexual assault prevention and response training is not consistently effective; and (4) factors such as a DOD-reported shortage of mental health care providers affect whether servicemembers who are victims of sexual assault can or do access mental health services. Left unchecked, these challenges can discourage or prevent some servicemembers from using the programs when needed.

GAO found, based on responses to its nongeneralizable survey administered to 3,750 servicemembers stationed at military installations in the United States and overseas and a 2006 DOD survey, the most recent available, that occurrences of sexual assault may be exceeding the rates being reported, suggesting that DOD and the Coast Guard have only limited visibility over the incidence of these occurrences. At the 14 installations where GAO administered its survey, 103 servicemembers indicated that they had been sexually assaulted within the preceding 12 months. Of these, 52 servicemembers indicated that they did not report the sexual assault. GAO also found that factors that discourage servicemembers from reporting a sexual assault include the belief that nothing would be done; fear of ostracism, harassment, or ridicule; and concern that peers would gossip.

Although DOD has established some mechanisms for overseeing reports of sexual assault, and the Coast Guard is beginning to do so, neither has developed an oversight framework-including clear objectives, milestones, performance measures, and criteria for measuring progress - to guide its efforts. In compliance with statutory requirements, DOD reports data on sexual assault incidents involving servicemembers to Congress annually. However, DOD's report does not include some data that would aid congressional oversight, such as why some sexual assaults could not be substantiated following an investigation. Further, the military services have not provided data that would facilitate oversight and enable DOD to conduct trend analyses. While the Coast Guard voluntarily provides data to DOD for inclusion in its report, this information is not provided to Congress because there is no requirement to do so. To provide further oversight of DOD's programs, Congress, in 2004, directed the Defense Task Force on Sexual Assault in the Military Services to conduct an examination of matters relating to sexual assault in the Armed Forces. However, as of July 2008, the task force had not yet begun its review. Without an oversight framework, as well as more complete data, decision makers in DOD, the Coast Guard, and Congress lack information they need to evaluate the effectiveness of the programs. 


\section{Contents}

\section{Letter}

Results in Brief

Background

Implementation of Sexual Assault Prevention and Response

Programs Is Hindered by Inconsistent Support, Training That Is

Not Consistently Effective, and Limitations on Access to Mental Health Services

Survey Data Suggest That Occurrences of Sexual Assault May

Exceed Rates Reported

DOD and the Coast Guard Have Established Some Mechanisms for

Overseeing Reports of Sexual Assault, but Lack an Oversight

Framework, and DOD Lacks Key Information from the Services $\quad 39$

Conclusions

Matter for Congressional Consideration

Recommendations for Executive Action

Agency Comments and Our Evaluation

Appendix I

Scope and Methodology

Appendix II

Comments from the Department of Defense

Appendix III

Comments from the Coast Guard

Appendix IV

Disposition of Sexual Assaults in DOD and the

Coast Guard

Appendix V

DOD and Coast Guard Data on Reported Sexual Assault Incidents for Fiscal Year 2007 


\section{Tables}

Table 1: Percentage of Selected Servicemembers Who Reported Having Received or Having Not Received Required Sexual Assault Prevention and Response Training in the Preceding 12 Months

Table 2: Percentage of Selected Servicemembers Who Reported Having Received or Having Not Received Sexual Assault Prevention and Response Training Prior to Deploying

Table 3: Percentage of Selected Servicemembers Who Reported Receiving Required Sexual Assault Prevention and Response Training and Also Reporting They Would Not Know or Were Not Sure of How to Report a Sexual Assault Using the Restricted Reporting Option

Table 4: Percentage of Selected Servicemembers Who Reported Having Received Required Sexual Assault Prevention and Response Training, by Format of the Training

Table 5: Number of Selected Servicemembers Who Reported Having been Sexually Assaulted During the Preceding 12 Months

Table 6: Number of Selected Servicemembers Who Reported Experiencing a Sexual Assault within the Preceding 12 Months by Type of Reporting Option Used

Table 7: Number of Surveys Administered, by Location and Gender

Table 8: Dispositions of Alleged Offenders Resulting from Investigations Completed in Fiscal Year 2007, as of September 30, 2007

Table 9: Reasons Commanders Did Not Take Action Against Alleged Offenders in Investigations Completed during Fiscal Year 2007

Table 10: Dispositions of Alleged Offenders Resulting from Investigations Completed in Fiscal Year 2007, as of September 30, 2007 
Table 11: Number of Unrestricted Reports of Sexual Assault in DOD Made by Victims Who Were Either Servicemembers or Nonservicemembers and by Gender during Fiscal Year 2007

Table 12: Number of Investigations of Unrestricted Reports of Sexual Assault in DOD by Type of Offense during Fiscal Year 2007

Table 13: Number of Sexual Assaults by Type of Initial Allegation and Gender of Victims for Investigations Completed during Fiscal Year 2007 as of March 15, 2007

Table 14: Number of Restricted Reports of Sexual Assault in DOD by Type of Offense and Gender during Fiscal Year 2007

Table 15: Number of Investigations of Unrestricted Reports of Sexual Assault in the Coast Guard by Type of Offense during Fiscal Year 2007

Table 16: Number of Alleged Offenders and Victims in Reported Sexual Assault Incidents Involving Coast Guard Members during Fiscal Year 2007

Table 17: Number of Sexual Assaults by Type of Initial Allegation and Gender of the Alleged Victim for Unrestricted Reports Made during Fiscal Year 2007 in the Coast Guard

\begin{tabular}{ll}
\hline Abbreviations \\
DOD & Department of Defense \\
EAPC & Employee Assistance Program Coordinator \\
SARC & Sexual Assault Response Coordinator \\
UCMJ & Uniform Code of Military Justice \\
VA & Department of Veterans Affairs
\end{tabular}

This is a work of the U.S. government and is not subject to copyright protection in the United States. It may be reproduced and distributed in its entirety without further permission from GAO. However, because this work may contain copyrighted images or other material, permission from the copyright holder may be necessary if you wish to reproduce this material separately. 

August 29, 2008

\section{Congressional Requesters}

Sexual assault is a crime that contradicts the core values that the Department of Defense (DOD), the military services, ${ }^{1}$ and the Coast Guard expect servicemembers to follow, such as treating their fellow members with dignity and respect. Within DOD and the Coast Guard, sexual assault also presents a force protection challenge and can negatively affect units' readiness and cohesion. In 2004, following a series of high-profile sexual assault cases involving servicemembers, Congress directed the Secretary of Defense to develop a comprehensive policy for DOD on the prevention of and response to sexual assaults involving servicemembers, including an option that would enable servicemembers to confidentially disclose an incident of sexual assault. Since July 2005, active duty servicemembers have had two options for reporting an alleged sexual assault: (1) restricted, which allows victims of sexual assault to disclose a sexual assault incident to specific individuals and receive medical care and other victim advocacy services without initiating a criminal investigation; and (2) unrestricted, which entails notification of the chain of command and may trigger a criminal investigation. Although these requirements do not apply to the Coast Guard, which is overseen by the Department of Homeland Security, the Coast Guard has adopted similar reporting options.

To help inform congressional deliberations on these issues, in August 2006, Congressman Christopher Shays, then Chairman of the House Committee on Government Reform, Subcommittee on National Security, Emerging Threats, and International Relations, asked GAO to examine sexual assault prevention and response programs at the military academies as well as at military installations within DOD and the Coast Guard and during deployments. In August 2007, Congressmen John Tierney, in his new position as Chairman of the House Committee on Oversight and Government Reform, Subcommittee on National Security and Foreign Affairs, signed on to the original request submitted by

${ }^{1}$ For purposes of this report, we use the term "military services" to refer collectively to the Army, Air Force, Navy, and Marine Corps. While the Coast Guard is a military service, it generally falls under the control of the Department of Homeland Security and not DOD. Therefore, we address the Coast Guard separately from the other military services. 
Congressman Shays. In response, we issued a report in January 2008 reviewing programs to address sexual assault and sexual harassment at the military and Coast Guard academies. ${ }^{2}$ That report found that, while the academies have taken steps to prevent, respond to, and resolve sexual assault and sexual harassment incidents, such incidents may be underreported, suggesting that the academies may not have full visibility over all sexual assault and sexual harassment incidents and that greater federal oversight of their efforts is needed. In that report, we made a number of recommendations to DOD to improve its visibility and oversight of reported incidents of sexual assault and sexual harassment at the military academies, and to the Coast Guard to improve its oversight of reported incidents of sexual assault and sexual harassment at the Coast Guard Academy. In commenting on that report, both DOD and the Coast Guard concurred or partially concurred with our recommendations and specified actions they would take to address them. For example, DOD stated that it was in the initial stages of identifying servicewide performance metrics to help assess the academy's programs, while the Coast Guard noted that it had recently published additional guidance and would work with DOD to help improve oversight of its program.

Subsequent to receiving the congressional request, the Senate Armed Services Committee directed GAO to review sexual assault prevention and response programs at DOD military installations and during deployments overseas. ${ }^{3}$ In addition, several individual senators requested that we examine issues surrounding mental health concerns that can result from sexual assault. On July 31, 2008, we testified before the House Committee on Oversight and Government Reform, Subcommittee on National Security and Foreign Affairs, on our preliminary observations of DOD's and the Coast Guard's sexual assault prevention and response programs. ${ }^{4}$ This report expands upon the preliminary observations we discussed at that hearing and addresses sexual assault prevention and response programs in the active components of DOD and the Coast Guard, including during deployments. Specifically, it evaluates the extent to which DOD and the

${ }^{2}$ GAO, Military Personnel: The DOD and Coast Guard Academies Have Taken Steps to Address Incidents of Sexual Harassment and Assault, but Greater Federal Oversight Is Needed, GAO-08-296 (Washington, D.C.: Jan. 17, 2008).

${ }^{3}$ Sen. Rep. No. 110-77 at 345 (2007).

${ }^{4}$ GAO, Military Personnel: Preliminary Observations on DOD's and the Coast Guard's Sexual Assault Prevention and Response Programs, GAO-08-1013T (Washington, D.C.: July 31, 2008). 
Coast Guard (1) have developed and implemented policies and programs to prevent, respond to, and resolve sexual assault incidents involving servicemembers; (2) have visibility over reports of sexual assault involving servicemembers; and (3) exercise oversight over reports of sexual assault involving servicemembers.

For our first objective, we reviewed legislative requirements; obtained and analyzed DOD's, the military services', and the Coast Guard's guidance and requirements for the prevention, response, and resolution of sexual assault; analyzed DOD's annual reports to Congress for calendar years $2004,2005,2006$, and fiscal year 2007; interviewed knowledgeable officials about implementation of the programs; and visited 15 military installations in the United States and overseas to assess implementation of the programs. At the installations we visited, we met with sexual assault prevention and response program coordinators, victim advocates, judge advocates, medical and mental health personnel, criminal investigative personnel, law enforcement personnel, and chaplains. We also met with various military commanders, ${ }^{5}$ including company and field grade officers, and senior enlisted servicemembers. We also obtained the perspective of more than 3,900 servicemembers by administering a total of 3,750 confidential surveys to a nonprobability sample of randomly selected servicemembers and conducting more than 150 one-on-one, structured interviews with randomly selected servicemembers at 14 of the 15 installations we visited. Our survey is the first since 2006 to obtain the perspectives of selected servicemembers in each military service and the Coast Guard on sexual assault issues and the first to assess sexual assault issues in the Coast Guard since the restricted reporting option became available in December 2007. Because we did not select survey and interview participants using a statistically representative sampling method, our survey results and the comments provided during our interview sessions are nongeneralizable and therefore cannot be projected across DOD, a service, or any single installation we visited. However, the survey results and comments provide insight into the command climate and implementation of sexual assault prevention and response programs at each location at the time of our visit. For our second objective, in addition to analyzing our confidential surveys and one-on-one structured interviews, we reviewed the results of surveys conducted by DOD and the

\footnotetext{
${ }^{5}$ For purposes of this report, we use the term "commanders" to refer to company grade officers (encompassing the ranks of 01-03) and field grade officers (encompassing the ranks of 04-06).
} 
Army and Navy since 2004; reviewed DOD's annual reports to Congress; and obtained and analyzed data for reported sexual assaults in both DOD and the Coast Guard for fiscal year 2007. We assessed the reliability of the reported sexual assault data by interviewing DOD and Coast Guard officials to understand the processes and databases used to collect and record the data, existing data quality control procedures, and known limitations of the data. We found these data were sufficiently reliable to present an overall description of reported incidents of sexual assault. For our third objective, we interviewed knowledgeable officials; obtained and analyzed various pertinent documents, such as meeting minutes for DOD's Sexual Assault Advisory Council; reviewed reports issued by the services' inspector generals and examined DOD's and the Coast Guard's responses to recommendations from prior related studies; and analyzed all DOD and Coast Guard installation-level data for reported sexual assaults for fiscal year 2007. Further details about our scope and methodology, including the development and administration of our survey and the one-on-one structured interviews, can be found in appendix I. In addition, copies of our survey questionnaires can be found in appendices VI and VII.

We conducted this performance audit from June 2007 through August 2008 in accordance with generally accepted government auditing standards. Those standards require that we plan and perform the audit to obtain sufficient, appropriate evidence to provide a reasonable basis for our findings and conclusions based on our audit objectives. We believe that the evidence obtained provides a reasonable basis for our findings and conclusions based on our audit objectives. developing and implementing policies and programs to prevent, respond to, and resolve reported sexual assault incidents involving servicemembers, and the Coast Guard has on its own initiative taken similar steps. However, DOD's guidance may not adequately address some important issues, and implementation of the programs is hindered by several factors. To their credit, DOD and the Coast Guard have issued guidance for preventing and responding to reports of sexual assault and have established offices to oversee sexual assault matters. The military services and the Coast Guard have also established and staffed key positions to manage programs at installations and require servicemembers to receive periodic training on their respective sexual assault prevention and response programs. However, DOD's guidance may not adequately address some important issues, such as how to implement the program when operating in deployed or joint environments. Further, we identified a 
number of factors that hinder implementation of the programs, including the following:

- While most commanders support the programs, some do not: At the installations we visited, we found that commanders - that is, company and field grade officers-had taken actions to address incidents of sexual assault and were generally supportive of sexual assault prevention and response programs; however, at some of the installations we visited we found evidence that not all commanders supported the programs. Further, we found that implementation of the programs may be hindered at installations where key program coordinator positions are a collateral duty. DOD's guidance calls for commanders and other leaders to advocate a strong sexual assault prevention and response program, and the Coast Guard's guidance similarly calls for commanders and other leaders to ensure compliance with the Coast Guard's policies and procedures. However, at three of the installations we visited, program officials told us of meeting with resistance from commanders when attempting to advertise, in barracks and work areas, the programs or the options for reporting a sexual assault. Program officials also told us that they lacked the resources to promote the programs and raise servicemembers' awareness of sexual assault matters. Further, some key program coordinators, such as Sexual Assault Response Coordinators or Employee Assistance Program Coordinators, lack the time and resources to devote to the programs. Neither DOD nor the Coast Guard has performed a systematic analysis to evaluate their processes for staffing key program coordinator positions, and thus both are hindered in their ability to ensure that key installation-level program officials can effectively perform their duties in implementing the programs.

- Training is not consistently effective: Although DOD and the Coast Guard require that all servicemembers receive periodic training on their respective sexual assault prevention and response programs, our nongeneralizable survey, interviews, and discussions with servicemembers and program officials revealed that a majority but not all servicemembers are receiving the required training, and that some who have received it still would not know or were not sure how to report a sexual assault using the restricted reporting option. We also found that neither DOD nor the Coast Guard has systematically evaluated the effectiveness of the training provided to date. Servicemembers who have not received the required training or who have received training that is not effective may not know how to mitigate the possibility of being sexually assaulted or how to seek assistance if needed, or risk reporting the assault in a way that limits their option to seek treatment while maintaining confidentiality.

- Access to mental health services may be limited: DOD and the Coast Guard require that sexual assault victims be made aware of available 
mental health services, and in 2007, DOD's Mental Health Task Force recommended that DOD take action to address factors that may prevent some servicemembers from seeking mental health care. However, we found that several factors, including a DOD-reported shortage of mental health care providers, the logistical challenges of operating overseas or in geographically remote locations, and servicemembers' perceptions of a stigma associated with mental health care, can affect whether servicemembers who are victims of sexual assault can or do access mental health services, and we could find no indication that DOD or the Coast Guard have performed an analysis to aid in addressing barriers to mental health care specifically for victims of sexual assault. To their credit, DOD and the Coast Guard screen servicemembers for mental health concerns, such as post-traumatic stress disorder, which can afflict victims of sexual assault.

We found, based on responses to our survey and a 2006 DOD survey, the most recent available, that occurrences of sexual assault may be exceeding the rates being reported, suggesting that DOD and the Coast Guard have only limited visibility over the incidence of these occurrences. We recognize that the precise number of sexual assaults involving servicemembers is not possible to determine, and that studies suggest sexual assaults are generally underreported in the United States.

Nonetheless, our findings indicate that some servicemembers may choose not to report sexual assault incidents for a variety of reasons, including the belief that nothing would be done or that reporting an incident would negatively impact their careers. In fiscal year 2007, DOD received 2,688 reports of alleged sexual assault, brought with either the restricted or unrestricted reporting option, involving servicemembers as either the alleged offenders or victims. The Coast Guard, which did not offer the restricted reporting option during fiscal year 2007, received 72 reports of alleged sexual assault brought with the unrestricted reporting option during that time period. However, servicemembers told us that they were aware of alleged sexual assault incidents involving other servicemembers that were not reported to program officials, and a 2006 Defense Manpower Data Center survey found that of the estimated 6.8 percent of women and 1.8 percent of men who experienced unwanted sexual contact ${ }^{6}$ during the prior 12 months, the majority chose not to report it. Notably, respondents

\footnotetext{
${ }^{6}$ The 2006 Gender Relations Survey of Active Duty Members defines unwanted sexual contact to include rape, nonconsensual sodomy (oral or anal sex) or indecent assault (unwanted, inappropriate sexual contact or fondling) that can occur regardless of gender, age, or spousal relationship.
} 
to our survey as well as to that and other DOD surveys identified common factors that discouraged servicemembers from reporting a sexual assault incident, including the belief that nothing would be done; concern that reporting an incident would negatively impact their careers or unit morale; or concern that a report made using the restricted reporting option would not remain confidential.

While DOD and the Coast Guard have established some mechanisms for overseeing reports of sexual assault involving servicemembers, both lack an oversight framework, and DOD lacks key information needed to evaluate the effectiveness of the department's sexual assault prevention and response program. DOD's instruction charges the Sexual Assault Prevention and Response Office (within the Office of the Deputy Under Secretary of Defense for Plans) with identifying and managing trends and establishing program evaluation, quality improvement, and oversight mechanisms to evaluate the effectiveness of the sexual response prevention and response program. Our prior work has demonstrated the importance of outcome-oriented performance measures to successful program oversight, and that an effective plan for implementing initiatives and measuring progress can help decision makers determine whether initiatives are achieving their desired results. ${ }^{7}$ However, neither DOD nor the Coast Guard has developed an oversight framework that includes clear objectives, milestones, performance measures, or criteria for measuring progress. Congress also lacks visibility over the incidence of sexual assaults involving Coast Guard members, because the Coast Guard is not required to provide these data to Congress. Further, because of a lack of clearly defined data collection elements, some data included in DOD's annual reports to Congress could be misinterpreted or may not provide information needed to facilitate congressional oversight or understanding of victims' use of the reporting options. Because the military services are not providing DOD with the installation- and case-specific data beyond what is statutorily required for inclusion in the department's annual report, DOD lacks the means to fully execute its oversight role. Furthermore, to provide oversight of DOD's program, in 2004 Congress directed the Secretary of Defense to establish the Defense Task Force on Sexual Assault in the Military Services to undertake an examination of matters relating to sexual assault in which members of the Armed Forces are either victims or offenders. As of July 2008, however, the task force has yet

${ }^{7}$ GAO, Results-Oriented Cultures: Implementation Steps to Assist Mergers and Organizational Transformations, GAO-03-669 (Washington, D.C.: July 2, 2003). 
to begin its review, although DOD considers its work to be an important oversight element. Without an oversight framework, as well as more complete data, decision makers in DOD, the Coast Guard, and Congress lack information they need to evaluate and oversee the programs.

We are suggesting that Congress may wish to improve oversight of sexual assault incidents in the Coast Guard by requiring the Coast Guard to submit to Congress sexual assault incident and program data annually that are methodologically comparable to those required of DOD. We are also making a number of recommendations to improve implementation of sexual assault prevention and response programs and improve oversight of the programs in DOD and the Coast Guard. With regard to DOD, to improve implementation of the program we are recommending that DOD review and evaluate its guidance for the prevention and response of sexual assault to ensure that adequate guidance is provided to effectively implement the program in deployed and joint environments; evaluate its processes for staffing and designating key installation-level program positions to ensure that these individuals have the ability and resources to fully carry out their responsibilities; review and evaluate its training to ensure the military services are meeting requirements and to enhance training effectiveness; systematically evaluate any factors that may prevent or discourage servicemembers from accessing mental health services following a sexual assault; and emphasize to all levels of command their responsibility for supporting the program, and review the extent to which resources are available to raise servicemembers' awareness of sexual assault matters. To enhance oversight of the program, we are recommending that DOD develop an oversight framework to guide continued program implementation and evaluate program effectiveness; take specific steps to improve the usefulness of its annual report to Congress as an oversight tool; direct the service secretaries to provide installation-level incident data to the Sexual Assault Prevention and Response Office; and direct the Defense Task Force on Sexual Assault in the Military Services to begin its examination immediately, now that all members of the task force have been appointed. With regard to the Coast Guard, we are recommending that it evaluate its processes for staffing key installation-level program positions to ensure that these individuals have the ability and resources to fully carry out their responsibilities, and that it develop an oversight framework to guide continued program implementation and evaluate program effectiveness. In written comments on a draft of this report, both DOD and the Coast Guard concurred with all of our recommendations. DOD's comments are reprinted in appendix II, and the Coast Guard's comments are reprinted in appendix III. 
In October 2004, Congress included a provision in the Ronald W. Reagan National Defense Authorization Act for Fiscal Year 2005 that required the Secretary of Defense to develop a comprehensive policy for DOD on the prevention of and response to sexual assaults involving members of the Armed Forces. ${ }^{8}$ The legislation required that the department's policy be based on the recommendations of the Department of Defense Task Force on Care for Victims of Sexual Assaults and on such other matters as the Secretary considered appropriate. ${ }^{9}$ Among other things, the legislation required DOD to establish a standardized departmentwide definition of sexual assault; establish procedures for confidentially reporting sexual assault incidents; and submit an annual report to Congress on reported sexual assault incidents involving members of the Armed Forces.

In October 2005, DOD issued DOD Directive 6495.01, ${ }^{10}$ which contains its comprehensive policy for the prevention of and response to sexual assault, and in June 2006 it issued DOD Instruction $6495.02,{ }^{11}$ which provides guidance for implementing its policy. DOD's directive defines sexual assault as "intentional sexual contact, characterized by the use of force, physical threat or abuse of authority or when the victim does not or cannot consent. It includes rape, nonconsensual sodomy (oral or anal sex), indecent assault (unwanted, inappropriate sexual contact or fondling), or attempts to commit these acts. Sexual assault can occur without regard to gender or spousal relationship or age of victim. "Consent" shall not be deemed or construed to mean the failure by the victim to offer physical resistance. Consent is not given when a person uses force, threat of force, coercion, or when a victim is asleep, incapacitated, or unconscious."

\footnotetext{
${ }^{8}$ Pub. L. No. 108-375, § 577 (2004).

${ }^{9}$ In February 2004, the Secretary of Defense directed the Under Secretary of Defense for Personnel and Readiness to undertake a 90-day review to assess sexual assault policies and programs in DOD and the services and recommend changes to increase prevention, promote reporting, enhance the quality and support provided to victims especially within combat theaters, and improve accountability for offender actions. Among the recommendations of the task force was that DOD establish a single point of accountability for all sexual assault policy matters within the department.

${ }^{10}$ Department of Defense Directive 6495.01, Sexual Assault Prevention and Response (SAPR) Program (Oct. 6, 2005).

${ }^{11}$ Department of Defense Instruction 6495.02, Sexual Assault Prevention and Response Program Procedures (June 23, 2006).
} 
The Under Secretary of Defense for Personnel and Readiness has the responsibility for developing the overall policy and guidance for the department's sexual assault prevention and response program. Under the Office of the Under Secretary of Defense for Personnel and Readiness, DOD's Sexual Assault Prevention and Response Office (within the Office of the Deputy Under Secretary of Defense for Plans) serves as the department's single point of responsibility for sexual assault policy matters. ${ }^{12}$ These include providing the military services with guidance, training standards, and technical support; overseeing the department's collection and maintenance of data on reported sexual assaults involving servicemembers; establishing mechanisms to measure the effectiveness of the department's sexual assault prevention and response program; and preparing the department's annual report to Congress.

In DOD, active duty servicemembers have two options for reporting a sexual assault: (1) restricted, and (2) unrestricted. The restricted reporting option permits a victim to confidentially disclose an alleged sexual assault to select individuals and receive care without initiating a criminal investigation. A restricted report may only be made to a Sexual Assault Response Coordinator (SARC), victim advocate, or medical personnel. Because conversations between servicemembers and chaplains are generally privileged, a victim may also confidentially disclose an alleged sexual assault to a chaplain. In contrast, the unrestricted reporting option informs the chain of command of the alleged sexual assault and may initiate an investigation by the military criminal investigative organization of jurisdiction.

Prior to December 2007, the Coast Guard only offered an option that would enable servicemembers to confidentially disclose an incident of sexual assault at the Coast Guard Academy. However, since then the Coast Guard has employed Coast Guard-wide a definition of sexual assault similar to DOD's as well as similar options for reporting a sexual assault in its guidance, Commandant Instruction $1754.10 \mathrm{C} .{ }^{13}$ Under the Coast Guard's instruction, however, if the chain of command learns of an alleged sexual

\footnotetext{
${ }^{12}$ Except for legal processes provided under the Uniform Code of Military Justice and Manual for Courts-Martial, and criminal investigative policy matters that are assigned to the Judge Advocates General of the military services and DOD's Inspector General, respectively.

${ }^{13}$ Commandant Instruction 1754.10C, Sexual Assault Prevention and Response Program (SAPRP) (Dec. 20, 2007).
} 
assault they are required to notify the Coast Guard's criminal investigative organization, the Coast Guard Investigative Service, which will initiate an investigation or inquiry.

At the installation level, the coordinators of the sexual assault prevention and response programs are known as SARCs in DOD and as Employee Assistance Program Coordinators (EAPC) in the Coast Guard. Other responders include victim advocates, judge advocates, medical and mental health providers, criminal investigative personnel, law enforcement personnel, and chaplains.

Implementation of Sexual Assault Prevention and Response Programs Is Hindered by Inconsistent Support, Training That Is Not Consistently Effective, and Limitations on Access to Mental Health Services
DOD has taken positive steps to respond to congressional direction by establishing policies and a program to prevent, respond to, and resolve reported sexual assault incidents involving servicemembers and the Coast Guard, on its own initiative, has taken similar steps; however, DOD's guidance may not address some important issues. Further, implementation of the programs is hindered by several factors, including (1) inconsistent support for the programs, (2) training that is not consistently effective, and (3) limited access to mental health services.
DOD Has Taken Some Steps to Respond to Congressional Direction, and the Coast Guard on Its Own Initiative Has Made Similar Progress
In response to statutory requirements and recommendations from the Department of Defense Care for Victims of Sexual Assaults Task Force, DOD has established a program to prevent, respond to, and resolve sexual assaults involving servicemembers. DOD's policy and implementing guidance for its program are contained in DOD Directive 6495.01 and DOD Instruction 6495.02, respectively. Specific steps that DOD has taken include:

- $\quad$ establishing a standardized departmentwide definition of sexual assault;

- establishing a confidential option to report sexual assault incidents, known as restricted reporting; 
- establishing a Sexual Assault Prevention and Response Office to serve as the single point of accountability for sexual assault prevention and response;

- requiring the military services to develop and implement their own policies and programs, based on DOD's policy, to prevent, respond to, and resolve sexual assault incidents;

- $\quad$ establishing training requirements for all servicemembers on preventing and responding to sexual assault; and

- reporting data on sexual assault incidents to Congress annually.

DOD's Directive and Instruction May Not Adequately Address Some Important Issues
Although not explicitly required by statute, the Coast Guard has had a sexual assault prevention and response program in place since 1997. In December 2007, the Coast Guard on its own initiative updated its instruction to mirror DOD's policy and to include a restricted option for reporting sexual assaults.

In DOD, each of the military services has also established a Sexual Assault Prevention and Response Office with responsibility for overseeing and managing sexual assault matters within that military service. ${ }^{14}$ The Coast Guard's Office of Work Life (within the Health, Safety and Work Life Directorate, which is under the Assistant Commandant for Human Resources), is responsible for overseeing and managing sexual assault matters within the Coast Guard.

While the establishment of DOD's program represents a noteworthy step, DOD's directive and instruction may not adequately address some important issues, such as how to implement the program when operating in a deployed environment or in joint environments. Program officials we met with overseas told us that DOD's guidance does not sufficiently take into account the realities of operating in a deployed environment, in which unique living and social circumstances can heighten the risks for sexual assault and program resources are more widely dispersed than they are in the United States, which can make responding to a sexual assault challenging. One program official we met with overseas told us that his area of responsibility includes six to seven installations spread out over an area the size of New Jersey, constituting a geographic challenge in terms of responding to sexual assaults. At another installation, we found no criminal investigative presence, and program officials told us that it can

\footnotetext{
${ }^{14}$ Except for the Navy, which refers to its program as Sexual Assault Victim Intervention, each of the military services refers to its program as Sexual Assault Prevention and Response.
} 
take 48 hours or longer for the criminal investigative organization with jurisdiction to respond to some sexual assaults. Similarly, program officials told us there is a need for better coordination of resources when a sexual assault occurs in a joint environment. At one overseas installation we visited, Coast Guard members told us that they were confused about which program they fell under-DOD's or the Coast Guard's-and thus who they should report an alleged sexual assault to. We also found that installations can have multiple responders responsible for responding to an assault, potentially leading to further confusion. Concerns over implementing the sexual assault prevention and response program in joint environments are also highlighted in the department's fiscal year 2007 annual report. ${ }^{15}$ For example, DOD noted the need to address challenges that arise in environments wherein two or more services are operating together, while the Army noted that challenges with joint environments have often resulted in unnecessary duplication of services and inconsistent application of policy with regard to sexual assault matters.

Implementation of Sexual Assault Prevention and Response Programs Is Hindered by Inconsistent Support from

Commanders and Limited Effectiveness of Program Coordinators for Whom Program Management Is a Collateral Duty

\author{
While Most Commanders \\ Support the Programs, Some \\ Do Not
}

Commanders in DOD and the Coast Guard have taken actions to address incidents of sexual assault and are generally supportive of sexual assault prevention and response programs; however, we found evidence that some commanders do not support the programs. In addition, implementation of the programs may be hindered at installations where key program coordinator positions are a collateral duty because servicemembers must balance their duties with mission-related priorities, especially in deployed environments.
While commanders - that is, company and field grade officers-in DOD and the Coast Guard have taken actions to address incidents of sexual assault, we found evidence that some commanders do not support the programs. According to DOD's instruction, commanders and other leaders are responsible for advocating a strong program and effectively implementing sexual assault prevention and response policies. The Coast Guard's instruction similarly requires that commanders and other leaders

\footnotetext{
${ }^{15}$ Department of Defense, Fiscal Year 2007 Report on Sexual Assault in the Military (Mar. $15,2008)$.
} 
ensure compliance with the Coast Guard's policies and procedures. At the installations we visited, we found that commanders were supportive of addressing incidents of sexual assault. For example, commanders told us that they set a zero tolerance policy for incidents of sexual assault, communicated the respective policies at command briefings, understood their roles and responsibilities in supporting the programs, and understood the need to protect victims. The results of a nongeneralizable survey we conducted support these statements. For example, at the 14 installations where we administered our survey, the percentage of servicemembers who indicated they thought their direct supervisor (military or civilian) would address sexual assault, should it occur at their current location, ranged from 91 to 98 percent.

However, we found evidence that some commanders do not support the programs. For example, at three of the installations we visited program officials told us of meeting with resistance from commanders when attempting to place, in barracks and work areas, posters or other materials advertising the program or the options for reporting a sexual assault. A victim advocate at one Navy installation we visited told us that her command did not support the program and that her command did not feel that servicemembers in the unit should be able to utilize DOD's restricted reporting option. According to the individual, the command demonstrated its resistance by routinely taking down any posters advertising the unit's victim advocates or DOD's reporting options. In some cases, commanders we spoke with told us that they supported the programs but did not like the restricted reporting option because they felt it hindered their ability to protect members of the unit or discipline alleged offenders.

Some program officials told us that some commanders do not support the programs because they do not understand them or do not consider sexual assault matters to be a priority in the military. The following are some examples of what we found:

- At some of the installations we visited, commanders we spoke with were unfamiliar with the options for reporting a sexual assault, mistakenly believing that servicemembers could use the restricted option and still report a sexual assault to them - that is, without their being obligated to then initiate an investigation.

- Army unit victim advocates at one location we visited told us that senior enlisted leaders tend to ignore sexual assault matters until they become public knowledge and affect the morale of the unit. 
- Marine Corps unit victim advocates at one location we visited told us that some commanders do not want to hear from them or from junior enlisted Marines about sexual assault matters.

- At some of the installations we visited, program officials told us that some commanders of all-male units do not believe that sexual assault matters are a problem for their units or that the programs are relevant to their units. For example, a SARC at one installation we visited told us that some commanders from all-male units have prevented her from providing required training to the units.

Commanders who do not emphasize and prioritize sexual assault prevention and response programs —including those in all-male units—or who do not understand the policies and procedures effectively limit servicemembers' knowledge about the program and ability to exercise their reporting options. Consequently, sexual assault prevention and response program coordinators' efforts to raise awareness at these installations may also be limited.

Program officials told us they need sufficient resources to appropriately implement sexual assault prevention and response programs. However, there is no direct funding for sexual assault prevention and response programs at military installations. To fund the programs, funds from other installation programs need to be utilized. At some of the installations we visited, SARCs and other program officials told us that they lacked sufficient funding to promote the programs, train servicemembers, or otherwise raise servicemembers' awareness of sexual assault matters. In such instances, program officials told us that they had to find creative ways to implement the programs. One Army SARC told us that because of limited funding she could not bring in any outside speakers during Sexual Assault Awareness Month and had to rely on donations from units to print posters advertising the program. Similarly, SARCs we met with in the Navy and Marine Corps told us that they had only limited resources to train servicemembers. In the Coast Guard, program officials told us that they were expected to comply with the Coast Guard's instruction to provide training to victim support personnel and servicemembers. However, they were not provided with funding and did not know how they were going to meet the new requirements. Program coordinators who are not provided sufficient funding by their commands cannot ensure that their program is appropriately implemented.

At the installations we visited, we found that commanders have taken action against alleged sexual assault offenders. In both DOD and the Coast Guard, commanders are responsible for discipline of misconduct, 
including sexual assault, and they have a variety of judicial and administrative options at their disposal. Commanders' options are specified in the Uniform Code of Military Justice (UCMJ) and the Manual for Courts-Martial and include (1) trial by courts-martial, (2) nonjudicial punishment, and (3) administrative actions. At the installations we visited, commanders told us that they were supportive of the need to dispose of sexual assault cases and were generally familiar with the options available to them. For further information on the disposition of sexual assaults in DOD and the Coast Guard, see appendix IV.

Program Coordinators Are Challenged in Providing Program Management as a Collateral Duty
To implement the sexual assault prevention and response program at military installations, DOD and the services rely largely on SARCs. DOD's instruction directs the military services to establish the position of the SARC and criteria for selecting them. However, DOD's instruction leaves to the military services' discretion whether these positions are filled by military members, DOD civilian employees, or DOD contractors, and thus whether SARCs perform their roles as full-time or collateral duties. We found that the military services are using a variety of models for staffing the SARC position. For example, at the installations we visited in the United States, the Army, Navy, and Air Force were using full-time civilian or contractor employees, while the Marine Corps was using both civilian and military servicemembers for whom the duty was collateral. At the installations we visited overseas, we found that the Army assigned this position to servicemembers as a collateral duty, the Navy assigned it to a full-time civilian employee, and the Air Force assigned it to servicemembers as a full-time duty. We found that the time and resources dedicated to implementing the sexual assault prevention and response program are more constrained where program coordinator positions are staffed by servicemembers for whom these duties are collateral. Program officials with whom we spoke told us that SARCs' ability to effectively implement DOD's program depended on whether they served in full-time or collateral-duty positions. For example, Army SARCs overseas told us that in addition to the sexual assault prevention and response program they are also responsible for supporting the Army's Equal Opportunity program, and that when they handled an equal opportunity complaint or had other mission requirements, those became their full-time job. As a result, they had less time to support the sexual assault prevention and response program. DOD has not systematically evaluated its policy for staffing SARCs; however, without evaluating its policy and the services' processes for filling the SARC position, DOD is hindered in its ability to ensure that the SARCs can effectively perform their function in managing the sexual assault prevention and response program. 
The 13 EAPC positions in the Coast Guard are staffed by full-time federal civilian employees who are responsible for simultaneously managing multiple work-life programs, including sexual assault prevention and response, for a designated geographic region. Officials in the Coast Guard's Office of Work Life as well an EAPC with whom we met acknowledged that because of the number of programs they are responsible for managing, the EAPCs do not have the time to effectively launch and implement the Coast Guard's sexual assault prevention and response program. As a result, these officials believe they will not be able to train servicemembers on the Coast Guard's program, including the new restricted reporting option, while also providing assistance to victims and managing other work-life programs. Officials at Coast Guard headquarters estimate that they need an additional 13 EAPCs across the Coast Guard to address their workload requirements. Without evaluating its processes for staffing these positions, the Coast Guard is hindered in its ability to ensure that its sexual assault prevention and response program is effectively implemented.

\section{Training Is Not Consistently Effective}

Not All Servicemembers Receive Required Training
Although DOD and the Coast Guard require servicemembers to receive periodic training on their respective sexual assault prevention and response programs, our nongeneralizable survey and interviews and discussions with servicemembers and program officials revealed that not all servicemembers are receiving the required training, and some servicemembers who have received it nevertheless may not understand how to report a sexual assault using the restricted reporting option. To date, neither DOD nor the Coast Guard has evaluated the effectiveness of the training provided. Additionally, the military services are not consistently meeting DOD's requirements for presenting training in specified formats to enable servicemembers to understand the nature of sexual assaults. Some servicemembers told us that the training they received was not engaging and, therefore, they did not pay attention; others told us that servicemembers do not always take the training seriously.

Both DOD and the Coast Guard require that servicemembers receive sexual assault prevention and response training annually; however, our survey and discussions with servicemembers revealed that not all servicemembers are receiving this training. In response to statutory requirements, ${ }^{16}$ DOD has established requirements for servicemembers to

\footnotetext{
${ }^{16}$ Pub. L. No. 108-375, § 577 (2004).
} 
receive periodic sexual assault prevention and response training. Specifically, DOD's instruction requires servicemembers to receive sexual assault prevention and response training both annually and prior to deploying to locations outside of the United States. Although not statutorily required to do so, the Coast Guard has developed its instruction largely to reflect DOD's policies, and also requires its members to receive training annually. DOD's and the Coast Guard's annual training is required to provide all servicemembers with information on their options for reporting a sexual assault and sexual assault issues, such as the meaning of consent, offender accountability, and victim care.

At the seven installations where we administered our survey in the United States, our survey revealed that a majority, but not all, servicemembers are receiving required annual training on their respective sexual assault prevention and response programs. Specifically, as table 1 shows, the percentage of servicemembers we surveyed at seven installations in the United States who indicated they had received the required training in the preceding 12 months ranged from 61 to 88 percent.

Table 1: Percentage of Selected Servicemembers Who Reported Having Received or Having Not Received Required Sexual Assault Prevention and Response Training in the Preceding 12 Months

\begin{tabular}{lrr}
\hline Installation & $\begin{array}{r}\text { Percentage of selected } \\
\text { servicemembers who } \\
\text { reported having received } \\
\text { required annual training }\end{array}$ & $\begin{array}{r}\text { Percentage of selected } \\
\text { servicemembers who } \\
\text { reported having not received } \\
\text { required annual training }\end{array}$ \\
\hline United States & 76 & 20 \\
\hline Camp Lejeune & 79 & 19 \\
\hline Fort Bliss & 86 & 11 \\
\hline Fort Drum & 85 & 11 \\
\hline Integrated Support & & 9 \\
Command Portsmouth & 88 & 34 \\
\hline Lackland Air Force Base & 61 & 21 \\
\hline Marine Corps Base & & \\
Quantico & 77 & \\
\hline Naval Station Norfolk & & \\
\hline Source: GAO. & & \\
\hline
\end{tabular}

Note: This table does not show the percentage of servicemembers who responded that they did "do not know" whether they received the required training. Therefore, the percentages in the table may not total to 100 percent for each installation.

ancludes servicemembers from Yorktown Training Center, Virginia. 
Our interviews and discussions with servicemembers and program officials also revealed that not all servicemembers had received the required annual training within the preceding 12 months. Such servicemembers incur the risks of not knowing how to mitigate the possibility of being sexually assaulted or how to seek assistance if needed, or risk reporting the assault in a way that limits their option to seek treatment while maintaining confidentiality. In some instances, we found that these servicemembers were aware that the training was required annually, but had not attended or received training within the preceding 12 months. For example, a junior officer at a Marine Corps installation told us that he had last received the required training 2 years earlier while stationed overseas, when the Marine Corps' program was initially rolled out. He said that he had not received any subsequent training because he had likely "slipped through the cracks." As another example, a junior enlisted servicemember at an Army installation told us that he had not received the required training within the preceding 12 months because he was on temporary duty assignment when his unit conducted the training. In other cases, we found that servicemembers were not familiar with the programs or had never received the required training. Program officials at the installations we visited told us that they face challenges in ensuring that all servicemembers receive the required training. For example, a SARC at an Army installation told us that while she informally tracks information on whether units have received required annual sexual assault prevention and response training, she has no way of knowing how many servicemembers within a unit have received it. She noted that tracking whether servicemembers have received required training is a unit-level responsibility. Her goal, which she noted is arbitrary, is to ensure that at least 80 percent of units have received this training.

According to DOD's instruction, military commanders, supervisors, and managers are responsible for the effective implementation of the services' respective sexual assault prevention and response programs. However, we found evidence that not all commanders had received the required training or were familiar with the options for reporting a sexual assault. A senior officer at an Air Force installation told us that he had never received sexual assault prevention and response training, was not familiar with DOD's options for reporting a sexual assault, and would encourage his servicemembers to address sexual assault matters by notifying their chain of command. Similarly, a senior officer at an Army installation we visited told us that he did not know about any other option for reporting a sexual assault other than by notifying their chain of command. With their commanders thus uninformed, servicemembers under their command might not be fully aware of their options for reporting a sexual assault. 
Also, at more than half of the installations we visited servicemembers and program officials told us that they believe commanders and other senior leaders do not always receive the required training, or if they do, do not understand the programs. For example, victim advocates at a Navy installation we visited told us that they do not believe many senior leaders receive required sexual assault prevention and response training. According to the victim advocates, leaders cannot support the program if they do not understand it.

Servicemembers and program officials we spoke with also told us that problems occur when commanders and other senior leaders have not received the required training or are not familiar with the programs. For example, the SARC at one installation we visited told us that it is important that commanders receive the required training so that they understand what they can and cannot do with regard to sexual assault matters. According to the official, commanders who have not received training and are not informed about the program sometimes take incorrect actions, such as initiating their own investigations of allegations of sexual assault made using the restricted reporting option.

In addition to its annual training requirement, DOD, though not the Coast Guard, requires that servicemembers receive sexual assault prevention and response training prior to deploying to locations outside of the United States. However, our survey revealed that not all servicemembers are receiving this training. Specifically, as table 2 shows, at the seven installations where we administered our survey overseas, the percentage of servicemembers who indicated they had received training prior to deploying ranged from 52 to 90 percent, while the percentage of servicemembers indicating they had not received training prior to deploying ranged from 6 to 42 percent. 
Table 2: Percentage of Selected Servicemembers Who Reported Having Received or Having Not Received Sexual Assault Prevention and Response Training Prior to Deploying

\begin{tabular}{lrr}
\hline & $\begin{array}{r}\text { Percentage of selected } \\
\text { servicemembers who } \\
\text { reported having received } \\
\text { required training prior to } \\
\text { deploying }\end{array}$ & $\begin{array}{r}\text { Percentage of selected } \\
\text { servicemembers who } \\
\text { reported having not received } \\
\text { required training prior to } \\
\text { deploying }\end{array}$ \\
\hline Overseas & & 21 \\
\hline Al Udeid Air Base & 68 & 19 \\
\hline Balad Air Base & 72 & 21 \\
\hline Camp Arifjan & 75 & 17 \\
\hline Camp Ramadi & 76 & 13 \\
\hline Camp Stryker & 80 & 6 \\
\hline Logistics Support Area & 90 & 42 \\
Anaconda & & \\
\hline Naval Support Activity & 52 & \\
Bahrain & & \\
\hline Source: GAO. & & \\
\hline
\end{tabular}

Note: This table does not show the percentage of servicemembers who responded that they did "do not know" whether they received the required training. Therefore, the percentages in the table may not total to 100 percent for each installation.

${ }^{a}$ Includes Coast Guard members under the operational command of U.S. Central Command.

Our interviews with individual servicemembers also revealed that not all servicemembers had received the required sexual assault prevention and response training prior to deploying. The SARC at one installation we visited told us that he believes many servicemembers are deploying overseas without having received the required predeployment training because too many servicemembers with whom he interacts are not familiar with the program. In some instances, we found that servicemembers may not be receiving the required training because DOD's predeployment training requirements are not always enforced. For example, a general officer we met with in Iraq told us that as units are preparing to deploy commanders may not emphasize all predeployment training requirements, including those pertaining to sexual assault prevention and response. As a result, according to the general officer, servicemembers who have not received this training may not take sexual assault matters seriously during deployment. Such servicemembers may also not understand how to obtain assistance if a sexual assault were to occur. Though servicemembers may not receive required sexual assault prevention and response training prior to deploying, we found that some 
steps are being taken to provide the training to servicemembers once they arrive in a deployed location. For example, at the installations we visited overseas we found that SARCs and victim advocates were actively publicizing the program and providing training to servicemembers and units upon their arrival.

Some Servicemembers Do Not Understand How to Use the Restricted Reporting Option
The majority of respondents to our survey indicated that they had received required sexual assault prevention and response training and would know how to report a sexual assault using the restricted reporting option. However, as table 3 shows, the percentage of servicemembers we surveyed who indicated that they would not know or were not sure of how to report a sexual assault using the restricted reporting option, despite having received the training, ranged from 13 to 43 percent for the seven installations where we administered our survey in the United States and from 13 to 28 percent for the seven installations where we administered our survey overseas. 
Table 3: Percentage of Selected Servicemembers Who Reported Receiving Required Sexual Assault Prevention and Response Training and Also Reporting They Would Not Know or Were Not Sure of How to Report a Sexual Assault Using the Restricted Reporting Option

\begin{tabular}{|c|c|c|}
\hline Installation & $\begin{array}{r}\text { Percentage of selected } \\
\text { servicemembers who } \\
\text { reported having received } \\
\text { required training and also } \\
\text { reporting they would know } \\
\text { how to report a sexual } \\
\text { assault using the restricted } \\
\text { reporting option }\end{array}$ & $\begin{array}{l}\text { Percentage of selected } \\
\text { servicemembers who } \\
\text { reported having received } \\
\text { required training and also } \\
\text { reporting they would not } \\
\text { know or were not sure how } \\
\text { to report a sexual assault } \\
\text { using the restricted } \\
\text { reporting option }\end{array}$ \\
\hline \multicolumn{3}{|l|}{ United States } \\
\hline Camp Lejeune & 68 & 32 \\
\hline Fort Bliss & 81 & 19 \\
\hline Fort Drum & 84 & 16 \\
\hline $\begin{array}{l}\text { Integrated Support } \\
\text { Command Portsmouth }^{\text {a }}\end{array}$ & 60 & 40 \\
\hline $\begin{array}{l}\text { Lackland Air Force } \\
\text { Base }\end{array}$ & 87 & 13 \\
\hline $\begin{array}{l}\text { Marine Corps Base } \\
\text { Quantico }\end{array}$ & 57 & 43 \\
\hline Naval Station Norfolk & 78 & 22 \\
\hline \multicolumn{3}{|l|}{ Overseas } \\
\hline Al Udeid Air Base & 85 & 15 \\
\hline Balad Air Base & 82 & 18 \\
\hline Camp Arifjan & 83 & 17 \\
\hline Camp Ramadi & 87 & 13 \\
\hline Camp Stryker & 72 & 28 \\
\hline $\begin{array}{l}\text { Logistics Support Area } \\
\text { Anaconda }\end{array}$ & 82 & 18 \\
\hline $\begin{array}{l}\text { Naval Support Activity } \\
\text { Bahrain }^{\mathrm{b}}\end{array}$ & 78 & 22 \\
\hline
\end{tabular}

Source: GAO.

ancludes servicemembers from Yorktown Training Center, Virginia.

${ }^{\mathrm{b}}$ Includes Coast Guard members under the operational command of U.S. Central Command.

Similarly, our interviews with servicemembers also revealed that some servicemembers who had received the required training were confused or unfamiliar with DOD's options for reporting a sexual assault, as illustrated by the following examples: 
- A junior enlisted servicemember at an Army installation told us that although he had received sexual assault prevention and response training as part of his annual training requirement, he did not believe that the Army allowed a report of sexual assault to be made without a formal investigation.

- A junior officer at an Air Force installation told us that his predeployment training covered sexual harassment and human trafficking but he was uncertain whether the training covered sexual assault matters or DOD's reporting options.

- A senior enlisted servicemember in Iraq told us that while she received sexual assault prevention and response training prior to deploying, the training focused on how females could protect themselves and did not cover DOD's reporting options.

The Military Services Do Not Consistently Meet Training Format Requirements
To help servicemembers understand the nature of sexual assaults, DOD's instruction requires that sexual assault prevention and response training be scenario-based, using real-life situations to demonstrate the entire cycle of reporting, response, and accountability procedures. DOD's instruction also requires that training for junior servicemembers include group participation and interaction. However, our survey revealed that the military services are not consistently meeting DOD's requirements for the format of the training. During the course of our review, we found that the services are utilizing a variety of formats, including instructor-led or computer- or web-based training, to provide servicemembers with required sexual assault prevention and response training. However, as table 4 shows, at 9 of the 14 locations where we administered our survey, more than half of the servicemembers indicated that the training they received did not include a participatory or scenario-based component. 
Table 4: Percentage of Selected Servicemembers Who Reported Having Received Required Sexual Assault Prevention and Response Training, by Format of the Training

\begin{tabular}{|c|c|c|}
\hline Installation & $\begin{array}{r}\text { Percentage of selected } \\
\text { servicemembers who } \\
\text { reported having received } \\
\text { required training that was } \\
\text { participatory or } \\
\text { scenario-based }\end{array}$ & $\begin{array}{l}\text { Percentage of selected } \\
\text { servicemembers who } \\
\text { reported having received } \\
\text { required training that was } \\
\text { not participatory or } \\
\text { scenario-based }\end{array}$ \\
\hline \multicolumn{3}{|l|}{ United States } \\
\hline Camp Lejeune & 43 & 54 \\
\hline Fort Bliss & 56 & 42 \\
\hline Fort Drum & 60 & 38 \\
\hline $\begin{array}{l}\text { Integrated Support } \\
\text { Command Portsmouth }\end{array}$ & 27 & 69 \\
\hline Lackland Air Force Base & 37 & 60 \\
\hline $\begin{array}{l}\text { Marine Corps Base } \\
\text { Quantico }\end{array}$ & 39 & 57 \\
\hline Naval Station Norfolk & 32 & 66 \\
\hline \multicolumn{3}{|l|}{ Overseas } \\
\hline Al Udeid Air Base & 21 & 72 \\
\hline Balad Air Base & 19 & 75 \\
\hline Camp Arifjan & 52 & 44 \\
\hline Camp Ramadi & 62 & 31 \\
\hline Camp Stryker & 56 & 36 \\
\hline $\begin{array}{l}\text { Logistics Support Area } \\
\text { Anaconda }\end{array}$ & 41 & 51 \\
\hline $\begin{array}{l}\text { Naval Support Activity } \\
\text { Bahrain }^{\circ}\end{array}$ & 29 & 69 \\
\hline
\end{tabular}

Source: GAO.

Notes: This table does not show the percentage of servicemembers who responded that they were "not sure" whether they received the required training and whether they received participatory or scenario-based training. Therefore, the percentages in the table may not total to 100 percent for each installation.

aThe Coast Guard's instruction does not include a requirement that sexual assault prevention and response training include a participatory or scenario-based component.

${ }^{\mathrm{b}}$ Includes servicemembers from Yorktown Training Center, Virginia.

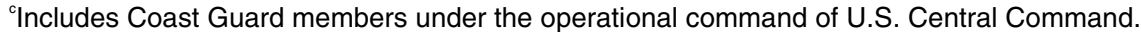

The Coast Guard's instruction does not specify any requirements for the format of its sexual assault prevention and response training. However, according to an official in the Coast Guard's Office of Work Life, the Coast 
Guard is in the process of reviewing its training requirements, including those for the format of the training. Further, the Coast Guard is considering establishing a requirement that sexual assault prevention and response training be interactive.

Servicemembers' Perceptions of Sexual Assault Prevention and Response Training Varies
At the installations we visited, servicemembers' perceptions of the required training they received varied. For example, one junior enlisted servicemember told us the training she received was very helpful and covered everything she would want to know about sexual assault matters, including the meaning of consent, the difference between sexual assault and sexual harassment, what one should do if sexually assaulted, and the differences between DOD's restricted and unrestricted reporting options. However, at about half the installations we visited, servicemembers and program officials told us the training relied heavily on power point briefings and some said that participants were not engaged. Victim advocates, who along with SARCs provide the required training, told us at one installation we visited that the training they provide to units does rely heavily on power point briefings, the material is not engaging, and many servicemembers do not pay attention during the training sessions. At more than half the installations we visited, servicemembers and program officials we spoke with told us that the training is not taken seriously and some described it as a vehicle for units to "check the box" indicating that they met the training requirement.

Servicemembers and program officials also told us that the training provided to junior personnel is not always interactive. Several servicemembers told us that junior servicemembers receive the same training as senior enlisted members and officers. The Deputy Commander at an Army installation we visited overseas described this training as aimed at a very broad spectrum of servicemembers and ranks and not very in-depth. Similarly, a senior enlisted servicemember at a Navy installation told us that the training she has attended includes both junior and senior servicemembers, which can be intimidating for junior servicemembers, who are consequently less likely to speak up or ask questions. The SARC at one installation we visited said that the training she provides units encompasses about 800 personnel at a time, which can make it difficult to allow for interaction or individual questions from any of the participants. 
Several Factors May Hamper Servicemembers' Access to Mental Health Care, Though DOD and the Coast Guard Screen for Post-Traumatic Stress Disorder

Access to Mental Health Services May Be Limited
DOD and the Coast Guard both require that sexual assault victims be made aware of the available mental health services. However, several factors, including a DOD-reported shortage of mental health care providers, difficulty in accessing mental health services overseas or in geographically remote locations, and servicemembers' perceptions of stigma associated with seeking mental health care, affect servicemembers' access to mental health care, and we could find no indication that DOD or the Coast Guard have performed an analysis to aid in addressing barriers to mental health care specifically for victims of sexual assault. To their credit, both DOD and the Coast Guard are taking steps to screen servicemembers for mental health disorders, such as post-traumatic stress disorder, which mental health providers in DOD with whom we spoke identified as one of the most common mental health concerns following a sexual assault.

Both DOD and the Coast Guard require that servicemembers who are victims of sexual assault be made aware of mental health services, such as counseling. DOD's instruction requires SARCs to coordinate medical and counseling services between military installations and deployed units for victims of sexual assault and collaborate with local community crisis counseling centers, as necessary, in order to augment or enhance DOD's program. Similarly, the Coast Guard's instruction requires that a health care professional ensure that any victim who reports a sexual assault be informed of his or her psychiatric care or counseling options. At the installations we visited, we found that program officials generally took steps to ensure that servicemembers who are sexually assaulted are made aware of their options for seeking mental health care and are able to access it, if desired. However, at some of the installations we visited we found instances in which program officials had not taken steps to ensure that servicemembers were aware of their options for seeking mental health care or otherwise had limited access to mental health care following a sexual assault. For example, at one installation we found that servicemembers had access only to the limited mental health services provided on base, and that the SARC did not know whether any memoranda of understanding were in place with local resources or practitioners in the community to provide servicemembers with additional options for accessing mental health care. With their SARC thus uninformed, any servicemember assaulted at the installation could be limited in his or her options for accessing mental health care if needed.

Though both DOD and the Coast Guard require that servicemembers who are victims of sexual assault be made aware of mental health services, neither knows how many servicemembers have sought or received mental health services following a sexual assault because there is no requirement 
to collect or track such information. According to knowledgeable officials within DOD, doing so could be challenging because servicemembers may seek treatment from civilian providers who are not required to report any information to DOD. Both DOD and the Coast Guard collect limited information on the number of sexual assault victims who are referred for counseling. However, the information DOD collects is limited to the initial referral for each restricted report of a sexual assault; it does not indicate whether the victim actually received the counseling to which he or she was referred. Similarly, the information the Coast Guard collects is limited to only whether the victim was offered counseling. Officials at the Department of Veterans Affairs (VA) told us VA collects data on the cumulative number of veterans to whom it has provided mental health care for conditions resulting from military sexual trauma-which includes both sexual harassment and sexual assault-during their military career. ${ }^{17}$ However, because DOD and VA collect different data, comparisons cannot be made.

Shortages of Mental Health Providers Can Diminish Access to Mental Health Services
Although DOD and the Coast Guard require that servicemembers who are victims of sexual assault be made aware of available mental health services, a DOD-reported shortage of health care providers-specifically mental health care providers-can hinder servicemembers' access to receiving such care. Such concerns are not new to DOD. For example, in 2007, the congressionally mandated DOD Task Force on Mental Health reported that the military health system lacks the fiscal resources and fully trained personnel needed to fulfill its mission to support psychological health in peacetime or to fulfill the enhanced requirements imposed during times of conflict. During the course of our review we found that concerns over a shortage of mental health providers persist. For example, officials at some of the installations we visited told us that one barrier to ensuring that victims of sexual assault receive mental health care if they desire it is the lack of adequate resources and staff at some installations. Similarly, mental health officials with the Navy's Bureau of Medicine and Surgery told us that the Navy does not have enough medical or mental health professionals to staff all allotted positions. However, during the course of our review we did find that the military services were taking steps to address this challenge. For example, DOD has established a memorandum

\footnotetext{
${ }^{17}$ The Secretary of Veterans Affairs is required to operate a program to provide counseling and treatment for veterans suffering from sexual trauma under 38 U.S.C. \$1720D. Veterans Health Administration Directive 2005-015, Military Sexual Trauma Counseling (Mar. 25, 2005), contains guidance on the documentation that is to be maintained on screening, referral, and treatment services provided to veterans under this program.
} 
of understanding with the Public Health Service to enable its uniformed providers to work in military treatment facilities.

Accessing Mental Health Services Is More Difficult Overseas or in Geographically Remote Locations
Servicemembers deployed overseas or based at geographically remote installations in the United States or overseas typically have more difficulty in obtaining mental health services because of inherent challenges associated with such locales. For example, servicemembers deployed to small forward operating bases in Afghanistan or Iraq may have to travel or be transported to other military installations in the region. Program officials told us that this process typically involves the servicemember notifying his or her commander, who is responsible for the use of transportation assets, which may require that the servicemember disclose the reason for seeking mental health care. However, disclosing that reason could jeopardize the member's ability to use the restricted reporting option and keep the sexual assault incident confidential. Servicemembers stationed in geographically remote locations may also have limited access to mental health care. At one installation we visited in the United States, officials told us that they had faced challenges hiring additional mental health providers given the installation's geographically remote location. However, they noted that recent hires of psychologists had reduced servicemembers' waiting time for counseling appointments at the installation from about 7 weeks to 2 days. Navy and Coast Guard members told us that access to mental care on ships is limited and that servicemembers must wait until they can be transported to another ship with mental health assets, or until their ship arrives in port to access mental health services. Servicemembers also told us that it can be difficult to leave their ships in order to receive such care.

Some mental health care officials we spoke with overseas said that the shortage of providers can make it even more difficult to seek mental health care, for any reason, when deployed overseas or in geographically remote locations in the United States or overseas. For example, at one installation we visited in Southwest Asia we found that servicemembers had access to only one mental health provider for only about 4 hours each week. In February 2008, the Army reported that such concerns remained largely unaddressed. Specifically, the Army's Mental Health Advisory Team reported that in 2007, soldiers who were deployed in support of operations in Afghanistan and Iraq were reporting more difficulty in accessing behavioral health care than they had reported in 2006, and that behavioral health personnel were reporting a shortage of assets and an increase in burnout rates. 
Perceptions of Stigma May Inhibit Servicemembers from Seeking Mental Health Services
Perceptions of stigma associated with seeking mental health care may also discourage servicemembers from doing so following a sexual assault. In 2007, the congressionally mandated DOD Task Force on Mental Health reported that stigma in the military associated with seeking mental health services remains a pervasive and critical barrier to accessing needed psychological care. Similarly, the Army's Mental Health Advisory Team reported in 2008 that stigma continues to be a major issue in the willingness of servicemembers to seek care. DOD officials told us that servicemembers often do not seek mental health care for this reason or because they believe doing so could negatively impact their careers, such as by affecting their ability to obtain a security clearance.

DOD recently took steps that may encourage servicemembers who require mental health care to seek professional help by successfully advocating a revision to Standard Form 86, Questionnaire for National Security Positions. ${ }^{18}$ Under the revision, applicants no longer need to disclose certain noncourt-ordered mental health care that they may have received in the preceding 7 years that was (1) strictly marital, family, or grief related, as long as it was not related to violence committed by the servicemember; or (2) strictly related to adjustments from service in a military combat environment. Further, in an April 2008 memorandum from the Secretary of Defense, DOD noted that professional care for mental health issues should not be perceived as jeopardizing an individual's security clearance. ${ }^{19}$ However, officials with DOD's Sexual Assault Prevention and Response Office told us that it is unclear whether these steps will encourage servicemembers who are victims of sexual assault to seek mental health care, or whether these revisions apply to servicemembers who have been sexually assaulted and seek mental health care.

\footnotetext{
${ }^{18}$ The Standard Form 86, Questionnaire for National Security Positions, is a governmentwide form applicable not only to DOD servicemembers and civilians who occupy sensitive positions but to individuals who occupy sensitive positions across the federal government.

${ }^{19}$ Secretary of Defense Memorandum, "Policy Implementation-Mental Health Question, Standard Form (86), Questionnaire for National Security Positions" (Apr. 18, 2008).
} 
DOD and the Coast Guard Screen Servicemembers for Post-Traumatic Stress Disorder Resulting from Traumatic Events That May Include Sexual Assault
Mental health providers in DOD told us that post-traumatic stress disorder is one of the most common mental health concerns following a sexual assault. However, mental health officials told us that because the onset for post-traumatic stress disorder varies-a victim may develop posttraumatic stress disorder immediately, or it can be delayed-victims of sexual assault who seek care after the assault are treated for symptoms such as depression and anxiety at the time of their visit. Similarly, Coast Guard medical officials told us that the EAPC will ensure that a victim of sexual assault meets with a health care provider, who may evaluate and treat the patient for anxiety, depression, post-traumatic stress disorder, or other conditions, and refer the patient to the appropriate mental health specialist for acute and chronic care.

DOD screens for mental health concerns, including post-traumatic stress disorder, as part of its system to assess the medical condition of servicemembers before and after deploying to locations outside the United States. The elements of DOD's system include the use of a predeployment health assessment, a postdeployment health assessment, and a postdeployment health reassessment. During these assessments, a servicemember completes a form that includes questions used to screen for mental health concerns, including post-traumatic stress disorder, but not specifically for sexual assault. As we previously reported, posttraumatic stress disorder can develop following exposure to combat, natural disasters, terrorist incidents, serious accidents, or violent personal assaults like rape. ${ }^{20}$

DOD's deployment health assessment questionnaires do not focus on a specific type of event, such as sexual assault; instead, the questionnaires ask servicemembers to self-report general health information that allows health care providers to screen for medical and mental health concerns. The postdeployment health assessment questionnaire contains a number of questions to screen respondents for depression, suicidal thoughts, acute stress, and post-traumatic stress disorder. For example:

Have you ever had any experience that was so frightening, horrible, or upsetting that, in the past month you:

- have had any nightmares about it or thought about it when you did not want to?

${ }^{20} \mathrm{GAO}$, DOD Health Care: Mental Health and Traumatic Brain Injury Screening Efforts Implemented but Consistent Pre-Deployment Medical Record Review Policies Needed, GAO-08-615 (Washington, D.C.: May 30, 2008). 
- tried hard not to think about it or went out of your way to avoid situations that remind you of it?

- were constantly on guard, watchful, or easily startled?

- felt numb or detached from others, activities or your surroundings?

A health care provider reviews the completed form and may refer the servicemember for further evaluation if necessary. Further, within 30 days of redeployment, servicemembers are required to meet with a trained health care provider to discuss their responses to the postdeployment health assessment and any mental health or psychosocial issues that may be associated with the deployment. ${ }^{21}$ According to officials with DOD's Sexual Assault Prevention and Response Office, a minimum of 4 weeks is needed to diagnose post-traumatic stress disorder, differentiating it from acute stress.

In the Coast Guard, officials told us that EAPCs are responsible for informing sexual assault victims of their psychiatric care or counseling options. During such meetings, health care providers screen and treat servicemembers for mental health disorders, including post-traumatic stress disorder, and refer them to mental health specialists for additional acute or chronic care as appropriate.

Survey Data Suggest That Occurrences of Sexual Assault May Exceed Rates Reported
We found, based on responses to our nongeneralizable survey and a 2006 DOD survey, the most recent available, that occurrences of sexual assault may be exceeding the rates being reported, suggesting that DOD and the Coast Guard have only limited visibility over the incidence of these occurrences. We recognize that the precise number of sexual assaults involving servicemembers is not possible to determine, and that studies suggest sexual assaults are generally underreported in the United States. Nevertheless, our findings indicate that some servicemembers may choose not to report sexual assault incidents for a variety of reasons including the belief that nothing would be done or that reporting an incident would negatively impact their careers.

In fiscal year 2007, DOD received 2,688 reports of alleged sexual assault made with either the restricted or unrestricted reporting option involving servicemembers as either the alleged offenders or victims. The Coast

\footnotetext{
${ }^{21}$ DOD defines a "trained health care provider" as a physician, physician assistant, nurse practitioner, advanced practice nurse, independent duty corpsman, independent duty medical technician, or Special Forces medical sergeant.
} 
Guard, which did not offer the restricted reporting option during fiscal year 2007, received 72 reports of alleged sexual assault made using the unrestricted reporting option during this same time period. For additional information on reported sexual assault incidents in DOD and the Coast Guard for fiscal year 2007, see appendix V.

At the 14 installations where we administered our survey, 103 servicemembers indicated that they had been sexually assaulted within the preceding 12 months, as shown in table 5. Of these, the number of servicemembers who indicated that they had been sexually assaulted within the preceding 12 months ranged from 3 to 11 per installation. Due to the transient nature of servicemembers, the alleged sexual assaults may not have occurred at the locations where we administered our survey.

Table 5: Number of Selected Servicemembers Who Reported Having been Sexually Assaulted During the Preceding 12 Months

\begin{tabular}{lrrrrr}
\hline Location & Male & Female & Gender not provided & Total & Total surveyed \\
\hline United States & 10 & 40 & 2 & $\mathbf{5 2}$ & $\mathbf{2 , 1 8 7}$ \\
\hline Overseas & 4 & 45 & 2 & $\mathbf{5 1}$ & $\mathbf{1 , 5 6 3}$ \\
\hline Total & $\mathbf{1 4}$ & $\mathbf{8 5}$ & $\mathbf{4}$ & $\mathbf{1 0 3}$ & $\mathbf{3 , 7 5 0}$ \\
\hline Source: GAO & & & & &
\end{tabular}

Source: GAO.

Note: Some servicemembers did not indicate their gender. Therefore, the number of males and females does not always sum to the total number of respondents who indicated they were sexually assaulted within the preceding 12 months.

Of the 103 servicemembers who responded to our survey indicating that they had been sexually assaulted within the preceding 12 months, 52 indicated that they did not report the sexual assault incident. The number who indicated they did not report the sexual assault ranged from 1 to 6 servicemembers per installation. Table 6 provides information on the number of respondents to our survey who reported experiencing a sexual assault within the preceding 12 months. 
Table 6: Number of Selected Servicemembers Who Reported Experiencing a Sexual Assault within the Preceding 12 Months by Type of Reporting Option Used

Number of

\begin{tabular}{|c|c|c|c|c|}
\hline \multirow[b]{2}{*}{ Location } & \multirow[b]{2}{*}{$\begin{array}{r}\text { Total number of selected } \\
\text { servicemembers who } \\
\text { indicated that they were } \\
\text { sexually assaulted within } \\
\text { the preceding } 12 \text { months }^{a}\end{array}$} & \multicolumn{3}{|c|}{ Used restricted reporting option } \\
\hline & & Males & Females & $\begin{array}{r}\text { Gender not } \\
\text { provided }^{\mathrm{b}}\end{array}$ \\
\hline United States & 52 & 2 & 5 & 1 \\
\hline Overseas & 51 & 1 & 4 & 1 \\
\hline Total & 103 & 3 & 9 & 2 \\
\hline
\end{tabular}


selected servicemembers who:

\begin{tabular}{|c|c|c|c|c|c|c|c|c|}
\hline Males & Females & $\begin{array}{c}\text { Gender not } \\
\text { provided }^{\mathrm{b}}\end{array}$ & Males & Females & $\begin{array}{r}\text { Gender not } \\
\text { provided }^{\text {b }}\end{array}$ & Males & Females & $\begin{array}{r}\text { Gender not } \\
\text { provided }^{\mathrm{b}}\end{array}$ \\
\hline 1 & 5 & 0 & 1 & 12 & 0 & 5 & 16 & 1 \\
\hline 0 & 8 & 1 & 0 & 4 & 0 & 4 & 26 & 0 \\
\hline 1 & 13 & 1 & 1 & 16 & 0 & 9 & 42 & 1 \\
\hline
\end{tabular}

Source: GAO.

${ }^{a}$ Totals do not sum to the total number of respondents that indicated that they were sexually assaulted in the past 12 months because some respondents did not indicate if or how they reported the assault.

${ }^{\mathrm{b}} \mathrm{Some}$ respondents did not indicate their gender.

Servicemembers also told us that they were aware of alleged sexual assault incidents involving other servicemembers that were not reported to program officials. DOD's fiscal year 2007 annual report and a Coast Guard program official with whom we spoke further support the view that servicemembers are not reporting all sexual assault incidents, as does the Defense Manpower Data Center's 2006 Gender Relations Survey of Active Duty Members ${ }^{22}$ administered between June and September 2006. Issued in March 2008, the Defense Manpower Data Center survey found that of the estimated 6.8 percent of women and 1.8 percent of men in DOD who experienced unwanted sexual contact ${ }^{23}$ during the prior 12 months, the majority (an estimated 79 percent of women and 78 percent of men) chose not to report it. ${ }^{24}$ The Defense Manpower Data Center did not include data for the Coast Guard in its report. However, at our request, the Defense Manpower Data Center provided information on the Coast Guard that

\footnotetext{
${ }^{22}$ Defense Manpower Data Center, 2006 Gender Relations Survey of Active Duty Members (DMDC Report No. 2007-022 (March 2008). The weighted response rate was 30 percent.

${ }^{23}$ The survey defines unwanted sexual contact to include rape, nonconsensual sodomy (oral or anal sex), or indecent assault (unwanted, inappropriate sexual contact, or fondling) that can occur regardless of gender, age, or spousal relationship.

${ }^{24}$ For the DOD female population, this is an estimate of 6.8 percent with a margin of error of $+/-1$ percent. For the male population, this is an estimate of 1.8 percent with a margin of error of $+/-0.6$ percent. The margins of error are calculated with a 95 percent confidence interval.
} 
shows that an estimated 3 percent of female and 1 percent of male respondents reported experiencing unwanted sexual contact during the prior 12 months..$^{25}$ According to a Defense Manpower Data Center official, additional information about respondents in the Coast Guard who chose not to report experiences about unwanted sexual contact is not available because the number of Coast Guard members who indicated they experienced unwanted sexual contact is very low and unreliable due to high margins of error.

Earlier surveys conducted by some of the military services also indicated that servicemembers may not have been reporting all incidents of sexual assault. The Navy conducted a survey of its members in 2005 to assess, among other things, the likelihood that servicemembers would report a sexual assault incident to Navy authorities, and while the majority of both enlisted members and officers responding indicated they would report a sexual assault if they were the victim, as many as an estimated 10 percent of enlisted sailors and 10 percent of officers responded that they were unlikely to do so. ${ }^{26}$ Similarly, a voluntary nonprobability survey conducted by the Naval Inspector General in 2004 through early 2005 determined that 57 percent of victims who were sexually assaulted at some point in their Navy career did not report the incident. ${ }^{27}$ Further, the Army noted as part of DOD's fiscal year 2007 annual report that recent Army survey data, which are not generalizable, indicate that as many as 70 percent of female soldiers who said they had experienced a sexual assault within the previous 12 months had not reported the incident. ${ }^{28}$

While the survey results suggest a disparity between the actual number of sexual assault incidents and the number of those reported, this is largely an expected result of anonymous surveys. Whereas formal reports, whether restricted or unrestricted, involve some level of personal

\footnotetext{
${ }^{25}$ For the Coast Guard female population, this is an estimate of 3 percent with a margin of error of $+/-3$ percent. For the male population, this is an estimate of 1 percent with a margin of error of $+/-1$ percent. The margins of error are calculated with a 95 percent confidence interval.

${ }^{26}$ The Navy's survey was based on a statistical random sample where the estimates were weighted to represent the full population of enlisted and officer men and women.

${ }^{27}$ The Naval Inspector General's survey was based on a voluntary nonprobability sample that cannot be generalized to the full population of enlisted and officer men and women.

${ }^{28}$ The Army's survey was based on a stratified random sample where the estimates were not weighted to represent the full population of enlisted and officer men and women.
} 
identification and therefore a certain amount of risk on the part of the victim, the risks and incentives for servicemembers making anonymous reports are very different. Hence, anonymous survey results tend to produce higher numbers of reported incidents. Another factor obscuring the visibility that DOD and Coast Guard officials can have over the incidence of sexual assault is the fact that many of the individuals to whom the assaults may be reported, including clergy and civilian victim care organizations, civilian friends, or family, are not required to disclose these incidents. As a result, while DOD and the Coast Guard strive to capture an accurate picture of the incidence of sexual assault, their ability is necessarily limited.

Our survey data revealed a number of reasons why servicemembers who experienced a sexual assault during the preceding 12 months did not report the incident. Commonly cited reasons by survey respondents at the installations we visited included: (1) the belief that nothing would be done; (2) fear of ostracism, harassment, or ridicule by peers; and (3) the belief that their peers would gossip about the incident. Survey respondents also commented that they would not report a sexual assault because of concern about being disciplined for collateral misconduct, such as drinking when not permitted to do so; not knowing to whom to make a report; concern that a restricted report would not remain confidential; the belief that an incident was not serious enough to report; or concern that reporting an incident would negatively impact their career or unit morale. The following are some examples of comments from survey respondents:

- A senior enlisted female commented that "many individuals do not come forward in the military out of fear of punishment because they have done something (i.e., drinking) that they could also get in trouble for."

- A senior enlisted female commented that "most females are afraid to say anything to anyone in their chain of command because that person will go back and tell everyone in this command and it will get around to the whole entire unit as well as Brigade."

- A junior enlisted male commented that "some servicemembers might feel like there is no point in telling anyone, especially if that person is higher rank than you because they might believe the higher ranking person would be believed over the lower ranking person."

- A senior enlisted male commented that "peer pressure and embarrassment is a huge factor in why sexual assault is not always reported."

- A male servicemember commented that he did not believe a sexual assault incident he experienced was "serious or offensive enough" to warrant reporting. 
- A junior enlisted male commented that "just because a member of the service might have all the resources they need to report an assault without fear of reprisal doesn't mean that all of them [will]. I believe many are afraid [the incident will be made] public, making the victim seem . . . loose with their sexual actions."

- Several servicemembers observed that reporting a sexual assault is perceived as something that can ruin a reputation. One junior enlisted female commented that "there are a lot of females who feel that an issue like sexual assault can ruin their reputation with other male soldiers or their unit."

The 2006 Gender Relations Survey of Active Duty Members identified similar reasons why servicemembers did not report unwanted sexual contact, including concern that reporting an incident could result in denial of promotions and professional and social retaliation. However, servicemembers also reported favorable results after reporting unwanted sexual contact to military authorities, including being offered counseling and advocacy services, medical and forensic services, legal services, and action being taken against alleged offenders. Respondents to our survey indicated they were supportive of the restricted reporting option as well. For example:

- A junior enlisted female observed that in her opinion servicemembers will be more likely to report an incident anonymously, commenting "I'm glad the [reporting] options are there."

- A female senior officer commented that "giving the victim a choice of making a [restricted] or [unrestricted] report is a positive change and allows that person the level of privacy they require."

- A male senior officer observed that as awareness of SARCs increases, there has been a corresponding increase in reporting, commenting that he believes "word is getting out and reports are beginning to filter in, troops seem to be gaining confidence to report incidents." 
DOD and the Coast Guard Have Established Some Mechanisms for Overseeing Reports of Sexual Assault, but Lack an Oversight Framework, and DOD Lacks Key Information from the Services
While DOD and the Coast Guard have established some mechanisms for overseeing reports of sexual assaults involving servicemembers, they lack an oversight framework, and DOD lacks key information from the services needed to evaluate the effectiveness of the department's sexual assault prevention and response program. Also, DOD and the Coast Guard lack an oversight framework because they have not established a comprehensive plan that includes such things as clear objectives, milestones, performance measures, and criteria for measuring progress, nor have they established evaluative performance measures with clearly defined data elements with which to analyze sexual assault incident data. DOD and the military services provide information on reports of alleged sexual assaults annually to Congress in accordance with statutory requirements, but the effectiveness of these reports for informing Congress about incidents of sexual assault in the military services is limited by DOD's lack of a consistent methodology for reporting incidents, and the means of presentation for some of the data is misleading. Further, DOD lacks access to data needed to conduct comprehensive cross-service analyses over time. Finally, the congressionally directed Defense Task Force on Sexual Assault in the Military Services has yet to begin its review, although DOD considers its work to be an important oversight element. Without an oversight framework, as well as more complete data, decision makers in DOD, the Coast Guard, and Congress lack information they need to evaluate and oversee the programs.
DOD and the Military Services Have Established Some Oversight Mechanisms
DOD's instruction establishes oversight mechanisms for the department's sexual assault prevention and response program and assigns oversight responsibility to DOD's Sexual Assault Prevention and Response Office (within the Office of the Deputy Under Secretary of Defense for Plans). ${ }^{29}$ DOD's Sexual Assault Prevention and Response Office is responsible for:

- developing programs, policies, and training standards for the prevention, reporting, response, and program accountability of sexual assaults involving servicemembers;

- developing strategic program guidance and joint planning objectives;

- collecting and maintaining sexual assault data; 
- establishing institutional evaluation, quality improvement, and oversight mechanisms to periodically evaluate the effectiveness of the department's program;

- assisting with identifying and managing trends; and

- preparing the department's annual report to congress.

To help oversee implementation of its sexual assault prevention and response program, in 2006 DOD established a Sexual Assault Advisory Council comprised of representatives from DOD's Sexual Assault Prevention and Response Office, the military services, and the Coast Guard. The Sexual Assault Advisory Council's responsibilities include advising the Secretary of Defense on the department's sexual assault prevention and response policies, coordinating and reviewing the department's policies and program, and monitoring progress. During the course of our review, the Sexual Assault Advisory Council began to develop preliminary baseline performance measures and evaluation criteria for assessing program implementation. However, DOD has not yet established time frames for completing and implementing these measures. DOD is also working with the military services to develop standards to assess program implementation and response during site visits planned for 2008.

While the military services have developed mechanisms to collect data, efforts to systematically review and assess implementation of their programs are limited and vary by military service. The following are examples of what we found:

- The Army, in response to recommendations made by its Inspector General, has developed a plan that includes specific actions to be taken and time frames for completion to improve its program. In addition, the Army has developed and implemented a Sexual Assault Data Management System to track reported incidents and associated demographic information about victims and alleged offenders.

- The Navy is reviewing sexual assault incident reports received from Navy installations, and program officials told us they proactively contact installations that have not reported any sexual assault incidents during the reporting period. Further, each installation's Fleet and Family Support Center conducts accreditation visits every 3 years to provide quality assurance and identify and resolve potential problems. For example, they have found that some servicemembers may not be aware of the reporting options and, in the past, some commands had not supported the program. While the Navy has not yet developed a database to track sexual assault 
incident data, program officials told us they plan to do so before the end of fiscal year 2008 .

- Commanders in the Marine Corps use commanders' protocols for responding to allegations of sexual assault to ensure they are accomplishing the intent of the program without overlooking any aspects. Further, the Marine Corps uses its Automated Inspection Reporting System to assess management and administration of the program at the installation level.

- Program officials in the Air Force told us they rely on SARCs to proactively provide feedback about the program through their chain of command and during monthly teleconferences. While Air Force officials acknowledge that they have not conducted either official or formal institutional reviews or assessments of the Air Force's program, they have asked the Air Force's Inspector General to review its first responder training and other aspects of the program to ensure compliance with DOD's policy. The Air Force collects and maintains information about reported sexual assault incidents using multiple databases.

DOD Does Not Have an Oversight Framework in Place to Evaluate the Effectiveness of Its Sexual Assault Prevention and Response Program
Though DOD has established some oversight mechanisms, it has not established an oversight framework, which is necessary to ensure the effective implementation of its sexual assault prevention and response program. Our prior work has demonstrated the importance of outcomeoriented performance measures to successful program oversight and shown that having an effective plan for implementing initiatives and measuring progress can help decision makers determine whether initiatives are achieving their desired results. ${ }^{30}$ DOD has not established an oversight framework because it has not established a comprehensive plan that includes such things as clear objectives, milestones, performance measures, and criteria for measuring progress, nor has it established evaluative performance measures with clearly defined data elements with which to analyze sexual assault incident data. Because DOD's sexual assault prevention and response program lacks an oversight framework, its program, as currently implemented, does not provide decision makers with the information they need to evaluate the effectiveness of the program, determine the extent to which the program is helping to prevent sexual assault from occurring, or ensure that servicemembers who are victims of sexual assault receive the care they need.

\footnotetext{
${ }^{30} \mathrm{GAO}-03-669$.
} 
As discussed above, DOD's directive assigns oversight responsibility to DOD's Sexual Assault Prevention and Response Office. However, this office has yet to establish metrics to facilitate program evaluation and assess effectiveness. For example, it has not developed specific metrics to:

- determine the frequency with which victims were precluded from making a confidential report using the restricted reporting option or reasons that precluded them from doing so; or

- track information on whether units have received required annual sexual assault prevention and response training, including how many servicemembers within a unit have received the training.

Additionally, DOD's Sexual Assault Prevention and Response Office has yet to establish performance goals-for example, a goal specifying the percentage of servicemembers within a unit who should receive required training. In the absence of such measures, Sexual Assault Prevention and Response Office officials told us that they currently determine the effectiveness of DOD's program based on how well the military services are complying with program implementation requirements identified by DOD. While they acknowledged that to date their focus has been on program implementation as opposed to program evaluation, these officials noted that the Sexual Assault Advisory Council is in the initial stages of developing performance measures and evaluation criteria to assess program performance and identify conditions needing attention. Presently, DOD is working with the military services to develop guidelines to permit, among other uses, consistent assessment of program implementation during site visits conducted by DOD's Sexual Assault Prevention and Response Office as well as by the military services at other times. However, time frames for developing and implementing these measures have not yet been established, and without such a plan and evaluative measures, the program does not provide decision makers with the information they need to evaluate the effectiveness and efficiency of the military services' efforts.

Without an oversight framework to guide program implementation, DOD risks that the military services will not collect all of the information needed to provide insight into the effectiveness of their programs. For example, officials have recognized that they will need additional data on sexual assault incidents both for purposes of oversight and to respond effectively to congressional inquiries as the program matures. However, the military services have encountered challenges in providing requested data because the request came after the start of the collection period. For example, with the exception of the Army, none of the military services was 
able to provide data as part of the fiscal year 2007 annual report to Congress on sexual assaults involving civilian victims, such as contractors and government employees. Without an oversight framework that includes clearly defined data collection elements, DOD's Sexual Assault Prevention and Response Office risks not being able to respond effectively to congressional requests or to oversee the program appropriately.

The Coast Guard Lacks an Oversight Framework and Congress Has No Visibility of Sexual Assault Incidents Involving Coast Guard Members
Oversight by the Coast Guard headquarters of its sexual assault prevention and response program is limited to the collection and maintenance of incident data and, like DOD, the Coast Guard has not established an oversight framework to guide implementation of its program. Although the Coast Guard recently revised its instruction to incorporate a restricted reporting option and to generally mirror DOD's sexual assault prevention and response program, according to Coast Guard officials their focus to date has been on program implementation as opposed to program evaluation. Like DOD, the Coast Guard has not developed an oversight framework that includes clear objectives, milestones, performance measures, and criteria for measuring progress, nor has the Coast Guard developed performance measures to assess its program. Coast Guard program officials told us that they plan to conduct reviews of their program for compliance and quality in the future and will continue to review reported incident data, and they plan to leverage any metrics developed by DOD to assess their program. Further, the Coast Guard Investigative Service has begun to conduct limited trend analysis on reported incidents, including the extent to which alcohol or drugs were involved in alleged sexual assaults. However, like DOD, the Coast Guard is not able to fully evaluate the results achieved by its efforts, and it is unclear whether its program is achieving its goals.

While there is no statutory reporting requirement for the Coast Guard, the Coast Guard voluntarily participates in DOD's annual reporting requirement by submitting data to DOD's Sexual Assault Prevention and Response Office. The Coast Guard Investigative Service collects data on unrestricted reports as part of its investigative responsibilities and shares these data with the Coast Guard Office of Work Life, which collects data on alleged assaults received using the restricted reporting option. The Coast Guard shares aggregate reported data with DOD's Sexual Assault Prevention and Response Office. However, DOD does not include these data in its annual report and the Coast Guard does not provide these incident data to Congress because neither is required to do so. As a result, Congress does not have visibility over the extent to which sexual assaults involving Coast Guard members occur. 
DOD Data Reported to Congress Could Be Misinterpreted
DOD's annual reports to Congress may not effectively characterize incidents of sexual assault in the military services because the department has not clearly articulated a consistent methodology for reporting incidents, and because the means of presentation for some of the data does not facilitate comparison. DOD's annual reports to Congress include data on the total number of restricted and unrestricted reported incidents of sexual assault; however, meaningful comparisons of the data cannot be made because the respective offices that provide the data to DOD measure incidents of sexual assault differently. For example, in the military services, SARCs, who focus on victim care, report data on the number of sexual assault incidents alleged using the restricted reporting option based on the number of victims involved. In contrast, the criminal investigative organizations, which report data on the number of sexual assault incidents alleged using the unrestricted reporting option, report data on a per "incident" basis, which may include multiple victims or alleged offenders. Thus, the lack of a common means of presentation for reporting purposes has prevented users of the reports from making meaningful comparisons or drawing conclusions from the reported numbers.

Further, while we identified some improvements in the fiscal year 2007 report in the way DOD discusses some data, DOD's annual report lacks certain data that we believe would facilitate congressional oversight or understanding of victims' use of the reporting options. For example, while DOD's annual report provides Congress with the aggregate numbers of investigations during the prior year for which commanders did not take action against alleged offenders, those aggregated numbers do not distinguish between cases in which evidence was found to be insufficient to substantiate an alleged assault versus the number of times a victim recanted an accusation or an alleged offender died. Also, though DOD's annual report documents the number of reports that were initially brought using the restricted reporting option and later changed to unrestricted, DOD's annual report includes these same figures in both categories-that is, the total number of restricted reports and the total number of unrestricted reports. An official in DOD's Sexual Assault Prevention and Response Office told us that because the military services do not provide detailed case data to DOD, the department is not able to remove these reports from the total number of restricted reports when providing information in its annual report. However, we believe that double listing the figures is confusing.

Also, while DOD's Sexual Assault Prevention and Response Office has collected and reported incident data since calendar year 2004, the 
department lacks a baseline for conducting trend analysis over time because of changes in the way data are reported. Comparisons among data reported during calendar years 2005 and 2006 are difficult to make because the restricted reporting option was not available during the entirety of calendar year 2005. Significantly, direct comparisons cannot be made between fiscal year 2007 and prior years because of inconsistencies in the reporting periods. For example, changes to sections of the UCMJ dealing with sexual assault that took effect on October 1, 2007, led DOD to change the period of data collection from calendar year to fiscal year. Consequently, incident data reported in DOD's calendar year 2006 annual report to Congress overlap with data reported in its fiscal year 2007 annual report for the months of October, November, and December 2006. However, because the military services provide incident data to DOD that are aggregated for each service, Sexual Assault Prevention and Response Office officials told us they cannot adjust the calendar year data to a fiscal year basis to facilitate trend analysis. Officials noted that each military service would need to manually adjust previously reported calendar year data to a fiscal year basis, and such an undertaking would be time intensive. Moreover, a Sexual Assault Prevention and Response Office official told us that these changes, which led DOD to revise the standard definition of sexual assault, will also prevent comparisons between fiscal year 2007 data and data in future years, except in general terms. Consequently, the way in which sexual assault incident data are collected and reported will change in the fiscal year 2008 annual report to Congress and, until investigations of sexual assault incidents reported prior to fiscal year 2008 are completed, both DOD's original and revised standard definitions of sexual assault will be in use. Finally, DOD has not conducted its own analysis of the information contained in the military services' annual reports or provided its assessment of their programs prior to forwarding these reports to Congress, in part because it is not explicitly required to include this type of assessment in its annual report. Without a firm baseline and consistent data collection, DOD will not be able to conduct trend analysis over time that provides insight into incident data collected, except in the most general terms.

DOD Lacks Access to Data to Conduct Comprehensive CrossService Analysis Over Time
DOD's Sexual Assault Prevention and Response Office is not able to conduct comprehensive cross-service trend analysis of sexual assault incidents because it does not have access to installation- or case-level data that would facilitate such analyses. DOD officials told us that the military services do not provide installation- or case-level incident data beyond those that are aggregated at the military-service level. These data are generally limited to information needed to meet statutory requirements for 
inclusion in the annual report to Congress. Service officials told us they do not want to provide installation- or case-level data to DOD because they are concerned that (1) data may be misinterpreted, (2) even nonidentifying data about the victim may erode victim confidentiality, and (3) servicemembers may not report sexual assaults if case-level data are shared beyond the service-level. However, without access to such information, DOD does not have the means to identify those factors, and thus to fully execute its oversight role, including assessing trends over time. For example, without case-level data, DOD cannot determine the frequency with which sexual assaults are reported in each of the geographic combatant commands. Since 2004, DOD has required the Joint Staff to provide periodic information on sexual assaults reported in the U.S. Central Command's area of responsibility because of the significant impact sexual assault has on mission readiness. However, DOD does not know the rate of reported sexual assault incidents in U.S. Central Command's area of responsibility as compared with the rate in other geographic combatant commands, because the department does not require the Joint Staff to provide such information.

Furthermore, installation- and case-level data may be useful to identify installations that over periods of time continue to have high rates of reported alleged sexual assault incidents as a percentage of the total population. For example, in analyzing the services' installation-level data we identified, for one of the military services, three installations with higher reporting rates for sexual assaults than other installations. Continuation of such trends at these installations over time could indicate best practices, such as supportive command climates, that encourage victims to report sexual assaults. Conversely, such trends may identify installations or units where additional training and resources to prevent sexual assaults may be needed. Such information, if available, could better inform decisions by officials in DOD's Sexual Assault Prevention and Response Office to select installations within each service to visit for program assessments and identify factors to consider when making programmatic corrections. 
Congressionally Directed Defense Task Force on Sexual Assault in the Military Services Has Not Yet Begun Its Review
To provide further oversight of DOD's sexual assault prevention and response program, the Ronald W. Reagan National Defense Authorization Act for Fiscal Year $2005^{31}$ required the Defense Task Force on Sexual Assault in the Military Services to conduct an examination of matters relating to sexual assault in cases in which members of the Armed Forces are either victims or offenders. ${ }^{32}$ As part of its examination, the law directs the task force to assess, among other things, DOD's reporting procedures, collection, tracking, and use of data on sexual assaults by senior military and civilian leaders, as well as DOD's oversight of its sexual assault prevention and response program. The law does not require an assessment of the Coast Guard's program. Senior officials within the Office of the Under Secretary of Defense for Personnel and Readiness have stated that they plan to use the task force's findings to evaluate the effectiveness of DOD's sexual assault prevention and response program. However, as of July 2008 this task force has yet to begun its review.

Senior task force staff members we spoke with attributed the delays to challenges in appointing the task force members and member turnover. As of July 2008, however, they told us that all 12 task force members had been appointed, and that their goal was to hold their first open meeting, and thus begin their evaluation, in August 2008. They also told us that they estimate that by the end of fiscal year 2008 DOD will have expended about $\$ 15$ million since 2005 to fund the task forces' operations. According to senior task force staff members, much of this funding has gone towards the task forces' operational expenses, including salaries for the civilian staff members, contracts, travel, and rent. The law directs that the task force submit its report to the Secretary of Defense and the Secretaries of the Army, Navy, and Air Force no later than 1 year after beginning its

\footnotetext{
${ }^{31}$ Pub. L. No. 108-375, § 576 (2004).

${ }^{32}$ The Defense Task Force on Sexual Assault in the Military Services is an extension of the Defense Task Force on Sexual Harassment and Violence at the Military Service Academies established by the Secretary of Defense pursuant to the National Defense Authorization Act for Fiscal Year 2004, Pub. L. No. 108-136, § 526 (2003). The Ronald W. Reagan National Defense Authorization Act for Fiscal Year 2005 directed that the task force studying the academies be renamed and begin carrying out the new functions required by the National Defense Authorization Act for Fiscal Year 2005 once it had completed its duties under the National Defense Authorization Act for Fiscal Year 2004. The National Defense Authorization Act for Fiscal Year 2005 also allowed the Secretary of Defense to change the composition of the task force after it completed its work related to the academies and before it began to carry out its new functions. The Defense Task Force on Sexual Harassment and Violence at the Military Service Academies submitted its report on June 30, 2005.
} 
examination. If such a goal were met, the task force's evaluation could be complete by August $2009 .{ }^{33}$ However, as of the time of our review, it was uncertain whether the task force will be able to meet this goal.

\section{Conclusions}

DOD and the Coast Guard have taken positive steps to prevent, respond to, and resolve reported incidents of sexual assault. However, a number of challenges-such as limited guidance for implementing DOD's policies in certain environments, some commanders' support and limited resources for the programs, training that is not consistently effective, and limited access to mental health services-could undermine the effectiveness of some of their efforts. Left unchecked, these challenges could undermine DOD's and the Coast Guard's efforts by eroding servicemembers' confidence in the programs or decreasing the likelihood that sexual assault victims will turn to the programs for help when needed. Also, although DOD and the Coast Guard have established some oversight mechanisms, without an oversight framework with specific goals, measures, and milestones for assessing results, DOD and the Coast Guard are limited in their ability to measure the success of their efforts. Further, without information on the incidence of sexual assault in the Coast Guard, Congress' visibility over the extent to which sexual assaults involving Coast Guard members occur is limited. Finally, without a firm baseline and consistent data collection, DOD will not be able to conduct trend analysis over time that enables it to determine where its program is working and where it is not, and therefore may have difficulty judging the overall successes, challenges, and lessons learned from its program. As a result, congressional decision makers may not have the visibility they need of the incidence of sexual assault reports involving servicemembers.

\footnotetext{
${ }^{33}$ Section 576 of Pub. L. No 108-375 (2004) directs the Defense Task Force on Sexual Assault in the Military Services to provide a report on the activities of DOD and the Armed Forces to respond to sexual assault and to include any recommendations for changes to policy and law that the task force considers appropriate to the Secretary of Defense and the Secretaries of the Army, Navy, and Air Force no later than 1 year after initiating its examination. In addition, the law also directs that 90 days after receiving the report the Secretary of Defense submit the report, along with the Secretary's evaluation of the report, to the Committees on Armed Services of the Senate and House of Representatives.
} 
Matter for

Congressional

Consideration
To improve oversight of sexual assault incidents involving servicemembers in the Coast Guard, Congress may wish to consider requiring the Coast Guard to submit to Congress sexual assault incident and program data annually that are methodologically comparable to those required of DOD.

\section{Recommendations for Executive Action}

We recommend that the Secretary of Defense take the following nine actions:

- To improve implementation of the sexual assault prevention and response program in DOD, direct the Under Secretary of Defense for Personnel and Readiness to:

- Review and evaluate the department's policies for the prevention and response of sexual assault to ensure that adequate guidance is provided to effectively implement the program in deployed environments and joint environments.

- Evaluate the military services' processes for staffing and designating key installation-level program positions, such as SARCs, at installations in the United States and overseas, to ensure that these individuals have the ability and resources to fully carry out their responsibilities.

- Review and evaluate sexual assault prevention and response training to ensure the military services are meeting training requirements and to enhance the effectiveness of the training.

- Systematically evaluate and develop an action plan to address any factors that may prevent or discourage servicemembers from accessing mental health services following a sexual assault.

- To ensure that the sexual assault prevention and response program has the strong support of military commanders and other senior leaders necessary for implementation, direct the service secretaries to emphasize to all levels of command their responsibility for supporting the program, and review the extent to which commanders support the program and resources are available to raise servicemembers' awareness of sexual assault matters.

- To enhance oversight of the sexual assault prevention and response program in DOD, direct the Under Secretary of Defense for Personnel and Readiness to:

- Require the Sexual Assault Prevention and Response Office to develop an oversight framework to guide continued program implementation and evaluate program effectiveness. At a minimum, such a framework 
should contain long-term goals, objectives, and milestones; performance goals; strategies to be used to accomplish goals; and criteria for measuring progress.

- Improve the usefulness of the department's annual report as an oversight tool both internally and for congressional decision makers by establishing baseline data to permit analysis of data over time, and reporting data so as to distinguish cases in which (1) evidence was insufficient to substantiate an alleged assault, (2) a victim recanted, or (3) the allegations of sexual assault were unfounded.

- To enhance oversight of the military services' sexual assault prevention and response programs, direct the service secretaries to provide installation-level incident data to the Sexual Assault Prevention and Response Office annually or as requested to facilitate analysis of sexual assault-related data and better target resources over time.

- To help facilitate the assessment and evaluation of DOD's sexual assault prevention and response program, direct the Defense Task Force on Sexual Assault in the Military Services to begin its examination immediately, now that all members of the task force have been appointed, and to develop a detailed plan with milestones to guide its work.

We recommend that the Commandant of the Coast Guard, in order to improve implementation and enhance oversight of the Coast Guard's sexual assault prevention and response program, take the following two actions:

- Evaluate its processes for staffing key installation-level program positions, such as the EAPC, to ensure that these individuals have the ability and resources to fully carry out their responsibilities.

- Develop an oversight framework to guide continued program implementation and evaluate program effectiveness. At a minimum, such a framework should contain long-term goals, objectives, and milestones; performance goals; strategies to be used to accomplish goals; and criteria for measuring progress.

Agency Comments and Our Evaluation
In written comments on a draft of this report, both DOD and the Coast Guard concurred with all of our recommendations. DOD's comments are reprinted in appendix II, and the Coast Guard's comments are reprinted in appendix III. The Coast Guard also provided technical comments which we incorporated where appropriate. 
In concurring with our first recommendation, that the department should review and evaluate its policies for the prevention of and response to sexual assault to ensure that adequate guidance is provided to effectively implement the program in deployed and joint environments, DOD asserted that it had originally brought this issue to our attention. We disagree with DOD's characterization of this issue. As noted in our report, program officials with whom we met overseas informed us of their concerns that DOD's guidance does not address some important issues-such as how to implement the program when operating in a deployed environment. In some instances, the military services also informed us of their concerns over the adequacy of DOD's guidance. However, officials with DOD's Sexual Assault Prevention and Response Office did not express any such concerns to us during the course of our review, nor did they indicate that they were taking any actions to address them. Nonetheless, DOD in its written comments cited several positive actions it is taking take to meet the intent of our recommendation, such as its use of Policy Assistance Team visits to ensure that all challenges have been identified.

In concurring with our recommendations aimed at improving implementation of the department's sexual assault prevention and response program-including that DOD should (1) evaluate the military services' processes for staffing key installation-level program positions, (2) review and evaluate sexual assault prevention and response training; and (3) systematically evaluate and develop an action plan to address any factors that may prevent or discourage servicemembers from accessing mental health services following a sexual assault-DOD commented that several efforts are currently underway or are planned to address these issues. For example, DOD stated that the department is currently utilizing Policy Assistance Team site visits to evaluate the effectiveness of SARCs as implemented by each of the military services, and to elicit feedback from servicemembers about training content, frequency, media, and effectiveness. We commend DOD for taking immediate steps in response to our recommendations, such as including a review of the military services' implementation of the SARC position and training as part of its Policy Assistance Team site visits. As DOD noted in its comments, additional efforts to address our recommendations are planned. We believe it is important for the department to continue to emphasize taking positive actions with regard to our recommendations.

In its concurrence with our recommendation that the department should emphasize to all levels of command their responsibility for supporting the program and should review the extent to which support and resources are available to raise servicemembers' awareness of sexual assault matters, 
DOD noted that a letter from the Secretary of Defense is currently in draft for dissemination to the service secretaries emphasizing commander involvement and support for the program. DOD further noted that it will examine whether there is a need to update commanders' training to enhance their understanding and support of the program. However, DOD offered no specific information with regard to the steps it will take to review the extent to which commanders support the program and resources are available to raise servicemembers' awareness of sexual assault matters. We continue to believe that conducting such an assessment is critical to understanding the extent to which commanders actually support the program.

In its concurrence with our recommendations for enhancing oversight of the department's sexual assault prevention and response programincluding that DOD should (1) develop an oversight framework to guide continued program implementation and evaluate program effectiveness, and (2) establish baseline data to facilitate analysis of data over timeDOD noted that it had established its sexual assault prevention and response program very rapidly to meet an emergent need, but that now that the program is established it must transition to a mature program with long-term goals, objectives, milestones, and criteria for measuring progress. We commend the department for committing to develop an oversight framework for its program.

In its concurrence with our recommendation that DOD should direct the military services to provide installation-level incident data to the Sexual Assault Prevention and Response Office annually or as requested, DOD noted that U.S. Central Command, the Army, the Navy, and the Air Force all have expressed concerns regarding the reporting of this installationlevel data. However, DOD also acknowledged - as we note in our reportthat access to installation-level data by DOD's Sexual Assault Prevention and Response Office is critical for oversight and visibility over alleged sexual assault incidents and stated it is drafting a letter for the Secretary of Defense's signature ordering the military services to provide installation-level data to DOD's Sexual Assault Prevention and Response Office.

Finally, in its concurrence with our recommendation that the department should direct the Defense Task Force on Sexual Assault in the Military Services to begin its examination immediately and to develop a detailed plan with milestones to guide its work, DOD noted that the task force's first meeting was held during mid-August 2008. Further, DOD provided additional information on the steps the task force plans to take to assess 
DOD's program as part of its evaluation, including conducting site visits and meeting with servicemembers and first responders. However, DOD provided no information regarding the milestones that will guide the task force's work. We continue to assert the importance of this key element of the plan the task force needs.

The Coast Guard also concurred with our recommendations aimed at improving implementation and enhancing oversight of its sexual assault prevention and response program-including that the Coast Guard should (1) evaluate its process for staffing key installation-level program positions and (2) develop an oversight framework to guide continued program implementation and evaluate program effectiveness. We commend the Coast Guard for its planned initiatives, including ensuring that program experts have the resources to fully conduct their duties and responsibilities, working with DOD to align its goals, strategies, and measurements for consistency and improved reporting, and seeking to coordinate an integrated approach and programmatic view to improve its program. However, we note that as part of these efforts it is important that the Coast Guard's efforts include an oversight framework with long-term goals, objectives, milestones, and criteria for measuring progress.

We are sending copies of this report to interested congressional members and staff; the Secretary of Defense; the Secretaries of the Army, the Navy, and the Air Force; the Commandant of the Marine Corps; and the Commandant of the Coast Guard. We will also make copies available to others upon request. In addition, the report will be available at no charge on the GAO Web site at http://www.gao.gov.

If you or your staff have any questions concerning this report, please contact me at (202) 512-3604 or farrellb@gao.gov. Contact points for our Offices of Congressional Relations and Public Affairs may be found on the last page of this report. Key contributors to this report are listed in appendix VIII.

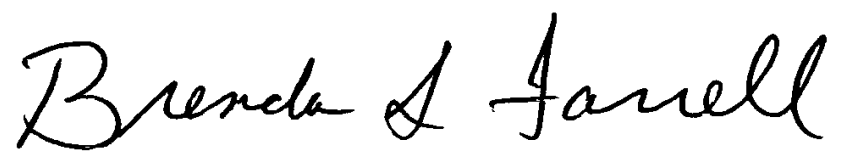

Brenda S. Farrell

Director, Defense Capabilities and Management 
List of Congressional Requesters

The Honorable Carl Levin

Chairman

The Honorable John McCain

Ranking Member

Committee on Armed Services

United States Senate

The Honorable John F. Tierney

Chairman

The Honorable Christopher Shays

Ranking Member

Subcommittee on National Security and Foreign Affairs

Committee on Oversight and Government Reform

House of Representatives

The Honorable Daniel K. Akaka

United States Senate

The Honorable Christopher S. Bond

United States Senate

The Honorable Barbara Boxer

United States Senate

The Honorable Tom Harkin

United States Senate

The Honorable Joseph I. Lieberman

United States Senate

The Honorable Claire McCaskill

United States Senate

The Honorable Patty Murray

United States Senate

The Honorable Barack Obama

United States Senate

The Honorable Bernard Sanders

United States Senate 


\section{Appendix I: Scope and Methodology}

To determine the extent to which the Department of Defense (DOD) and the Coast Guard have developed and implemented policies and programs to prevent, respond to, and resolve sexual assault incidents involving servicemembers, we reviewed legislative requirements and obtained and analyzed DOD's, the military services', and the Coast Guard's guidance and requirements for the prevention, response, and resolution of sexual assault. We also interviewed officials in DOD, the Army, the Air Force, the Navy, the Marine Corps, and the Department of Homeland Security and the Coast Guard to obtain a comprehensive understanding of their efforts to implement programs to prevent and respond to reported incidents of sexual assault. We also obtained and analyzed DOD's annual reports to Congress for calendar years 2004, 2005, 2006, and fiscal year 2007 and compared the statutory requirements for DOD's annual report to Congress to the data included in the annual reports. In addition, we visited 15 military installations in the United States and overseas where we met with program officials and responders to discuss their experiences preventing and responding to incidents of sexual assault and the challenges they face implementing sexual assault prevention and response programs. The locations we visited were selected based on a number of factors, including units' mission, availability of personnel given training or mission requirements, and recent deployment histories. We focused our overseas efforts on military installations located in the U.S. Central Command's area of responsibility because of past congressional concerns about the prevalence of sexual assaults in deployed locations and combat zones. At the installations we visited, we met with Sexual Assault Response Coordinators and victim advocates in DOD; Employee Assistance Program Coordinators in the Coast Guard; and judge advocates, medical and mental health personnel, criminal investigative personnel, law enforcement personnel, and chaplains in DOD and the Coast Guard. We also met with military commanders, including company and field grade officers, and senior enlisted servicemembers to discuss the steps they have taken to establish a command climate that discourages sexual assault from occurring, as well as their personal experiences responding to and resolving reported incidents of alleged sexual assault in their units. We also obtained servicemembers' perspectives on issues regarding command support, training, and access to medical and mental health services by administering a nonprobability survey to selected servicemembers and conducting one-on-one structured interviews with servicemembers at 14 of the 15 installations we visited. To understand how commanders dispose of sexual assault cases, we reviewed the Uniform Code of Military Justice and Manual for Courts-Martial and reviewed data reported by DOD for fiscal year 2007. To obtain an understanding of the processes used to treat mental health disorders, we met with knowledgeable officials from DOD, 
the military services, the Coast Guard, and the Department of Veterans Affairs.

To determine the extent to which DOD and the Coast Guard have visibility over reports of sexual assault involving servicemembers, we obtained and analyzed data for reported sexual assaults in both DOD and the Coast Guard for fiscal year 2007. To assess the reliability of the reported sexual assault data, we discussed these data with officials in DOD and the Coast Guard as well as with officials in the military services to gain an understanding of the processes and databases used to collect and record incident data, and to understand existing data quality control procedures and known limitations of the data. In comparing sexual assault data we received directly from DOD installation(s) with installation-level data we received from the services, we found some discrepancies that officials were not able to explain. Even with these discrepancies, we found these data were sufficiently reliable to present an overall description of reported incidents of sexual assault. While we also reviewed DOD's annual reports to Congress for calendar years 2004, 2005, and 2006, changes in the way DOD collects and reports incident data preclude direct comparisons and analysis across calendar and fiscal years. To understand why servicemembers may not report sexual assault incidents, we obtained servicemembers' perspectives on issues regarding sexual assault prevention and response programs in the military services and the Coast Guard through our survey and one-on-one structured interviews of servicemembers at 14 of the 15 installations we visited. We also reviewed the results of surveys conducted by DOD and the military services since 2004. In reviewing the survey documentation provided by the Defense Manpower Data Center and the Army and the Navy, we found these data were sufficiently reliable and we present these survey results to illustrate that multiple survey research sources indicate that there may be underreporting by those who experience sexual assaults.

To determine the extent to which DOD and the Coast Guard exercise oversight over reports of sexual assault involving servicemembers, we interviewed key officials with DOD's and the military services' respective Sexual Assault Prevention and Response offices and the Coast Guard's Office of Work Life to obtain a comprehensive understanding of the processes, procedures, and controls used for monitoring and overseeing the programs. We also interviewed representatives of the Defense Task Force on Sexual Assault in the Military Services, which is statutorily required to undertake an examination of sexual assault matters in the Armed Forces, to discuss the task force's progress. We reviewed various pertinent documents, including meeting minutes for DOD's Sexual Assault 
Advisory Council, federal internal control standards, ${ }^{1}$ and prior GAO reports on the use of performance measures to evaluate programmatic efforts. We also reviewed reports issued by the services' inspector generals and examined DOD's and the Coast Guard's responses to recommendations from prior related studies. In addition, we analyzed installation-level data for reported sexual assaults in both DOD and the Coast Guard for fiscal year 2007.

To obtain servicemembers' perspectives on issues regarding sexual assault prevention and response programs in DOD and the Coast Guard, we administered a total of 3,750 confidential surveys to a nonprobability sample of randomly selected servicemembers and conducted more than 150 one-on-one, structured interviews with randomly selected servicemembers at 14 of the 15 locations we visited. In the United States, the locations we visited included Camp Lejeune, North Carolina; Fort Bliss, Texas; Fort Drum, New York; Integrated Support Command Portsmouth, Virginia; Lackland Air Force Base, Texas; Marine Corps Base Quantico, Virginia; and Naval Station Norfolk, Virginia. Overseas, the locations we visited included Al Udeid Air Base, Qatar; Balad Air Base, Iraq; Camp Arifjan, Kuwait; Camp As Saliyah, Qatar; Camp Ramadi, Iraq; Camp Stryker, Iraq; Logistics Support Area Anaconda, Iraq; and Naval Support Activity, Bahrain. We did not administer our survey or conduct one-on-one structured interviews at Camp As Saliyah at the request of the Army because many of the servicemembers stationed there are on rest and relaxation tours during their overseas deployment. Of the 3,750 confidential surveys we administered, 711 surveys were administered in Iraq; 852 in Kuwait, Qatar, and Bahrain collectively; and 2,187 at locations across the United States. We considered conducting surveys of servicemembers using probability samples that would allow generalizing the results to all servicemembers at each installation we visited. However, because of the difficulties in identifying accurate and complete lists of servicemembers present at an installation as of a specific date from which to draw samples, particularly for installations outside the United States, and the administrative burden it would have placed on the installation commands, we did not pursue this. Instead, we conducted nonprobability surveys with randomly selected servicemembers to reflect all ranks and both men and women at 14 of the 15 installations we visited. Table 7

\footnotetext{
${ }^{1}$ See GAO, Standards for Internal Control in the Federal Government, GAO/AIMD-00-21.3.1 (Washington, D.C.: November 1999) and Internal Control Management and Evaluation Tool, GAO-01-1008G (Washington, D.C.: August 2001).
} 
provides information on the number of servicemembers we surveyed at each location.

Table 7: Number of Surveys Administered, by Location and Gender

\begin{tabular}{|c|c|c|c|c|}
\hline Installation & Males & Females & $\begin{array}{l}\text { Gender not } \\
\text { provided }\end{array}$ & Total \\
\hline \multicolumn{5}{|l|}{ U.S. Army } \\
\hline Camp Arifjan, Kuwait & 234 & 194 & 5 & 433 \\
\hline Camp As Saliyah, Qatar & $\mathrm{n} / \mathrm{a}$ & $\mathrm{n} / \mathrm{a}$ & $\mathrm{n} / \mathrm{a}$ & $n / a$ \\
\hline Camp Stryker, Iraq & 64 & 64 & 1 & 129 \\
\hline Fort Bliss, Texas & 165 & 128 & 9 & 302 \\
\hline Fort Drum, New York & 89 & 94 & 10 & 193 \\
\hline Logistics Support Area Anaconda, Iraq & 113 & 85 & 2 & 200 \\
\hline \multicolumn{5}{|l|}{ U.S. Air Force } \\
\hline Al Udeid Air Base, Qatar & 124 & 132 & 0 & 256 \\
\hline Balad Air Base, Iraq & 78 & 72 & 1 & 151 \\
\hline Lackland Air Force Base, Texas & 207 & 168 & 8 & 383 \\
\hline \multicolumn{5}{|l|}{ U.S. Navy } \\
\hline Naval Station Norfolk, Virginia ${ }^{\mathrm{b}}$ & 131 & 114 & 6 & 251 \\
\hline Naval Support Activity Bahrain ${ }^{c}$ & 108 & 52 & 3 & 163 \\
\hline \multicolumn{5}{|l|}{ U.S. Marine Corps } \\
\hline Camp Lejeune, North Carolina & 179 & 167 & 14 & 360 \\
\hline Camp Ramadi, Iraq & 137 & 92 & 2 & 231 \\
\hline Marine Corps Base Quantico, Virginia & 160 & 138 & 7 & 305 \\
\hline \multicolumn{5}{|l|}{ U.S. Coast Guard } \\
\hline $\begin{array}{l}\text { Integrated Support Command Portsmouth, } \\
\text { Virginia }\end{array}$ & 218 & 170 & 5 & 393 \\
\hline Total & 2,007 & 1,670 & 73 & 3,750 \\
\hline
\end{tabular}

Source: GAO.

${ }^{a}$ We did not administer our survey at Camp As Saliyah at the request of the Army because many of the servicemembers stationed there are on rest and relaxation tours during their overseas deployment.

${ }^{\mathrm{b}}$ Includes servicemembers from Yorktown Training Center, Virginia.

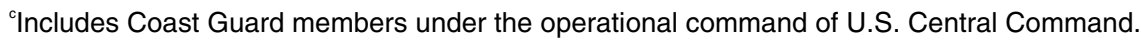

To select the participants for our surveys and one-on-one structured interviews, we requested that the locations we visited provide us with a list of available personnel. To the extent possible, we requested that this list not include personnel who were deployed, on temporary duty status, 
or otherwise not available to attend our survey sessions at the time of our visit. From the lists provided we randomly selected participants based on gender and rank. Participants were categorized according to the following ranks: junior enlisted (encompassing the ranks of E1-E4); mid-enlisted (encompassing the ranks of E5-E6); senior enlisted (encompassing the ranks of E7-E9); warrant officers and company grade officers (encompassing the ranks of W1-W5 and O1-O3); and field grade officers (encompassing the ranks of O4-O6).

To ensure maximum participation by selected servicemembers, we provided the locations we visited with lists of primary and alternate selections for both the survey sessions and one-on-one structured interviews. Because of the sensitivity of the information we were seeking, we took several steps to help assure a confidential environment during our survey sessions. First, we did not document the names of participants in any of our sessions. Further, we surveyed participants separately based on rank and gender; for instance, junior enlisted men were surveyed separately, as were junior enlisted women. We used this same approach for mid- and senior enlisted servicemembers; warrant and company grade officers; and field grade officers. Finally, we had male GAO analysts survey male servicemembers and female GAO analysts survey female servicemembers. Similarly, in an attempt to encourage an open discussion during our one-on-one structured interviews, but still protect the confidentiality of the servicemembers, we did not document their names. Because we did not select survey and interview participants using a statistically representative sampling method, our survey results and the comments provided during our interview sessions are nongeneralizable and therefore cannot be projected across DOD, a service, or any single installation we visited. However, the survey results and comments provide insight into the command climate and implementation of sexual assault prevention and response program at each location at the time of our visit.

To develop our survey questions, we reviewed several DOD surveys and studies of issues such as command climate and sexual harassment and sexual assault in the military. We also reviewed the military services' and the Coast Guard's policies and training materials for programs to prevent and respond to incidents of sexual assault. Because the scope of our review included focusing on military installations in the United States and the U.S. Central Command area of responsibility, we developed two survey questionnaires - the first focusing on the perspective of a servicemember stationed in the United States (see app. VI) and the second on that of a servicemember deployed outside the United States (see app. VII). We worked with social science survey specialists to develop our survey 
questionnaires. Because these were not sample surveys, there are no sampling errors. However, the practical difficulties of conducting any survey may introduce errors, commonly referred to as nonsampling errors. For example, differences in how a particular question is interpreted, in the sources of information that are available to respondents, or how the data are entered into a database can introduce unwanted variability into the survey results. We took steps in the development of the questionnaires, the data collection, and data analysis to minimize these nonsampling errors. For example, prior to administering the survey, we pretested the content and format of the questionnaire with servicemembers at Marine Corps Base Quantico, Virginia and Fort Meade, Maryland to determine whether (1) the survey questions were clear, (2) the terms used were precise, (3) respondents were able to provide the information we were seeking, and (4) the questions were unbiased. We made changes to the content and format of our final questionnaires based on the results of our pretesting.

We administered our surveys and conducted our one-on-one structured interviews at the locations we visited between September 2007 and March 2008. Because our surveys and questions asked participants to consider the frequency with which some things, such as training, have occurred over the past 12 months, participants' responses may cover the period between September 2006 and March 2008.

We visited or contacted the following organizations during our review:

\section{Department of Defense}

- Defense Manpower Data Center, Arlington, Virginia

- Defense Task Force on Sexual Assault in the Military Services, Alexandria, Virginia

- Office of the Under Secretary of Defense for Personnel and Readiness

- Office of the Deputy Under Secretary of Defense for Plans, Washington, D.C.

- Sexual Assault Prevention and Response Program Office, Washington, D.C.

- Office of the Assistant Secretary of Defense for Health Affairs, Falls Church, Virginia

- Defense Center of Excellence for Psychological Health and Traumatic Brain Injury, Rosslyn, Virginia

- U.S. Central Command, MacDill Air Force Base, Florida 


\section{Office of the Chairman, Joint Chiefs of Staff}

- J-1, Manpower and Personnel, Washington, D.C.

- J-4, Logistics, Washington, D.C.

\section{Department of the Army}

- Office of the Assistant Secretary of the Army for Manpower and Reserve Affairs, Washington, D.C.

- Office of the Chief of Chaplains, Crystal City, Virginia

- Office of the Chief of Public Affairs, Washington, D.C.

- Office of the Deputy Chief of Staff, G-1 Personnel

- Sexual Assault Prevention and Response Program Office, Rosslyn, Virginia

- Office of the Inspector General, Washington, D.C.

- Office of the Judge Advocate General, Rosslyn, Virginia

- Office of the Provost Marshall General, Washington, D.C.

- Office of the Surgeon General, Fort Sam Houston, Texas

- Army Central Command, Fort McPherson, Georgia

- Army Combat Readiness Center, Fort Rucker, Virginia

- Army Criminal Investigation Command, Fort Belvoir, Virginia

- Army Family and Morale, Welfare and Recreation Command, Alexandria, Virginia

- Army Forces Command, Fort McPherson, Georgia

- Army Medical Command, Fort Sam Houston, Texas

- Army Research Institute, Arlington, Virginia

- Army Training and Doctrine Command, Fort Monroe, Virginia - Army Military Police School, Fort Leonard Wood, Missouri

- Camp Arifjan, Kuwait

- Camp As Saliyah, Qatar

- Camp Stryker, Iraq

- Fort Bliss, Texas

- Fort Drum, New York

- Fort Meade, Maryland

- Logistics Support Area Anaconda, Iraq

\section{Department of the Air Force}

- Office of the Chief of Chaplains, Bolling Air Force Base, Washington, D.C.

- Office of the Inspector General, Arlington, Virginia

- Office of the Judge Advocate General, Washington, D.C.

- Office of Special Investigations, Andrews Air Force Base, Maryland

- Office of the Surgeon General, Falls Church, Virginia 
- Sexual Assault Prevention and Response Program Office, Washington, D.C.

- Air Education and Training Command, Randolph Air Force Base, Texas

- Al Udeid Air Base, Qatar

- Balad Air Base, Iraq

- Lackland Air Force Base, San Antonio, Texas

\section{Department of the Navy}

- Bureau of Medicine and Surgery, Washington, D.C.

- Bureau of Naval Personnel, Millington, Tennessee

- Commander, Navy Installation Command, Washington, D.C.

- Fleet and Family Support Program, Counseling, Advocacy, and Prevention Program, Washington, D.C.

- Naval Criminal Investigative Service, Washington, D.C.

- Naval Education Training Command, Pensacola, Florida

- Center for Personal and Professional Development, Virginia Beach, Virginia

- Navy Medical Manpower Personnel Training and Education Command, Bethesda, Maryland

- Office of the Assistant Secretary of the Navy, Manpower and Reserve Affairs, Washington, D.C.

- Office of the Naval Inspector General, Washington, D.C.

- Office of the Chief of Navy Chaplains, Washington, D.C.

- Office of the Judge Advocate General, Washington, D.C.

- Naval Station Norfolk, Virginia

- Naval Support Activity, Bahrain

\section{United States Marine Corps}

- Criminal Investigative Division, Arlington, Virginia

- Manpower and Reserve Affairs

- Sexual Assault Prevention and Response Office, Quantico, Virginia

- Office of the Chaplains, Arlington, Virginia

- Office of the Judge Advocate Division, Arlington, Virginia

- Camp Lejeune, North Carolina

- Camp Ramadi, Iraq

- Marine Corps Base Quantico, Virginia

\section{Department of Homeland Security}

- Office for Civil Rights and Civil Liberties, Washington, D.C. 


\section{Coast Guard}

- Coast Guard Investigative Service, Arlington, Virginia

- Health and Safety Directorate, Office of Work Life, Washington, D.C.

- Office of the Chaplain of the Coast Guard, Washington, D.C.

- Office of Civil Rights, Washington, D.C.

- Office of the Coast Guard Headquarters Chaplain, Washington, D.C.

- Office of Military Justice, Washington, D.C.

- Fifth District, Sector Hampton Roads

- Integrated Support Command Portsmouth, Portsmouth, Virginia

- Yorktown Training Center, Yorktown, Virginia

- Patrol Forces Southwest Asia, Naval Support Activity, Bahrain

\section{Department of Veterans Affairs}

- Veteran's Health Administration

- National Center for Posttraumatic Stress Disorder, White River Junction, Vermont

- Women Veteran's Health Division, Washington, D.C.

We conducted this performance audit from June 2007 through August 2008 in accordance with generally accepted government auditing standards. Those standards require that we plan and perform the audit to obtain sufficient, appropriate evidence to provide a reasonable basis for our findings and conclusions based on our audit objectives. We believe that the evidence obtained provides a reasonable basis for our findings and conclusions based on our audit objectives. 


\section{Appendix II: Comments from the Department of Defense}

\section{UNDER SECRETARY OF DEFENSE \\ 4000 DEFENSE PENTAGON \\ WASHINGTON, D.C. $20301-4000$}

AUG 182008

Ms. Brenda S. Farrell

Director, Defense Capabilities and Management

U. S. Government Accountability Office

441 G Street, N.W.

Washington, DC 20548

Dear Ms. Farrell:

This is the Department of Defense (DoD) response to the GAO draft report, GAO-08924, "MILITARY PERSONNEL: DoD's and the Coast Guard's Sexual Assault Prevention and Response Programs Face Implementation and Oversight Challenges," dated July 18, 2008 (GAO Code 351062). I appreciate the opportunity to review and comment on the draft GAO report.

The Department concurs with the overall draft report as written. However, specific responses for each of the nine recommendations have been provided as Enclosure (1) to support each position and for your consideration.

There are no technical changes noted.

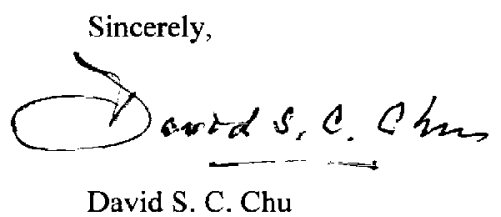

Enclosure:

As stated 
GAO DRAFT REPORT - DATED JULY 18, 2008

GAO CODE 351062/GAO-08-924

“MILITARY PERSONNEL: DoD's and the Coast Guard's Sexual Assault Prevention and Response Programs Face Implementation and Oversight Challenges"

\section{DEPARTMENT OF DEFENSE COMMENTS TO THE RECOMMENDATIONS}

RECOMMENDATION 1: The GAO recommends that the Secretary of Defense direct the Under Secretary of Defense for Personnel and Readiness to review and evaluate the Department's policies for the prevention and response of sexual assault to ensure that adequate guidance is provided to effectively implement the program in deployed environments and joint environments.

\section{DOD RESPONSE: Concur.}

- It should be noted that the Department brought this issue to the GAO's attention. OSD SAPR in the coordination with the Service SAPR programs, CENTCOM and Joint Chiefs of Staff (JCS) J-1 have been working to address the very complex challenges involved with a multi-pronged approach.

- This issue is being addressed both the policy and training subcommittees of the Department Sexual Assault Advisory Council (SAAC), which are examining general policy guidance and specific training requirements respectively. Any proposed modifications will be incorporated into policy.

- Issues regarding joint environments are being addressed in a new draft of our Response Standards. DoD is working with CENTCOM and JCS J-1 to ensure that our response standards provide adequate guidance.

- DoD is utilizing Policy Assistance Team (PAT) visits and Office Calls to Combatant Commands to ensure that all challenges have been identified. A PAT visit to USPACOM was completed in August 2008. Office calls to USSOCOM J-1 and USCENTCOM J-1 were held in July 2008. DoD is currently planning travel to other Combatant Commands in FY09 to further address this recommendation.

RECOMMENDATION 2: The GAO recommends that the Secretary of Defense direct the Under Secretary of Defense for Personnel and Readiness to evaluate the Military Services' processes for staffing and designating key installation-level program positions, such as Sexual Assault Response Coordinators, at installations in the United States and overseas, to ensure that these individuals have the ability and resources to fully carry out their responsibilities.

DOD RESPONSE: Concur.

Enclosure (1) 
Appendix II: Comments from the Department

of Defense

- PAT visits and Command Office Calls are currently being used to evaluate the effectiveness of SARCs as implemented by each of the military services. Personnel status (contractor, civilian, military), funding, and mission effectiveness are items of interest for the PAT visits and Office Calls.

- The Defense Task Force - Sexual Assault in the Military Services (DTF-SAMS) will be evaluating the effectiveness of staffing configurations and will likely make recommendations on this topic.

- The Army non-concurred on this recommendation, indicating that it believes that this is an operational matter beyond the scope of DoD policy. The Department recognizes that each Military Service has operational requirements that drive certain staffing models of Sexual Assault Prevention and Response (SAPR) personnel. However, the Department has an oversight responsibility in the recommended evaluation to ensure consistency of excellence across the Services.

RECOMMENDATION 3: The GAO recommends that the Secretary of Defense direct the Under Sccretary of Defense for Personnel and Readiness to review and evaluate sexual assault prevention and response training to ensure the Military Services are meeting training requirements and to enhance the effectiveness of the training.

\section{DOD RESPONSE: Concur.}

- Policy Assistance Visits are soliciting feedback from Service Members about training content, frequency, media, and effectiveness.

- DoD's Prevention Strategy will recommend best practices for effective prevention education, and suggest metrics for program evaluation.

- For FY2008 Report to Congress, OSD plans to request a summary of training and education programs from each service.

- OSD further plans to request each Military Service review training programs at each level (Accession, Professional Military Education, First Responder, etc) to ensure maximum compliance with the requirements described in Department policy. OSD also will require each Military Service to provide outcome metrics demonstrating efficacy of training and educational programs.

RECOMMENDATION 4: The GAO recommends that the Secretary of Defense direct the Under Secretary of Defense for Personnel and Readiness to systematically evaluate and develop an action plan to address any factors that may prevent or discourage Service members from accessing mental health services following a sexual assault.

\section{DOD RESPONSE: Concur.}


Appendix II: Comments from the Department

of Defense

- Work in this area is already underway as part of the Department's response to the recommendations of the DoD Mental Health Task Force. The Defense Center of Excellence (DCoE) for Psychological Health and Traumatic Brain Injury is the focal point for improvements to military mental healthcare. One of DCoE's missions is to address factors that may prevent or discourage Service members from accessing mental health services for any purpose. $\mathrm{DCoE}$ is enhancing the military's campaign to reduce the stigma of seeking help through partncrships with the Uniformed Services University of the Health Sciences, National Institutes of Health, the Department of Veterans Affairs, the Substance Abuse and Mental Health Services Agency, DoD coalition partners, and others in the public and private sectors. The Department believes that an important part of reducing stigma is education. The $\mathrm{DCoE}$ will be proposing a standardized curriculum for psychological health and TBI education for leaders, Service members, and family mcmbers. In the interim, each Service will implement training that adheres to the Department's overarching principles and is adaptable to the culture of its own Service.

- DoD tracks Restricted Reporting and service referrals in the Annual Report to Congress, and will encourage the Military Services to continue to publicize the benefits of Restricted Reporting, which include confidential referral and access of mental healthcare.

- DoD will review whether SAPR commander training across the Services needs to be updated to encourage assistance seeking by all under their command. In addition, SAPRO will continue to work with DCoE to ensure that sexual assault victims are appropriately considered in all upcoming initiatives to decrease stigma and improve command climate for help seeking.

RECOMMENDATION 5: The GAO recommends that the Secretary of Defense direct the Service Secretaries to emphasize to all levels of command their responsibility for supporting the program, and review the extent to which commanders support the program and resources are available to raise Service members' awareness of sexual assault matters.

\section{DOD RESPONSE: Concur.}

- A letter from SECDEF is currently in draft for dissemination to Service Secretaries, emphasizing commander involvement and support of the SAPR program.

- DoD will also examine whether we need to update training products for commanders to enhance their understanding and support of SAPR.

RECOMMENDATION 6: The GAO recommends that the Secretary of Defense direct the Under Secretary of Defense for Personnel and Readiness to require the Sexual Assault Prevention and Response Office to develop an oversight framework to guide continued program implementation and evaluate program effectiveness. At a minimum, such a framework should contain long-term goals, objectives, and milestones; performance goals; strategies to be used to accomplish goals; and criteria for measuring progress.

Enclosure (1) 
Appendix II: Comments from the Department

of Defense

\section{DOD RESPONSE: Concur.}

- Policy Assistance Visits are currently underway to assess program implementation and effectiveness.

- DoD was required to stand up its SAPR programs very rapidly to meet an emergent need. Now that the programs are established, we must transition to a mature program. As part of that transition, DoD will develop an oversight framework with long-term goals, objectives, milestones and criteria to measure progress.

- DoD agrees with USCENTCOM's comment that development of an oversight framework should include JCS and Service Headquarters, and clearly identify the reporting chain for training status and achievement of goals and milestones.

RECOMMENDATION 7: The GAO recommends that the Secretary of Defense direct the Office of the Under Secretary of Defense for Personnel and Readiness to improve the usefulness of the Department's annual report as an oversight tool both internally and for congressional decision makers by establishing baseline data to permit analysis of data over time, and reporting data so as to distinguish cases in which (1) evidence was insufficient to substantiate an alleged assault, (2) a victim recanted, or (3) the allegations of sexual assault were unfounded.

\section{DOD RESPONSE: Concur.}

- DoD believes a comprehensive data collection and analysis is vital to policy analysis and program implementation. Thus, a Department-wide sexual assault database initiative is currently underway. DoD provided feedback to Congress on a draft of FY09 NDAA that would mandate the improvement of data collection.

- In addition, the Legal and Investigative working group of the SAAC policy subcommittee is meeting on August 20 regarding the issue of how case outcomes are distinguished. The goal is to ensure that data reporting requirements are clearly articulated and that common terminology is used.

- DoD concurs with USCENTCOM comment and will review the reporting chain to ensure that it is clear, particularly in joint and deployed environments.

RECOMMENDATION 8: The GAO recommends that the Secretary of Defense direct the Service Secretaries to provide installation-level incident data to the Sexual Assault Prevention and Response Office annually or as requested to facilitate analysis of sexual assault related data and better target resources over time.

\section{DOD RESPONSE: Concur.}

- In order to conduct comprehensive analysis of the program, DoD believes installation-level data must be provided to SAPRO annually or as requested. The Department is currently drafting a letter for SECDEF signature, ordering the Military Services to provide installation data to SAPRO.

- DoD recognizes that USCENTCOM, Army, Navy and Air Force expressed concerns regarding reporting installation level data but we believe it is necessary for accurate oversight and visibility of sexual assault incidents. It is the Department's plan to build

Enclosure (1) 
Appendix II: Comments from the Department

of Defense

a robust analysis system that addresses the concerns of the Military Services, as well as considers the contextual implications and limitations of such data.

- DoD is working to secure funding for a database that will improve Department data collection. This database will be designed by OSD working in conjunction with the Chairman of the Joint Chiefs of Staff as well as the Services. In addition, DoD does not believe that methods of protecting the installation level data must be put in place to address the concerns raised. The Department concurs that the data should not be released outside of DoD.

RECOMMENDATION 9: The GAO recommends that the Secretary of Defense direct the Defense Task Force on Sexual Assault in the Military Services to begin its examination immediately, now that all members of the task force are appointed, and to develop a detailed plan with milestones to guide its work.

\section{DOD RESPONSE: Concur.}

The Defense Task Force on Sexual Assault in the Military Services (DTFSAMS) was initially the Defense Task Force on Sexual Harassment and Violence at the Military Academies (DTFSHVMA). It was created by the NDAA for FY04 and issued its report in June 2005. That Task Force was extended by the National Defense Authorization Act for FY05. After DTFSHVMA completed its mission, its name was changed to DTF SAMS and the mission was changed to an examination of sexual assault in the Armed Forces. It will assess and make recommendations on key areas in sexual assault prevention and response. D'TF SAMS is comprised of subject matter experts representing the Department of Defense as well as the private sector. The Task Force held its first administrative meeting in May. The first official meeting is scheduled for 11-15 August. During the course of its work, DTF SAMS will visit a number of installations in the continental United States and the Combat Theater to evaluate policies, program execution and measures of effectiveness. Specifically, the Task Force will focus on active duty military service members assigned to training bases such as Basic Training, Advanced Skill Training and Instructor Trainers. Recruiting bases will also be of high interest to the Task Force. Additionally, at each installation, Task Force members will conduct interviews with commanders, officers and enlisted personnel, as well as the first response personnel who provide services and treatment to the victim and the offender to ensure there is an effective and coordinated approach to sexual assault prevention and response. Sexual assault response coordinator and victim advocates, as well as law enforcement personnel, military criminal investigators, JA officers, healthcare professionals, and chaplains are among the key first response personnel the Task Force will meet with to determine how well our SAPR programs are being implemented. We welcome the work of the Task Force and the recommendations it will propose at the conclusion of its work. It is important for us to know whether the policies and programs we have put in place are working; if they can be improved and if there are things that we missed. We will carefully evaluate every recommendation of the Task Force and make necessary changes in a timely manner.

DoD agrees with USCENTCOM comment that Combatant Commands, Joint Commands and forward deployed JTFs are unique and should be examined separately as they may require different milestones.

Enclosure (1) 


\section{Appendix III: Comments from the Coast Guard}

\section{Homeland Security}

August 25, 2008

Ms. Brenda S. Farrell

Director

Defense Capabilities and Management

U.S. Government Accountability Office

441 G Street, NW

Washington, DC 20548

Dear Ms. Farrell:

Thank you for the opportunity to review and comment on the Government Accountability Office's (GAO's) draft report entitled MILITARY PERSONNEL: DOD's and the Coast Guard's Sexual Assault Prevention and Response Programs Face Implementation and Oversight Challenges (GAO-08-924). Technical comments have been provided under separate cover.

The United States Coast Guard concurs with the two GAO recommendations directed to the Commandant and appreciates the efforts of GAO in documenting areas for improvement. The Coast Guard is currently is taking corrective actions to address these recommendations.

Recommendation 1: Evaluate its processes for staffing key installation-level program positions, such as the Employee Assistance Program Coordinators (EAPCs), to ensure that these individuals have the ability and resources to fully carry out their responsibilities.

Response: The Coast Guard will evaluate and analyze its processes to ensure that program experts have the resources to fully conduct their duties and responsibilities.

Recommendation 2: Develop an oversight framework to guide continued program implementation and evaluate program effectiveness. At a minimum, such a framework should contain long-term goals, objectives, and milestones; performance goals; strategies to be used to accomplish goals; and criteria for measuring progress.

Response: The Coast Guard will work with DoD to align goals and strategies as well as measurements for consistency and improved reporting. Our newly appointed Sexual Assault Prevention and Response program manager at Coast Guard headquarters will be responsible for coordinating an integrated approach and programmatic view to improve the sexual assault prevention and response program. We would also welcome Coast Guard participation in the Defense (Armed Forces) Task Force on Sexual Assault in the Military Services to leverage resources and best practices. 
Thank you again for the opportunity to comment on this draft report and we look forward to working with you on future homeland security issues.

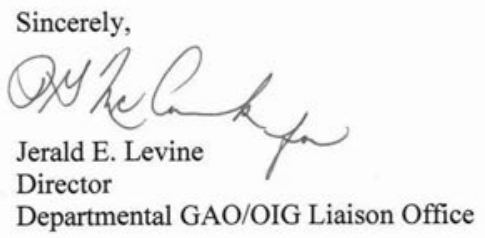




\section{Appendix IV: Disposition of Sexual Assaults in DOD and the Coast Guard}

In both the Department of Defense (DOD) and the Coast Guard, commanders are responsible for discipline of misconduct, including sexual assault, and they have a variety of judicial and administrative options at their disposal. Commanders' options are specified in the Uniform Code of Military Justice (UCMJ) and the Manual for CourtsMartial $^{1}$ and include:

- Trial by courts-martial, the most severe disposition option, which can lead to many different punishments including death, prison time, forfeiture of pay and allowances, reduction in rank, and punitive separation from military service.

- Nonjudicial punishment, pursuant to Article 15 of the UCMJ, which allows for a number of punishments such as reducing a members' grade, forfeiture of pay, adding extra duty, and imposing restrictions on freedom.

- Administrative actions, which are corrective measures that may result in a variety of actions such as issuing a reprimand, admonition, counseling, extra military instruction, or the administrative withholding of privileges. Other actions include rehabilitation and reassignment, administrative reduction for inefficiency, bar to reenlistment, and administrative separation.

Commanders may also elect to take no action if evidence of an offense is not sufficient.

In determining punishment, commanders may elect to utilize many administrative options in conjunction with courts-martial convictions or nonjudicial punishments. The use of such actions can have significant negative career and employment repercussions for the accused, both within the military and in the civilian community.

\footnotetext{
${ }^{1}$ In October 2004, Congress included a provision in the Ronald W. Reagan National Defense Authorization Act for Fiscal Year 2005, Pub. L. No. 108-375, § 571 (2004) that required the Secretary of Defense to review the UCMJ and Manual for Courts-Martial "with the objective of determining what changes are required to improve the ability of the military justice system to address issues relating to sexual assault and to conform the UCMJ and the Manual for Courts-Martial more closely to other Federal laws and regulations that address such issues." The Secretary was required to submit a report including recommendations for revisions to the Committees on Armed Services of the Senate and House of Representatives following his review. Congress then amended Article 120 of the UCMJ in the National Defense Authorization Act for Fiscal Year 2006, Pub. L. No. 109-163, § 552 (2006). This change included consolidating criminal sex offenses into Article 120 and became effective October 1, 2007.
} 
The Manual for Courts-Martial provides a list of factors that commanders should consider when determining how to dispose of a criminal offense. These factors include:

- the character and military service of the accused,

- the nature of and circumstances surrounding the offense and the extent of harm caused,

- the appropriateness of the authorized punishment to the particular accused or offense,

- possible improper motives of the accuser,

- reluctance of the victim or others to testify,

- cooperation of the accused in the apprehension or conviction of others,

- the availability and likelihood of prosecution by another jurisdiction and the existence of jurisdiction over the accused and the offender, and

- the availability and admissibility of evidence.

Ordinarily, the immediate commander of an individual accused or suspected of committing an offense is responsible for determining how to dispose of the offense. However, the immediate commander who lacks sufficient authority to take action may forward the matter to a superior commander for disposition. A decision by a lower-level commander does not prevent a different disposition by a superior commander. Further, commanders' decisions are typically made after consulting with the supporting legal office (e.g., judge advocate).

Disposition of Investigations of Sexual Assault within DOD
DOD collects and reports data in its annual report to Congress on the disposition of reported sexual assault incidents in the military. Investigations of sexual assaults and the outcomes of these cases may cross reporting periods, and commanders may not always have jurisdiction to take actions against some alleged offenders. DOD reported that there were 1,955 completed investigations of reported sexual assault cases in fiscal year 2007 resulting from all unrestricted reports of alleged sexual assault incidents made during or prior to fiscal year 2007. These 1,955 completed investigations involved 2,212 alleged offenders including servicemembers who fall under a military commander's legal authority and nonservicemembers, such as civilians or foreign nationals, who may not be subject to military law. Some cases had multiple alleged offenders, victims, or both. Of the 2,212 alleged offenders resulting from all investigations completed in fiscal year 2007, commanders had sufficient evidence of a crime to support taking actions against 600 (27 percent) of these alleged offenders. Action against 572 alleged offenders was still pending as of September 30, 2007; once these dispositions are completed, 
Table 8: Dispositions of Alleged Offenders Resulting from Investigations Completed in Fiscal Year 2007, as of September 30, 2007

\begin{tabular}{lrrrr}
\hline & \multicolumn{2}{c}{$\begin{array}{c}\text { Number of alleged } \\
\text { offenders against whom } \\
\text { action was taken in reports } \\
\text { made }\end{array}$} & & \begin{tabular}{r} 
Total number of \\
\cline { 2 - 3 } $\begin{array}{l}\text { Type of command action } \\
\text { taken against alleged } \\
\text { offenders }\end{array}$
\end{tabular} \\
\cline { 2 - 4 } & $\begin{array}{r}\text { prior to fiscal } \\
\text { year 2007 }\end{array}$ & $\begin{array}{r}\text { during fiscal } \\
\text { year 2007 }\end{array}$ & $\begin{array}{r}\text { completed dispositions } \\
\text { during fiscal year 2007 }\end{array}$ \\
\hline Courts-martial & 78 & 103 & $\mathbf{1 8 1}$ \\
\hline Nonjudicial punishment & 81 & 120 & $\mathbf{2 0 1}$ \\
\hline $\begin{array}{l}\text { Administrative actions or } \\
\text { discharges }\end{array}$ & 92 & 126 & $\mathbf{2 1 8}$ \\
\hline $\begin{array}{l}\text { Total command actions taken } \\
\text { against alleged offenders }\end{array}$ & $\mathbf{2 5 1}$ & $\mathbf{3 4 9}$ & $\mathbf{6 0 0}$ \\
\hline
\end{tabular}

Source: DOD.

As shown in table 9, commanders did not take direct action against 1,040 alleged offenders for a variety of reasons. For example, some of these alleged offenders were not subject to military law, other alleged offenders could not be identified, and in some instances the alleged sexual assault was unsubstantiated, unfounded, or there was insufficient evidence that an offense occurred.

Table 9: Reasons Commanders Did Not Take Action Against Alleged Offenders in Investigations Completed during Fiscal Year 2007

\begin{tabular}{lrrr}
\hline & \multicolumn{2}{c}{$\begin{array}{c}\text { Number of alleged offenders } \\
\text { against whom commanders did } \\
\text { not take action in reports made }\end{array}$} & \\
\cline { 2 - 4 } $\begin{array}{l}\text { Reasons commanders did not take } \\
\text { action against an alleged offender }\end{array}$ & $\begin{array}{r}\text { Prior to fiscal } \\
\text { year 2007 }\end{array}$ & $\begin{array}{r}\text { During fiscal } \\
\text { year 2007 }\end{array}$ & Total \\
\hline $\begin{array}{l}\text { Under civilian court action or foreign } \\
\text { authority }\end{array}$ & 41 & 70 & $\mathbf{1 1 1}$ \\
\hline Unidentified alleged offender & 32 & 100 & $\mathbf{1 3 2}$ \\
\hline
\end{tabular}




\begin{tabular}{lrrr}
\hline & \multicolumn{2}{c}{$\begin{array}{c}\text { Number of alleged offenders } \\
\text { against whom commanders did } \\
\text { not take action in reports made }\end{array}$} & \\
\cline { 2 - 4 } $\begin{array}{l}\text { Reasons commanders did not take } \\
\text { action against an alleged offender }\end{array}$ & $\begin{array}{r}\text { Prior to fiscal } \\
\text { year 2007 }\end{array}$ & $\begin{array}{r}\text { During fiscal } \\
\text { year 2007 }\end{array}$ & Total \\
\hline $\begin{array}{l}\text { Unsubstantiated, unfounded, lacked } \\
\text { sufficient evidence, victim recanted, or } \\
\text { alleged offender died }\end{array}$ & 265 & 532 & 797 \\
\hline Total & & $\mathbf{3 0 2}$ & $\mathbf{1 , 0 4 0}$ \\
\hline Source: DOD. & & &
\end{tabular}

Although DOD does not track information about indirect actions commanders may take against offenders who are not subject to military law, judge advocates at installations we visited overseas told us that commanders could bar a foreign national or contractor who commits a crime from the installation, but were otherwise limited in actions they could take against alleged offenders who are not subject to the UCMJ. They told us that generally, commanders must rely on foreign governments to prosecute foreign nationals who commit crimes. Officials also stated that because there is no formal system to track individuals barred from installations, it is not possible to ensure that foreign nationals barred from one base are barred from all bases in a geographic region. Commanders also have limited avenues to address misconduct or crimes committed by contractors.

\section{Disposition of} Investigations of Sexual Assault within the Coast Guard
During fiscal year 2007, the Coast Guard Investigative Service completed investigations for 62 of the 72 sexual assault incidents reported during fiscal year 2007. For these 62 completed investigations, the Coast Guard identified 67 alleged offenders including servicemembers who are under a military commander's legal authority as well as nonservicemembers who may not be subject to military law. Of the 67 alleged offenders, commanders had sufficient evidence of a crime to support taking action against 19 alleged offenders (see table 10). 
Table 10: Dispositions of Alleged Offenders Resulting from Investigations Completed in Fiscal Year 2007, as of September 30, 2007

\begin{tabular}{|c|c|}
\hline $\begin{array}{l}\text { Type of command action taken against } \\
\text { alleged offenders }\end{array}$ & $\begin{array}{r}\text { Number of alleged offenders against } \\
\text { whom action was taken in reports } \\
\text { made during fiscal year } 2007\end{array}$ \\
\hline Courts-martial & 7 \\
\hline Nonjudicial punishment & 5 \\
\hline Discharge in lieu of courts-martial & 1 \\
\hline Discharge in lieu of disciplinary actions & 2 \\
\hline Other administrative actions & 4 \\
\hline $\begin{array}{l}\text { Total command actions taken against } \\
\text { alleged offenders }\end{array}$ & 19 \\
\hline Number of pending dispositions & 23 \\
\hline
\end{tabular}

Actions against 23 alleged offenders were still pending as of April 30, 2008. Commanders did not take action against 25 alleged offenders because evidence was unsubstantiated, unfounded, insufficient, the victim recanted, or the alleged offender died; the alleged offender was not identified; or the alleged offender was a nonservicemember who was not subject to the UCMJ. 


\section{Appendix V: DOD and Coast Guard Data on Reported Sexual Assault Incidents for Fiscal Year 2007}

The Department of Defense (DOD) is required by law ${ }^{1}$ to collect and report data on sexual assault incidents involving servicemembers in active duty status $^{2}$ to Congress annually. The Coast Guard collects similar data, but does not report these data to Congress because it is not statutorily required to do so. ${ }^{3}$ Servicemembers on active duty in DOD may report an alleged sexual assault using either the unrestricted or restricted reporting options. As previously discussed, an unrestricted report of an alleged sexual assault incident is provided to the chain of command or law enforcement for investigation. The military criminal investigative organizations within each military service and the Coast Guard are responsible for investigating crimes, including sexual assaults in which servicemembers are either alleged offender(s) or victim(s) and for documenting case data including information on alleged offenders and victims and the disposition of cases. A restricted report is a confidential report of an alleged sexual assault that can be made without initiating an investigation or notifying the chain of command. Within DOD, a restricted report may be made to either a Sexual Assault Response Coordinator (SARC) or a victim advocate at an installation; within the Coast Guard, a restricted report may be made to the Employee Assistance Program Coordinator (EAPC) or victim support person; and within both DOD and the Coast Guard a restricted report may also be made to medical personnel. When a restricted report is made, a commander is usually notified by the SARC or EAPC that an assault has occurred; however, the commander should not be informed of the victim's identity or any other information that could lead to identification, such as gender or rank. The

\footnotetext{
${ }^{1}$ Pub. L. No. 108-375, $§ 577$ (2004). Additional reporting requirements are included in the National Defense Authorization Act for Fiscal Year 2006, Pub. L. No 109-163, § 596 (2006) and the John Warner National Defense Authorization Act for Fiscal Year 2007, Pub. L. No 109-364, § 583 (2006).

${ }^{2}$ DOD's Sexual Assault Prevention and Response Office provides two separate annual reports to Congress. One report provides information on sexual assault incidents involving cadets at the military academies. The second report provides incident data for reported sexual assaults involving all servicemembers on active duty, including cadets at the military academies. See GAO-08-296 for information on sexual assaults involving the military academies and the Coast Guard Academy.

${ }^{3}$ Data collected by DOD and the Coast Guard on alleged sexual assault incidents are not comparable to data published by the Federal Bureau of Investigations' Uniform Crime Reporting program for sexual assaults. The Uniform Crime Reporting Program records founded cases of rape and attempted rape against women, while DOD tracks all reports of sexual assault including rapes, nonconsensual sodomy, indecent assault, and attempts thereof, against both men and women. Moreover, while the Uniform Crime Reporting Program deletes reports of rape and attempted rape that are later proven to be unfounded, DOD does not.
} 
SARC in DOD or the EAPC in the Coast Guard generally collects limited data about the alleged victim and the alleged incident because the purpose of the restricted reporting option is to provide assistance to victims rather than collect incident-related statistics. In DOD, SARCs provide these data to their service-level Sexual Assault Prevention and Response Office, whereas in the Coast Guard the EAPC provides similar data to the Office of Work Life. Regardless of the reporting option used, victims in both DOD and the Coast Guard can receive medical care, advocacy, and counseling services. At any time, an alleged victim may choose to change from a restricted report to an unrestricted report and participate in an investigation.

Unrestricted Reports Made during Fiscal Year 2007 in DOD
Of the 2,688 reports of sexual assault incidents that DOD received during fiscal year 2007, 2,085 were made using the unrestricted reporting option. However, a number of these reports were not substantiated as of September 30, 2007, when DOD compiled data for inclusion in its fiscal year 2007 annual report to Congress. According to DOD officials, a case may not be substantiated for a number of reasons. For example, a victim may recant an accusation, thus preventing an investigation from proceeding; evidence may be found insufficient to substantiate the alleged assault; or the alleged offender may have died. As of September 30, 2007, DOD reported that about 36 percent (741) of investigations of alleged sexual assault were ongoing. According to DOD's fiscal year 2007 annual report, in 72 percent $(1,511)$ of the 2,085 unrestricted reports of alleged sexual assault, the alleged victims were servicemembers; in the remaining 28 percent (574) of unrestricted reports the alleged victims were nonservicemembers, such as civilians or foreign nationals. About 60 percent of these reports involved an alleged rape and about one-third involved alleged indecent assaults. DOD also reported that about 9 percent (133) of all sexual assaults reported during fiscal year 2007 using the unrestricted reporting option were made by males who were either servicemembers or nonservicemembers. Table 11 shows the number of servicemembers and victims by gender who reported a sexual assault incident during fiscal year 2007 using the unrestricted reporting option. 
Appendix V: DOD and Coast Guard Data on

Reported Sexual Assault Incidents for Fiscal

Year 2007

Table 11: Number of Unrestricted Reports of Sexual Assault in DOD Made by Victims Who Were Either Servicemembers or Nonservicemembers and by Gender during Fiscal Year 2007

\begin{tabular}{lrrr}
\hline Gender & Servicemember & Nonservicemember & Total \\
\hline Male & 129 & 4 & $\mathbf{1 3 3}$ \\
\hline Female & 941 & 367 & $\mathbf{1 , 3 0 8}$ \\
\hline Total & $\mathbf{1 , 0 7 0}$ & $\mathbf{3 7 1}$ & $\mathbf{1 , 4 4 1}$ \\
\hline
\end{tabular}

Source: GAO analysis of DOD data.

Table 12 shows the number of investigations of reports of alleged sexual assault made during fiscal year 2007 by type of alleged offense and whether the victim was a servicemember or nonservicemember. Because reported data are incident-based and a single sexual assault may involve more than one subject or victim, the numbers of investigations and reports in table 12 do not necessarily reflect the number of actual alleged victims or offenders.

Table 12: Number of Investigations of Unrestricted Reports of Sexual Assault in DOD by Type of Offense during Fiscal Year 2007

\begin{tabular}{lrrrrr}
\hline & \multicolumn{4}{c}{ Type of offense } \\
\cline { 2 - 5 } Number of investigations with... & Rape & $\begin{array}{r}\text { Sodomy } \\
\text { (forcible) }\end{array}$ & $\begin{array}{r}\text { Indecent } \\
\text { assault }\end{array}$ & $\begin{array}{r}\text { Attempts to commit } \\
\text { these offenses }\end{array}$ & $\begin{array}{r}\text { Total number of } \\
\text { unrestricted reports }\end{array}$ \\
\hline Servicemember as alleged victim & 868 & 91 & 551 & 1 \\
\hline Nonservicemember as alleged victim & 391 & 33 & 150 & 0 \\
\hline Total & $\mathbf{1 , 2 5 9}$ & $\mathbf{1 2 4}$ & $\mathbf{7 0 1}$ & $\mathbf{5 1 4}$ \\
\hline
\end{tabular}

Source: DOD.

Note: Some of these cases may be reports of incidents that occurred prior to military service or before fiscal year 2007.

According to DOD's fiscal year 2007 annual report, these 2,085 reports involved 2,243 alleged victims, of whom 1,620 were servicemembers and 623 were nonservicemembers. The 2,085 unrestricted reports involved 1,908 alleged offenders who were servicemembers and 92 who were nonservicemembers. The identities of 305 alleged offenders were unknown.

DOD reported that about 8 percent of victims for all investigations completed during fiscal year 2007 were males. Table 13 shows the number of completed investigations by type of sexual assault and gender of victim. 
Table 13: Number of Sexual Assaults by Type of Initial Allegation and Gender of Victims for Investigations Completed during Fiscal Year 2007 as of March 15, 2007

\begin{tabular}{lrrrr}
\hline & \multicolumn{4}{c}{$\begin{array}{c}\text { Number of sexual assaults by type of initial allegation and gender } \\
\text { for servicemembers and nonservicemembers }\end{array}$} \\
\cline { 2 - 6 } Gender & Rape & Sodomy & $\begin{array}{r}\text { Indecent } \\
\text { assault }\end{array}$ & $\begin{array}{r}\text { Total sexual } \\
\text { assaults }\end{array}$ \\
\hline Male & 4 & 33 & 55 & $\mathbf{9 2}$ \\
\hline Female & 661 & 45 & 374 & $\mathbf{1 , 0 8 0}$ \\
\hline Total & 665 & $\mathbf{7 8}$ & 429 & $\mathbf{1 , 1 7 2}$ \\
\hline
\end{tabular}

Source: GAO analysis and summary of qualitative data provided by DOD for fiscal year 2007.

Note: These data are as of March 15, 2008. These numbers may not be precise because they are based on manually coded data that DOD compiles from individual cases. These numbers were not independently verified by the military services. Investigations completed after March 15, 2007, are not included in these data.

Restricted Reports Made during Fiscal Year 2007 in DOD
During fiscal year 2007, DOD reported that servicemembers initially made 705 reports of alleged sexual assault using the restricted reporting option. However, in 102 of these instances, victims chose to change from a restricted to unrestricted report. ${ }^{4}$ According to DOD, about 69 percent (489) of the 705 restricted reports involved an alleged rape and almost 18 percent (125) involved alleged indecent assaults. Table 14 shows the number of alleged reports of sexual assault made using the restricted reporting option by type of alleged offense during fiscal year 2007.

Table 14: Number of Restricted Reports of Sexual Assault in DOD by Type of Offense and Gender during Fiscal Year 2007

\begin{tabular}{lrrrrrr}
\hline & \multicolumn{7}{c}{ Number of reported } & \\
\cline { 2 - 7 } Number of reports with... & Rapes & $\begin{array}{r}\text { Sodomy } \\
\text { (forcible) }\end{array}$ & $\begin{array}{r}\text { Indecent } \\
\text { assaults }\end{array}$ & $\begin{array}{r}\text { Attempts to } \\
\text { commit these } \\
\text { offenses }\end{array}$ & $\begin{array}{r}\text { Unknown } \\
\text { types of } \\
\text { offenses }\end{array}$ & $\begin{array}{r}\text { Total number of } \\
\text { restricted reports }\end{array}$ \\
\hline Male as alleged victim & 3 & 21 & 10 & 3 & 4 & $\mathbf{4 1}$ \\
\hline Female as alleged victim & 478 & 19 & 112 & 27 & 14 & $\mathbf{6 5 0}$ \\
\hline $\begin{array}{l}\text { Gender of alleged victim } \\
\text { unknown }\end{array}$ & 8 & 0 & 2 & $\mathbf{3 0}$ & $\mathbf{2 2}$ & $\mathbf{7 0 5}$ \\
\hline $\begin{array}{l}\text { Total number } \\
\text { servicemembers as } \\
\text { alleged victims }\end{array}$ & $\mathbf{4 8 9}$ & $\mathbf{4 0}$ & $\mathbf{1 2 4}$ & & & \\
\hline
\end{tabular}

${ }^{4}$ These 102 reports are included in the total number of reports made using the unrestricted reporting option. DOD also includes these 102 cases as part of the total number of restricted reports made during fiscal year 2007 when reporting data in its annual report. 
Appendix V: DOD and Coast Guard Data on

Reported Sexual Assault Incidents for Fiscal

Year 2007

Source: DOD.

Note: Some of these cases may be reports of incidents that occurred prior to military service or prior to fiscal year 2007.

According to a DOD official, because the military services do not provide case-level data to DOD, the department is not able to determine the type of offense for the 102 restricted reports that were changed to unrestricted reports. DOD reported that male servicemembers made almost 7 percent (41) of the 705 initial reports of sexual assaults using the restricted reporting option during fiscal year 2007. Because no investigation is conducted when a victim reports a sexual assault using the restricted reporting option, the numbers of reports in table 14 reflect the number of actual alleged victims.

\section{Sexual Assault Incidents in} the Coast Guard
Since January 2004, the Coast Guard has voluntarily collected data on sexual assaults involving its members as either the alleged offender or victim, although it is not subject to the same statutory requirements as DOD for collecting these data or reporting such information to Congress. The Coast Guard, which did not offer a restricted reporting option until December 2007, documented 72 total reports of alleged sexual assaults involving Coast Guard members during fiscal year 2007. As shown in table 15 , the majority of these reports were for alleged rape and the majority of alleged victims were Coast Guard members. However, not all of these reported alleged sexual assaults have been substantiated because investigations may have been ongoing, evidence was found to be insufficient to substantiate the allegation, or victims may have recanted accusations. For example, the Coast Guard reported 10 investigations of alleged sexual assaults were ongoing as of April 2008.

Table 15: Number of Investigations of Unrestricted Reports of Sexual Assault in the Coast Guard by Type of Offense during Fiscal Year 2007

\begin{tabular}{lrrrrr}
\hline & \multicolumn{3}{c}{ Type of offense } \\
\cline { 2 - 5 } Number of investigations with... & Rape & Sodomy & $\begin{array}{r}\text { Indecent } \\
\text { assault }\end{array}$ & $\begin{array}{r}\text { Attempts to commit } \\
\text { these offenses }\end{array}$ & $\begin{array}{r}\text { Total number of } \\
\text { unrestricted reports }\end{array}$ \\
\hline Servicemember as alleged victim & 22 & 3 & 26 & 2 & 0 \\
\hline Nonservicemember as alleged victim & 18 & 0 & 1 & $\mathbf{5 3}$ \\
\hline Total & $\mathbf{4 0}$ & $\mathbf{3}$ & $\mathbf{2 7}$ & $\mathbf{2}$ \\
\hline
\end{tabular}

Source: Coast Guard Investigative Service.

Note: All alleged assaults involved Coast Guard members as alleged victims. 
Appendix V: DOD and Coast Guard Data on

Reported Sexual Assault Incidents for Fiscal

Year 2007

Because data are incident-based and a single assault may involve more than one alleged offender or victim, the number of reports in table 15 does not necessarily reflect the number of actual alleged offenders or victims. The Coast Guard Investigative Service determined that 78 alleged offenders and 78 alleged victims were involved in the 72 incidents reported during fiscal year 2007. The majority of alleged offenders and victims were Coast Guard members, as shown in table 16.

Table 16: Number of Alleged Offenders and Victims in Reported Sexual Assault Incidents Involving Coast Guard Members during Fiscal Year 2007

\begin{tabular}{lrr}
\hline $\begin{array}{l}\text { Affiliation of alleged offenders } \\
\text { and victims }\end{array}$ & $\begin{array}{r}\text { Number of alleged } \\
\text { offenders }\end{array}$ & $\begin{array}{r}\text { Number of alleged } \\
\text { victims }\end{array}$ \\
\hline Servicemember & 66 & 57 \\
\hline Nonservicemember & 5 & 21 \\
\hline Unknown & 7 & 0 \\
\hline Total & $\mathbf{7 8}$ & $\mathbf{7 8}$ \\
\hline
\end{tabular}

Source: GAO presentation of Coast Guard data.

${ }^{a}$ Servicemembers include Coast Guard members as well as those members affiliated with the other military services, such as the Army and Navy. All investigations completed during fiscal year 2007 involved Coast Guard members as alleged offenders except for two cases that in which the alleged offenders were affiliated with the Army and Navy.

The Coast Guard identified 67 victims in the completed investigations, 51 of whom were servicemembers in the Coast Guard or another military service and 16 of whom were not servicemembers. All but one victim in the completed investigations were female. Table 17 shows the number of completed investigations by type of sexual assault and gender of the victim.

Table 17: Number of Sexual Assaults by Type of Initial Allegation and Gender of the Alleged Victim for Unrestricted Reports Made during Fiscal Year 2007 in the Coast Guard

\begin{tabular}{lrrrrr}
\hline & \multicolumn{2}{c}{$\begin{array}{c}\text { Number of sexual assaults by type of initial allegation and gender } \\
\text { for unrestricted reports made during fiscal year 2007 }\end{array}$} \\
\cline { 2 - 7 } Gender & Rape & $\begin{array}{r}\text { Attempted } \\
\text { rape }\end{array}$ & Sodomy & $\begin{array}{r}\text { Indecent } \\
\text { assault }\end{array}$ & $\begin{array}{r}\text { Total number of } \\
\text { alleged sexual } \\
\text { assault victims }\end{array}$ \\
\hline Male & 0 & 0 & 1 & 0 & $\mathbf{1}$ \\
\hline Female & 41 & 2 & 2 & 32 & $\mathbf{7 7}$ \\
\hline Total & 41 & $\mathbf{2}$ & 3 & 32 & 78 \\
\hline Source: Coast Guard Investigative Service. & & & &
\end{tabular}

Source: Coast Guard Investigative Service. 


\section{Appendix VI: Survey Administered at Installations in the United States}

United States Government Accountability Office

\section{G A O Sexual Assault in the Military Services}

\section{Purpose}

This survey is part of a review the U.S. Government Accountability Office (GAO)—an agency of the Congress-is conducting of sexual assault prevention and response programs in the military services. The purpose of this survey is to provide insight into the effectiveness of each service's sexual assault policies, training, procedures, and response capabilities. Findings will be used in reports and testimony to Congress.

Providing information on this survey is voluntary and anonymous. All responses are strictly confidential, and no individual responses will be reported. Please do not write your name on this questionnaire. We appreciate you taking the time to complete this important survey.

\section{Directions for Completing This Survey}

We encourage you to answer each question as completely as possible. Before choosing an answer, please read the full question and all response choices carefully. There are no right or wrong answers Rather, you should answer each question the way that best reflects your personal opinions and experiences. The survey should take approximately $25-30$ minutes to complete.

This survey asks about both sexual harassment and sexual assault. When reading the questions, please note whether we are referring to experiences with sexual harassment or sexual assault. 
Appendix VI: Survey Administered at

Installations in the United States

\section{Command Climate toward Sexual Harassment}

As a reminder, DOD defines sexual harassment as follows:

Sexual harassment - a form of sexual discrimination that involves unwelcome sexual advances, requests for sexual favors, and other verbal or physical conduct of a sexual nature when

submission to such conduct is made either explicitly or implicitly a term or condition of a person's job, pay, or career, or submission to or rejection of such conduct by a person is used as a basis for career or employment decisions affecting that person, or such conduct has the purpose or effect of unreasonably interfering with an individual's work performance or creates an intimidating, hostile, or offensive working environment (DODD 1350.2)

1. At your current location, do you think your direct supervisor (military or civilian) creates a climate that discourages sexual harassment from occurring?

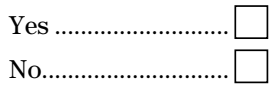

Not sure.

2. If sexual harassment should occur at your current location, do you think your direct supervisor (military or civilian) would address it?

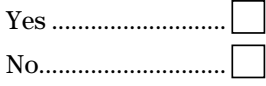

Not sure. 
Appendix VI: Survey Administered at

Installations in the United States

Unit-Command or operational unit to which you are assigned.

Deployed location-Stationed at a location other than your home station.

Temporary Duty (TDY)/Temporary Additional Duty (TAD)-Travel in which personnel remain under the direct control of their parent organizations (e.g., meetings, conferences, attendance at school or course of instruction).

Home station-The permanent location of active duty units and Reserve Component units This location may be either inside or outside the Continental United States.

3. In your opinion, is sexual harassment a problem in the following?

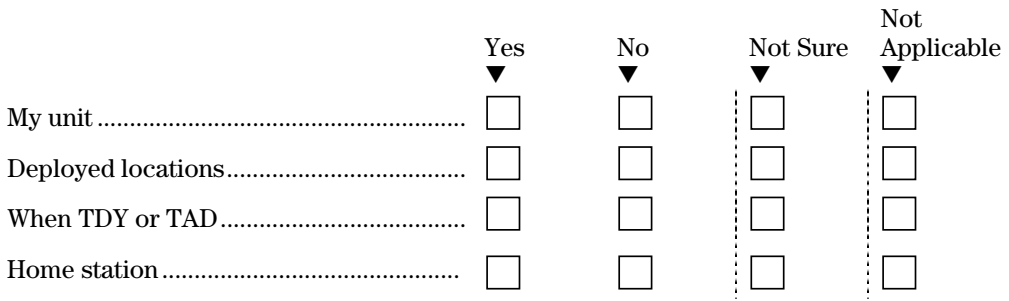

4. How much do your concerns about sexual harassment incidents in the military impact your intention to remain in the military once your commitment is met?
A great deal
Somewhat
Not at all. 
Appendix VI: Survey Administered at

Installations in the United States

\section{Command Climate toward Sexual Assault}

As a reminder DOD defines sexual assault as follows.

Sexual assault - intentional sexual contact, characterized by use of force, physical threat or abuse of authority or when the victim does not or cannot consent. It includes rape, nonconsensual sodomy (oral or anal sex), indecent assault (unwanted, inappropriate contact or fondling), or attempts to commit these acts. Sexual assault can occur without regard to gender or spousal relationship or age of victim. "Consent" shall not be deemed or construed to mean the failure by the victim to offer physical resistance. Consent is not given when a person uses force, threat of force, coercion, or when the victim is asleep, incapacitated or unconscious. (DODD 6495.01)

5. At your current location, do you think your direct supervisor (military or civilian) creates a climate that discourages sexual assault from occurring?

Yes ......................... $\square$

No............................

Not sure.

6. If sexual assault should occur at your current location, do you think your direct supervisor (military or civilian) would address it?

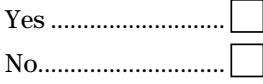

Not sure.

7. At your current location, how likely would you be to report a sexual assault of another servicemember?

Extremely likely

Very likely....

Moderately likely

Somewhat likely

Not at all likely 
8. Would you report a personal experience of sexual assault to the following authorities, individuals, or organizations at your current location?

\begin{tabular}{|c|c|c|}
\hline Yes & $\begin{array}{ll} & \text { Not } \\
\text { No } & \text { Sure }\end{array}$ & $\begin{array}{l}\text { Not } \\
\text { Applicable }\end{array}$ \\
\hline \multicolumn{3}{|l|}{ Officer in your chain of command........................ } \\
\hline \multicolumn{3}{|l|}{$\begin{array}{l}\text { Staff noncommissioned officer (NCO) in your } \\
\text { chain of command }\end{array}$} \\
\hline \multicolumn{3}{|l|}{$\begin{array}{l}\text { Noncommissioned officer }(\mathrm{NCO}) \text { in your } \\
\text { chain of command }\end{array}$} \\
\hline \multicolumn{3}{|l|}{ 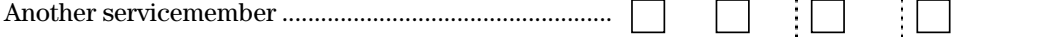 } \\
\hline \multicolumn{3}{|l|}{ 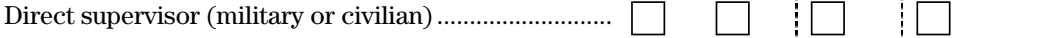 } \\
\hline \multicolumn{3}{|l|}{ 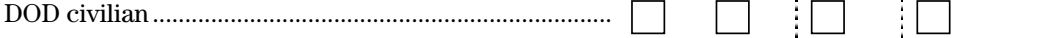 } \\
\hline \multicolumn{3}{|l|}{ 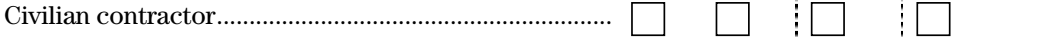 } \\
\hline \multicolumn{3}{|l|}{ Civilian assault crisis centers/hotline/ helpline .............. } \\
\hline \multicolumn{3}{|l|}{ 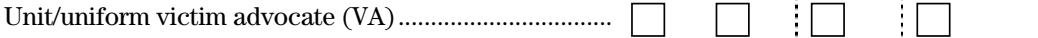 } \\
\hline \multicolumn{3}{|l|}{ 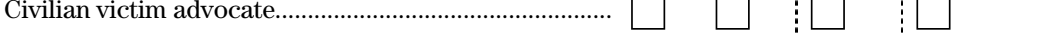 } \\
\hline \multicolumn{3}{|l|}{ Sexual assault response coordinator (SARC) ................. } \\
\hline \multicolumn{3}{|l|}{ 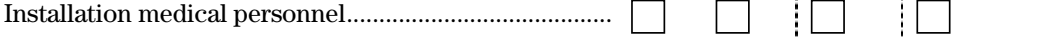 } \\
\hline \multicolumn{3}{|l|}{ 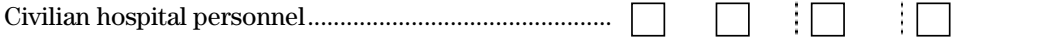 } \\
\hline \multicolumn{3}{|l|}{$\begin{array}{l}\text { Military criminal investigative organizations } \\
\text { (e.g., OSI, CID, NCIS, CGIS) }\end{array}$} \\
\hline \multicolumn{3}{|l|}{$\begin{array}{l}\text { Military police } \\
\text { (e.g., Provost Marshall, Master of Arms) ........................... }\end{array}$} \\
\hline \multicolumn{3}{|l|}{ 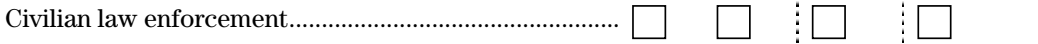 } \\
\hline \multicolumn{3}{|l|}{ 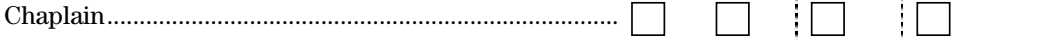 } \\
\hline \multicolumn{3}{|l|}{ 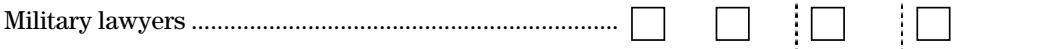 } \\
\hline \multicolumn{3}{|l|}{ 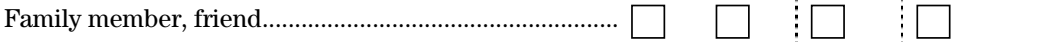 } \\
\hline (n) & : & \\
\hline
\end{tabular}


Appendix VI: Survey Administered at

Installations in the United States

9. How safe do you feel at your current location from being sexually assaulted in the following places?

$\begin{array}{llllll}\text { Extremely } & \begin{array}{l}\text { Very } \\ \text { safe }\end{array} & \begin{array}{l}\text { Moderately } \\ \text { safe }\end{array} & \begin{array}{l}\text { Somewhat } \\ \text { safe }\end{array} & \begin{array}{l}\text { Not at all } \\ \text { safe }\end{array} \\ \text { At work/on duty............................ } & \begin{array}{l}\text { Not } \\ \text { applicable }\end{array} \\ \text { In barracks/living and sleeping } \\ \text { area on installation grounds ........... }\end{array}$

10. In your opinion, is sexual assault a problem in the following?

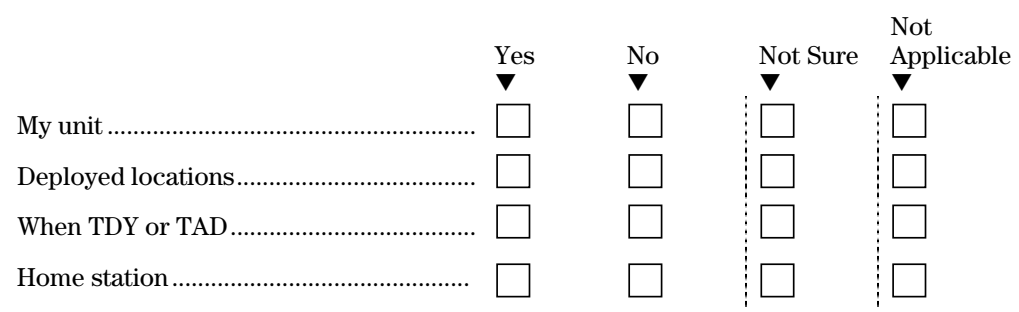

11. How much do your concerns about sexual assault incidents in the military impact your intention to remain in the military once your commitment is met?
A great deal
Somewhat
Not at all 
Appendix VI: Survey Administered at

Installations in the United States

12. Do you agree or disagree with the statement: "Tolerance for sexual harassment creates a perception that sexual assault may be acceptable."

Strongly agree

Agree

Neither agree nor disagree

Disagree

Strongly disagree

\section{Sexual Assault Prevention and Response Training}

13. Have you attended training that addressed sexual assault issues at any time during the past 12 months?

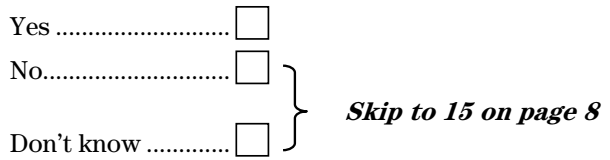

14. Was the sexual assault-related training you received during the past 12 months in the following formats?

Presentation by an instructor, such as SARC ..................................


Appendix VI: Survey Administered at

Installations in the United States

15. Would you know how to do the following at your current location?

\begin{tabular}{|c|c|c|}
\hline & Yes & $\begin{array}{l}\text { No } \\
\nabla\end{array}$ \\
\hline 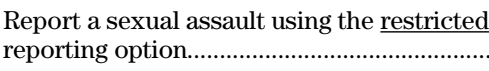 & & \\
\hline 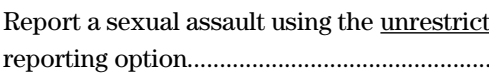 & & \\
\hline $\begin{array}{l}\text { Avoid situations that might increase the } \\
\text { risk of sexual assault ...................................... }\end{array}$ & & \\
\hline Obtain medical care following a sexual ass & & \\
\hline $\begin{array}{l}\text { Obtain counseling or mental health care } \\
\text { following a sexual assault ............................. }\end{array}$ & & \\
\hline Contact your sexual assault response coorc & & \\
\hline Contact your victim advocate (VA)............. & & \\
\hline $\begin{array}{l}\text { Obtain additional resources or information } \\
\text { on the areas above }\end{array}$ & & \\
\hline
\end{tabular}


We understand that this is a very difficult subject. We would like to reiterate that all responses are confidential, and no individual's information is identifiable.

16. How much of a problem are the following situations at your current location?

$\begin{array}{llll}\text { Serious } & \text { Moderate } & \text { Minor } & \text { Not a } \\ \text { problem } & \text { problem } & \text { problem } & \text { problem } \\ \boldsymbol{\nabla} & \boldsymbol{\nabla} & \boldsymbol{\nabla}\end{array}$

Sexual stories or jokes that were offensive to you ......

Others referring to people of your gender in insulting or offensive terms ..

Unwelcome attempts to draw you into a discussion of sexual matters (e.g., attempts to discuss or comment on your sex life).

Offensive remarks about your appearance, body, or sexual activities.

Gestures or body language of a sexual nature that embarrassed or offended you .....

Bribes or some kind of reward for special treatment to engage in sexual behavior.

Threats of retaliation or revenge for not being sexually cooperative (such as by mentioning an upcoming review or evaluation)

Touching in a way that made you feel uncomfortable, such as attempts to stroke, fondle, or kiss you

Implications of better assignments or better treatment if you were sexually cooperative

Bad treatment for refusing to have sex . 
Appendix VI: Survey Administered at

Installations in the United States

17. If you were sexually assaulted and could obtain medical and/or mental health care while (a) remaining anonymous and (b) being certain that there would not be an investigation, would you report the incident?

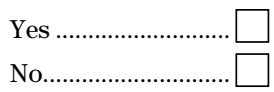

Not sure

18. Were you sexually assaulted during the past 12 months while in the military?

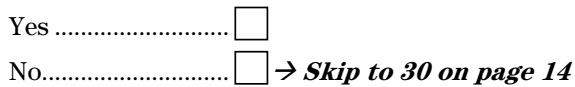

19. In which of the following locations did the incident occur?

At home installation inside the United States.

At home installation outside the United States

At a deployed location.

While TDY or TAD

20. Did you report the incident in any of the following ways to any authorities, individuals, or organizations?

I used restricted (confidential) reporting..

I used unrestricted reporting...

I reported it, but I'm not sure whether I used restricted

(confidential) or unrestricted reporting

I did not report the incident.

$\rightarrow$ Skip to 22 on page 12 
Appendix VI: Survey Administered at

Installations in the United States

21. To which authorities, individuals, or organizations did you report the incident?

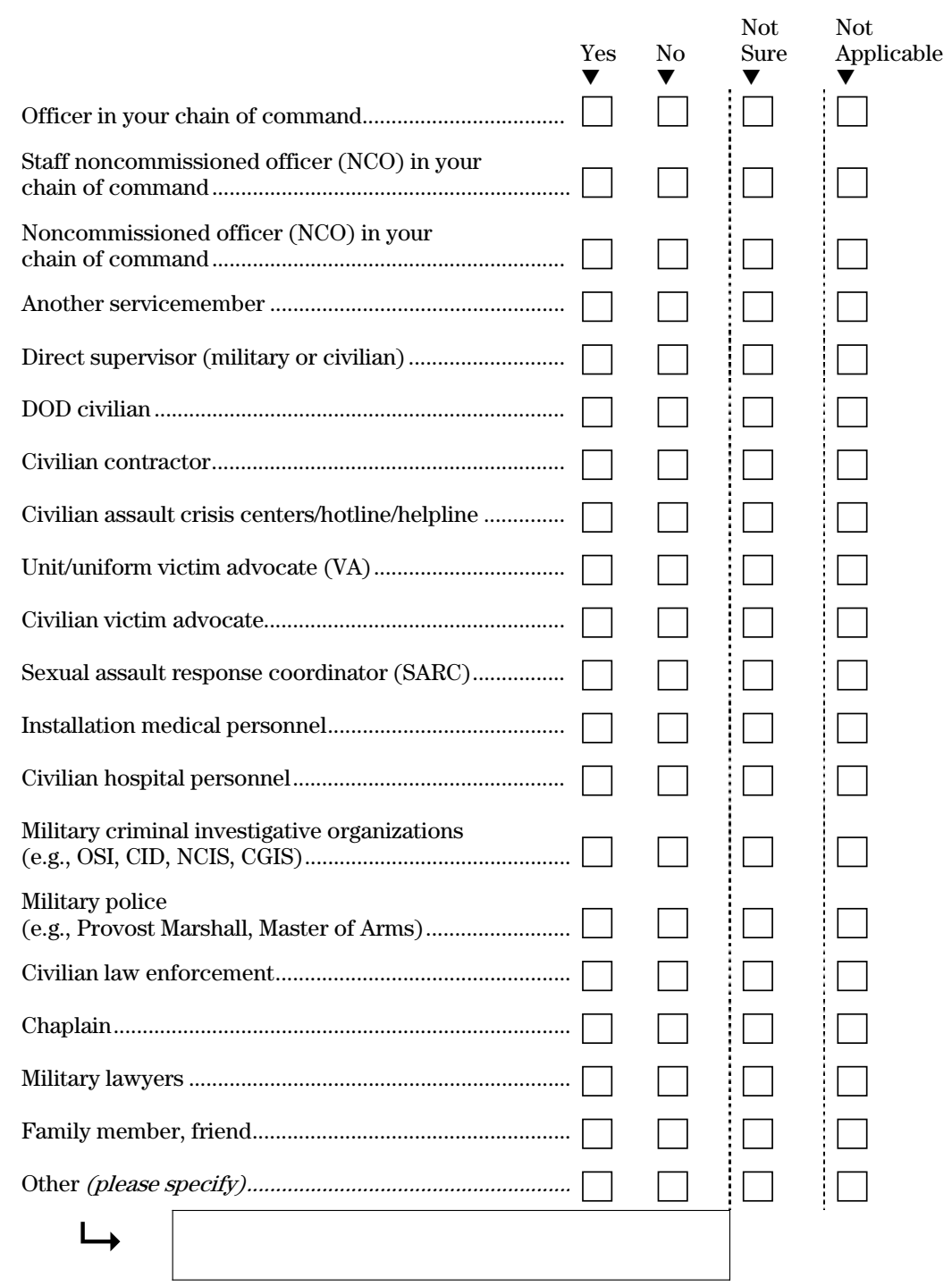

Please Skip to Question 23 on page 12 after completing Question 21 
Appendix VI: Survey Administered at

Installations in the United States

22. For which of the following reason(s) did you not report the incident?

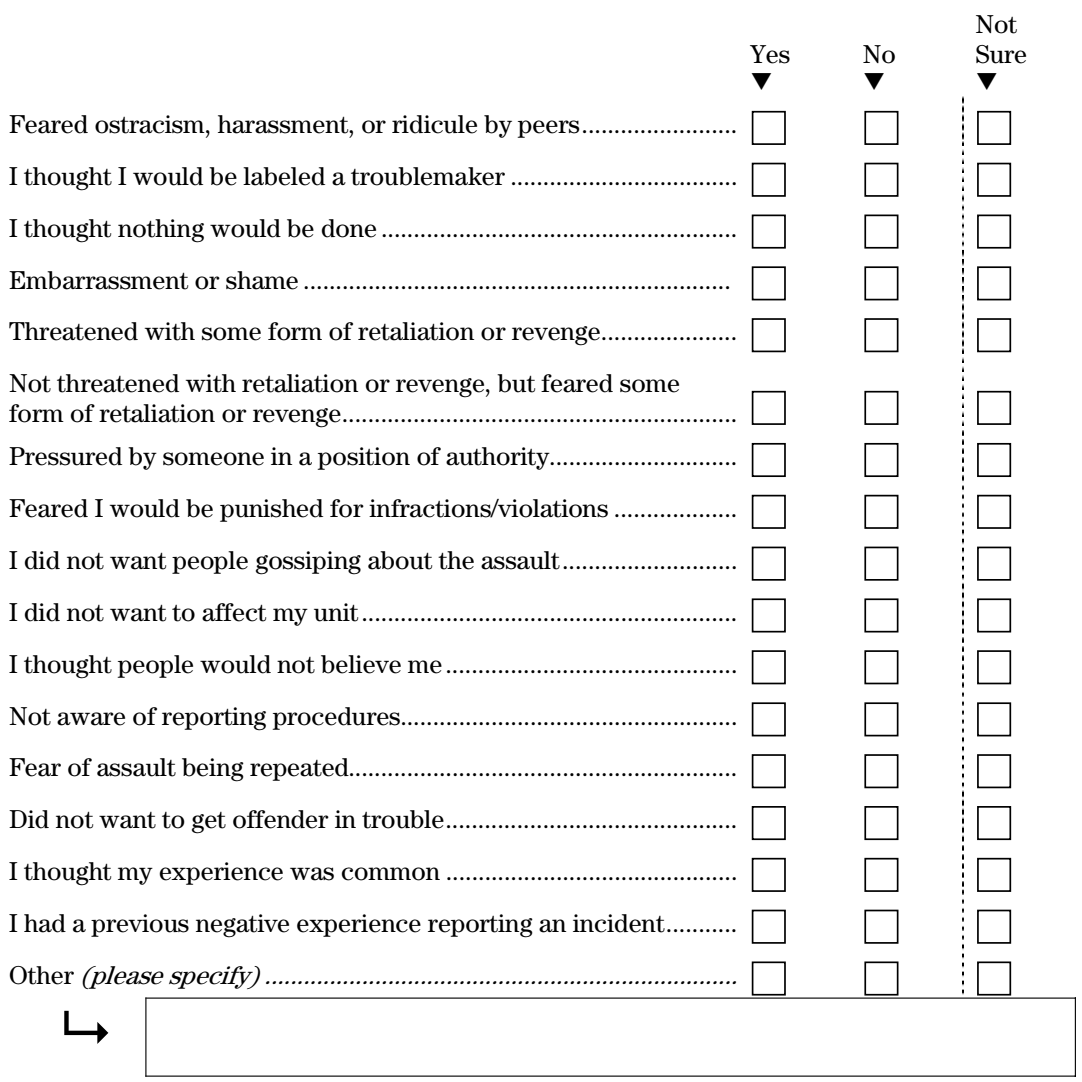

23. Did you receive medical care as a result of the incident?

I received medical care.

I did not receive medical care because

care was not available.

I did not seek medical care . 
Appendix VI: Survey Administered at

Installations in the United States

24. Where did you receive medical care for the incident?

Military treatment facility (MTF).

Civilian hospital.

Other (please specify).

$\longrightarrow$

25. How satisfied or dissatisfied were you with the quality of medical care you received?

Very satisfied

Satisfied

Neither satisfied nor dissatisfied

Dissatisfied.

Very dissatisfied.

26. Why were you satisfied or dissatisfied with the quality of medical care you received?

\section{Did you receive counseling or mental health care as a result of the incident?}

I received counseling or mental health care

I did not received counseling or mental health care

because assistance was not available

I did not seek counseling or mental health care 
Appendix VI: Survey Administered at

Installations in the United States

28. How satisfied or dissatisfied were you with the quality of counseling or mental health care you received?

Very satisfied

Satisfied

Neither satisfied nor dissatisfied

Dissatisfied

Very dissatisfied.

29. Why were you satisfied or dissatisfied with the quality of mental health care or counseling you received?

\section{Deployment}

30. Have you served away from your home station at any time during the past 12 months?

Yes ..........................


Appendix VI: Survey Administered at

Installations in the United States

31. Which of the following location(s) did you serve in during the past 12 months?

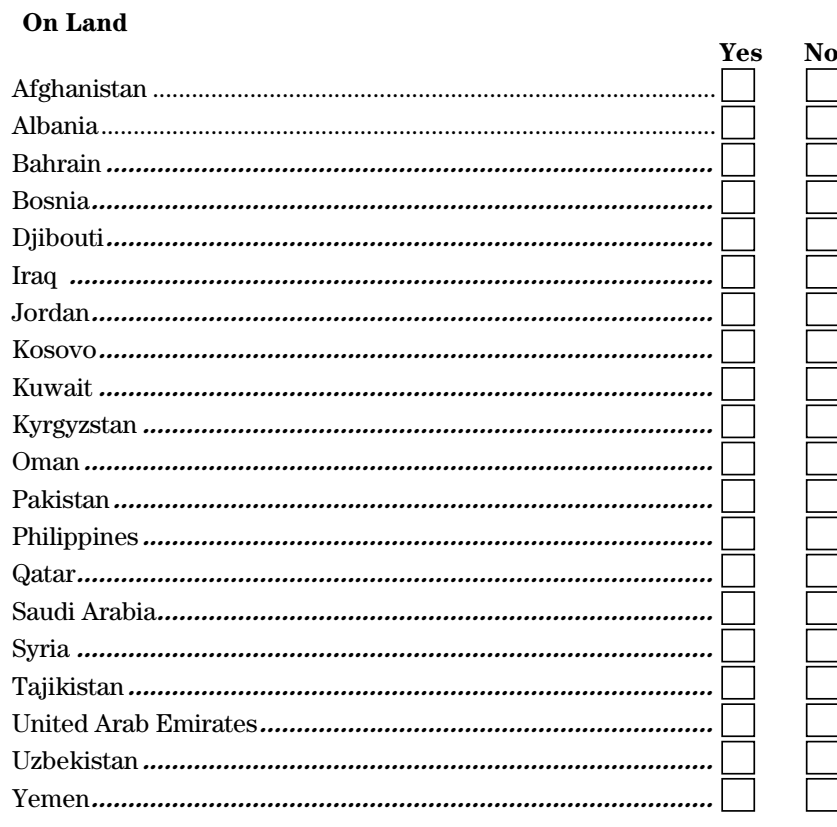

At Sea

Persian/Arabian Gulf

(Arabian Sea North of 10 degrees north

latitude and west of 68 degrees east longitude,

Gulf of Aden, Gulf of Oman, Persian Gulf, or Red Sea .........

Kosovo Area

(Adriatic Sea or Ionian Sea North of the $39^{\text {th }}$ Parallel)

Other

Another location not listed above

(please specify)

$\longrightarrow$

32. Of the locations you indicated above, where did you serve the longest amount of time?

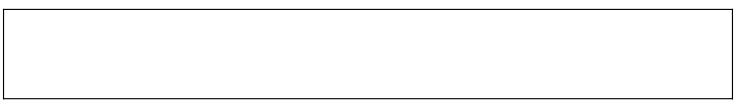


Appendix VI: Survey Administered at

Installations in the United States

33. From which installation did you deploy?

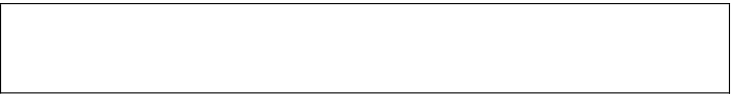

34. Did you receive pre-deployment training that addressed sexual assault?

Yes

No

Not sure.

\section{Experiences at Home Station versus When Deployed}

Unit - Command or operational unit to which you are assigned.

Home station-The permanent location of active duty units and Reserve Component units. This location may be either inside or outside the Continental United States.

Deployed-Stationed at a location other than your home station.

PLEASE ANSWER THE FOLLOWING QUESTIONS FROM THE PERSPECTIVE OF THE LOCATION YOU INDICATED IN QUESTION 32.

35. Do you think sexual harassment incidents are taken more or less seriously when at home station or when deployed?

More seriously when at home station

Equally seriously when at home station as when deployed........

Less seriously when at home station

36. Do you think sexual assault incidents are taken more or less seriously at home station or when deployed?

More seriously when at home station

Equally seriously when at home station as when deployed ........

Less seriously when at home station 
Appendix VI: Survey Administered at

Installations in the United States

37. Do you think servicemembers in your unit would be more or less likely to report a sexual assault of another servicemember when at home station or when deployed?

More likely at home station.

Equally likely at home station as when deployed......

Less likely at home station

Not sure.

38. How safe did you feel from being sexually assaulted at the following times and locations while you were deployed?

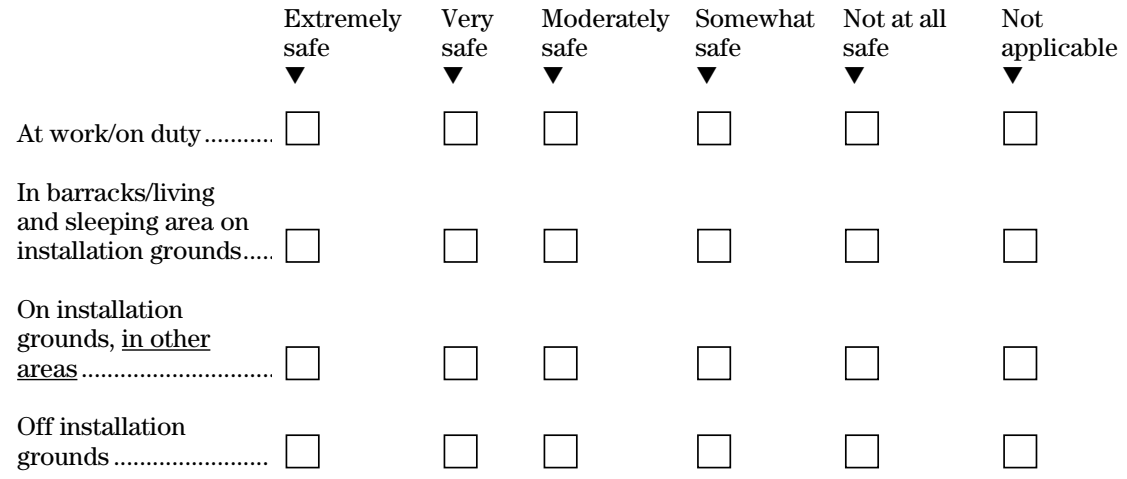

39. Do you believe the risk for a sexual assault to occur is less or greater when at home station versus when deployed?

The risk is less when at home station.

The risk is the same at home station as

when deployed.

$\rightarrow$ Skip to 41 on page 18

The risk is greater at home station 
Appendix VI: Survey Administered at

Installations in the United States

40. Why do you believe the risk of a sexual assault occurring differs when at home station versus when deployed?

Temporary Duty (TDY)/Temporary Additional Duty (TAD)-Travel in which personnel remain under the direct control of their parent organizations (e.g., meetings, conferences, attendance at school or course of instruction).

41. Have you been TDY or TAD at any time during the past 12 months?

Yes

No

$\rightarrow$ Skip to 44 on page 19

42. Do you believe the risk for a sexual assault to occur is less or greater when at home station versus when TDY or TAD?

The risk is less when at home installation

The risk is the same at home installation as when TDY or TAD

The risk is greater at home installation 
Appendix VI: Survey Administered at

Installations in the United States

43. Why do you believe the risk of a sexual assault differs when at home station versus when TDY or TAD? Please explain.

\section{Demographics}

44. What is your current pay grade?

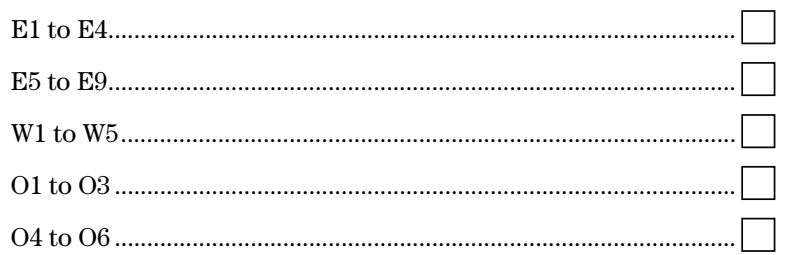

45. What is your branch of service?

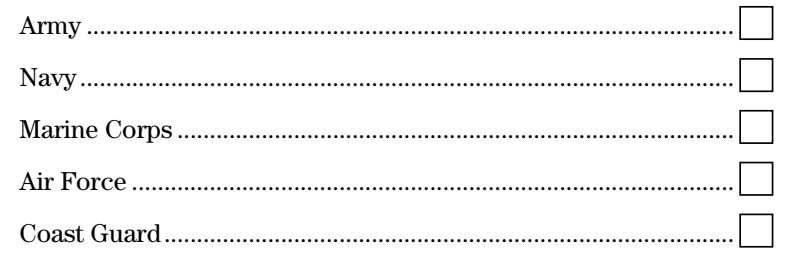

46. What is your component?

Active duty...

Reserve

National Guard... 
Appendix VI: Survey Administered at

Installations in the United States

47. What is your age range?

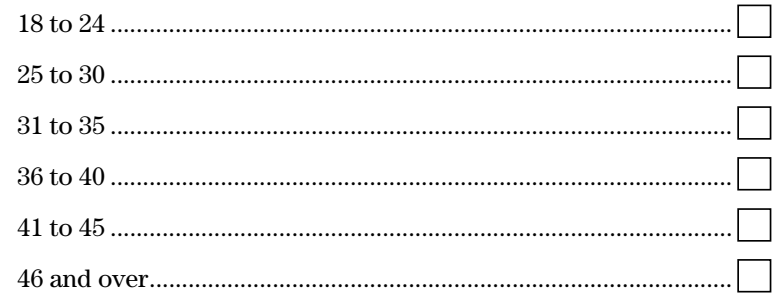

48. What is your gender?

Male....

Female

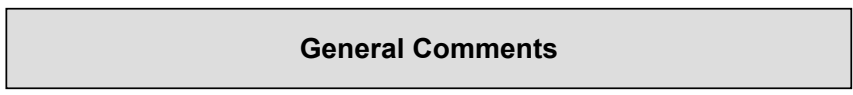

49. With respect to the military services' sexual assault prevention and response programs, what message would you have us (GAO) take back to Congress? 


\section{Appendix VII: Survey Administered at Installations Overseas}

United States Government Accountability Office

\section{G A O Sexual Assault in the Military Services}

\section{Purpose}

The U.S. Government Accountability Office (GAO), an agency of the Congress, is conducting this survey as part of a review on sexual assault prevention and response programs in the military services. The purpose of this survey is to provide insight into the effectiveness of each service's sexual assault policies, training, procedures, and response capabilities. Findings will be used in reports and testimony to Congress.

Providing information on this survey is voluntary and anonymous. All responses are strictly confidential, and no individual responses will be reported. Please do not write your name on this questionnaire. We appreciate you taking the time to complete this important survey.

\section{Directions for Completing This Survey}

We encourage you to answer each question as completely as possible. Before choosing an answer, please read the full question and all response choices carefully. There are no right or wrong answers. Rather, you should answer each question the way that best reflects your personal opinions and experiences. The survey should take approximately 25-30 minutes to complete.

This survey asks about both sexual harassment and sexual assault. When reading the questions, please note whether we are referring to experiences with sexual harassment or sexual assault. 


\section{Command Climate toward Sexual Harassment}

As a reminder, DOD defines sexual harassment as follows:

Sexual harassment - a form of sexual discrimination that involves unwelcome sexual advances, requests for sexual favors, and other verbal or physical conduct of a sexual nature when

submission to such conduct is made either explicitly or implicitly a term or condition of a person's job, pay, or career, or submission to or rejection of such conduct by a person is used as a basis for career or employment decisions affecting that person, or such conduct has the purpose or effect of unreasonably interfering with an individual's work performance or creates an intimidating, hostile, or offensive working environment (DODD 1350.2)

1. At your current location, do you think your direct supervisor (military or civilian) creates a climate that discourages sexual harassment from occurring?

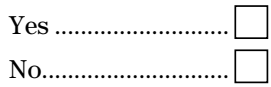

Not sure

2. If sexual harassment should occur at your current location, do you think your direct supervisor (military or civilian) would address it?

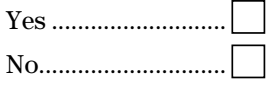

Not sure. 
Unit —Command or operational unit to which you are assigned.

Deployed location-Stationed at a location other than your home station.

Temporary Duty (TDY)/Temporary Additional Duty (TAD)-Travel in which personnel remain under the direct control of their parent organizations (e.g., meetings, conferences, attendance at school or course of instruction).

Home station-The permanent location of active duty units and Reserve Component units. This location may be either inside or outside the Continental United States.

3. In your opinion, is sexual harassment a problem in the following?

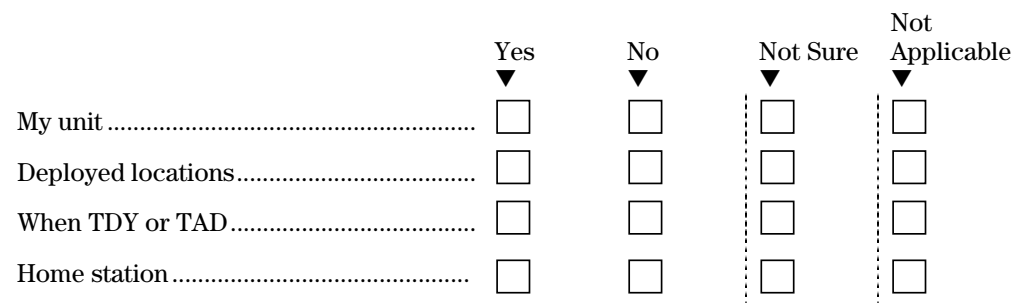

4. How much do your concerns about sexual harassment incidents in the military impact your intention to remain in the military once your commitment is met?
A great deal......
Somewhat
Not at all 
As a reminder DOD defines sexual assault as follows:

Sexual assault - intentional sexual contact, characterized by use of force, physical threat or abuse of authority or when the victim does not or cannot consent. It includes rape, nonconsensual sodomy (oral or anal sex), indecent assault (unwanted, inappropriate contact or fondling), or attempts to commit these acts. Sexual assault can occur without regard to gender or spousal relationship or age of victim. "Consent" shall not be deemed or construed to mean the failure by the victim to offer physical resistance. Consent is not given when a person uses force, threat of force, coercion, or when the victim is asleep, incapacitated or unconscious. (DODD 6495.01)

5. At your current location, do you think your direct supervisor (military or civilian) creates a climate that discourages sexual assault from occurring?

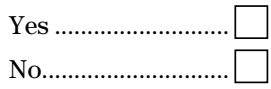

Not sure.

6. If sexual assault should occur at your current location, do you think your direct supervisor (military or civilian) would address it?

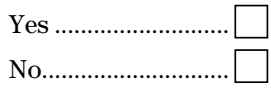

Not sure.

7. At your current location, how likely would you be to report a sexual assault of another servicemember?

Extremely likely

Very likely

Moderately likely

Somewhat likely

Not at all likely 
8. Would you report a personal experience of sexual assault to the following authorities, individuals, or organizations at your current location?

\begin{tabular}{|c|c|c|}
\hline Yes & $\begin{array}{ll} & \text { Not } \\
\text { No } & \text { Sure }\end{array}$ & $\begin{array}{l}\text { Not } \\
\text { Applicable }\end{array}$ \\
\hline \multicolumn{3}{|l|}{ Officer in your chain of command........................ } \\
\hline \multicolumn{3}{|l|}{$\begin{array}{l}\text { Staff noncommissioned officer (NCO) in your } \\
\text { chain of command }\end{array}$} \\
\hline \multicolumn{3}{|l|}{$\begin{array}{l}\text { Noncommissioned officer }(\mathrm{NCO}) \text { in your } \\
\text { chain of command }\end{array}$} \\
\hline \multicolumn{3}{|l|}{ 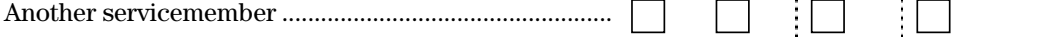 } \\
\hline \multicolumn{3}{|l|}{ 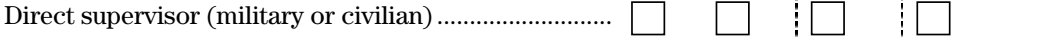 } \\
\hline \multicolumn{3}{|l|}{ 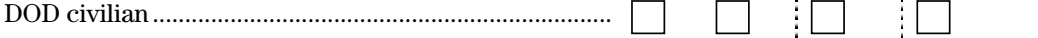 } \\
\hline \multicolumn{3}{|l|}{ 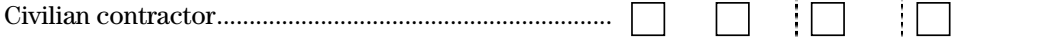 } \\
\hline \multicolumn{3}{|l|}{ Civilian assault crisis centers/hotline/ helpline .............. } \\
\hline \multicolumn{3}{|l|}{ 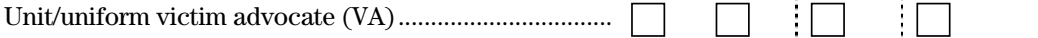 } \\
\hline \multicolumn{3}{|l|}{ 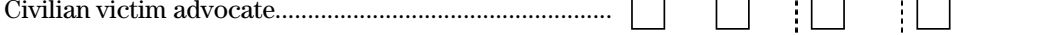 } \\
\hline \multicolumn{3}{|l|}{ Sexual assault response coordinator (SARC) ................. } \\
\hline \multicolumn{3}{|l|}{ 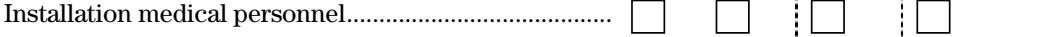 } \\
\hline \multicolumn{3}{|l|}{ 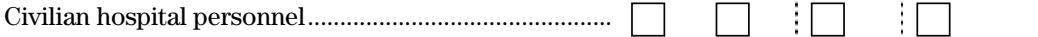 } \\
\hline \multicolumn{3}{|l|}{$\begin{array}{l}\text { Military criminal investigative organizations } \\
\text { (e.g., OSI, CID, NCIS, CGIS) }\end{array}$} \\
\hline \multicolumn{3}{|l|}{$\begin{array}{l}\text { Military police } \\
\text { (e.g., Provost Marshall, Master of Arms) ........................... }\end{array}$} \\
\hline \multicolumn{3}{|l|}{ 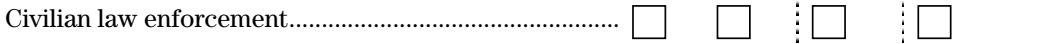 } \\
\hline \multicolumn{3}{|l|}{ 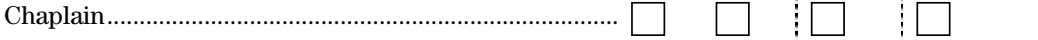 } \\
\hline \multicolumn{3}{|l|}{ 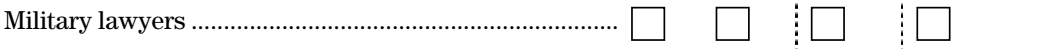 } \\
\hline \multicolumn{3}{|l|}{ 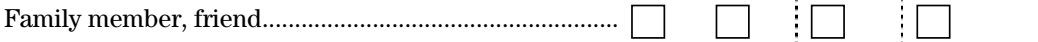 } \\
\hline (n) & : & \\
\hline
\end{tabular}


9. How safe do you feel at your current location from being sexually assaulted in the following places?

\begin{tabular}{|c|c|c|c|c|c|c|}
\hline & $\begin{array}{l}\text { Extremely } \\
\text { safe } \\
\nabla\end{array}$ & $\begin{array}{l}\text { Very } \\
\text { safe } \\
\nabla\end{array}$ & $\begin{array}{l}\text { Moderately } \\
\text { safe } \\
\boldsymbol{\nabla}\end{array}$ & $\begin{array}{l}\text { Somewhat } \\
\text { safe } \\
\nabla\end{array}$ & $\begin{array}{l}\text { Not at all } \\
\text { safe } \\
\nabla\end{array}$ & $\begin{array}{l}\text { Not } \\
\text { applicable } \\
\nabla\end{array}$ \\
\hline 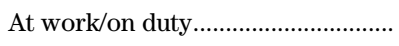 & $\square$ & L & L & L & $\square$ & L \\
\hline $\begin{array}{l}\text { In barracks/living and sleeping } \\
\text { area on installation grounds ............ }\end{array}$ & & L & L & & 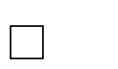 & 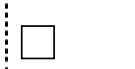 \\
\hline $\begin{array}{l}\text { On installation grounds, } \underline{\text { in other }} \\
\text { areas.............................................. }\end{array}$ & & $\square$ & $\square$ & & $\square$ & $\square$ \\
\hline f installation grounds... & & $\square$ & $\square$ & - & $\square$ & L \\
\hline
\end{tabular}

10. In your opinion, is sexual assault a problem in the following?

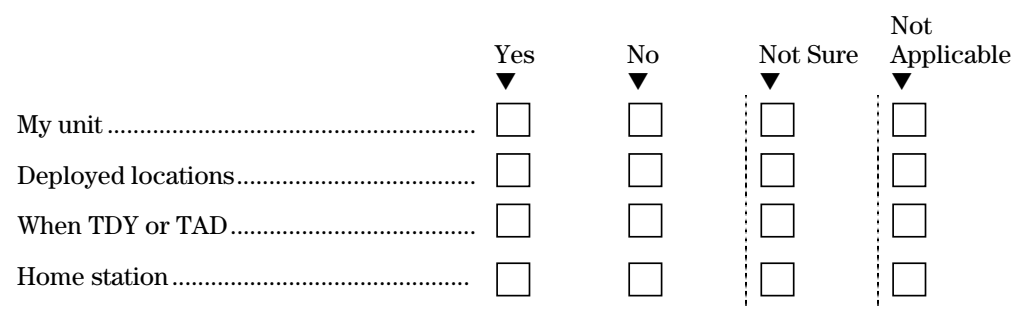

11. How much do your concerns about sexual assault incidents in the military impact your intention to remain in the military once your commitment is met?

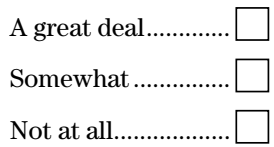

12. Do you agree or disagree with the statement: "Tolerance for sexual harassment creates a perception that sexual assault may be acceptable."

Strongly agree

Agree.

Neither agree nor disagree

Disagree

Strongly disagree 


\section{Sexual Assault Prevention and Response Training}

13. Did you receive pre-deployment training that addressed sexual assault prior to deploying to your current location?

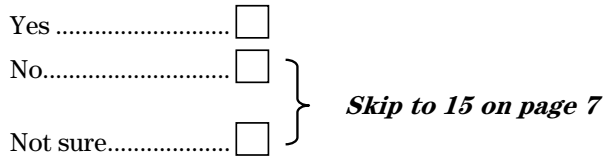

14. Was the training you received that addressed sexual assault prior to deploying in the following formats?

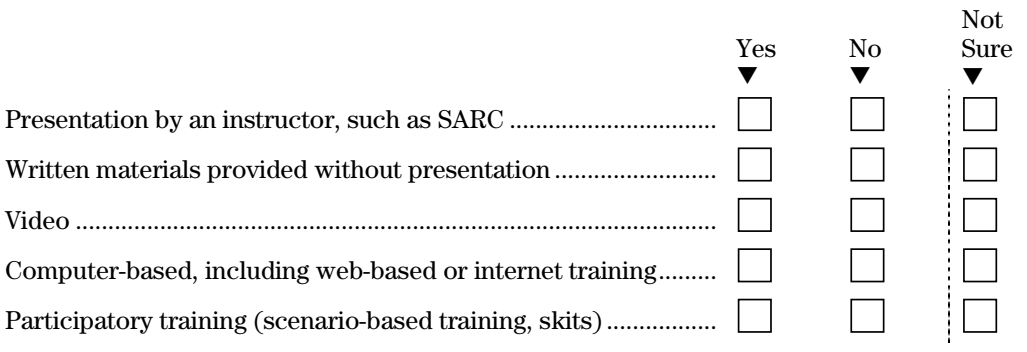

15. Have you attended training that addressed sexual assault issues since you arrived at your current location?

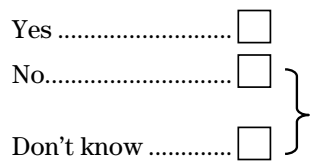

Skip to 17 on page 8 
16. Was the sexual assault-related training you received at your current location in the following formats?

Presentation by an instructor, such as SARC ...........................

\section{Would you know how to do the following at your current location?}

\begin{tabular}{|c|c|c|}
\hline & $\begin{array}{l}\text { Yes } \\
\nabla\end{array}$ & No \\
\hline $\begin{array}{l}\text { Report a sexual assault using the restricted } \\
\text { reporting option........................................................ }\end{array}$ & & \\
\hline 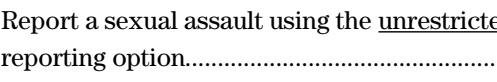 & & \\
\hline 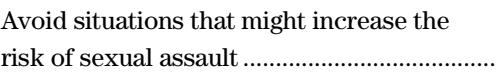 & & \\
\hline Obtain medical care following a sexual assa & & \\
\hline $\begin{array}{l}\text { Obtain counseling or mental health care } \\
\text { following a sexual assault ............................. }\end{array}$ & & \\
\hline Contact your sexual assault response coord & & \\
\hline Contact your victim advocate (VA).... & & \\
\hline $\begin{array}{l}\text { Obtain additional resources or information } \\
\text { on the areas above }\end{array}$ & & \\
\hline
\end{tabular}


We understand that this is a very difficult subject. We would like to reiterate that all responses are confidential, and no individual's information is identifiable.

18. How much of a problem are the following situations at your current location?

$\begin{array}{llll}\text { Serious } & \text { Moderate } & \text { Minor } & \text { Not a } \\ \text { problem } & \text { problem } & \text { problem } & \text { problem } \\ \nabla & \boldsymbol{\nabla} & \boldsymbol{\nabla} & \end{array}$

Sexual stories or jokes that were offensive to you

Others referring to people of your gender in insulting or offensive terms ..

Unwelcome attempts to draw you into a discussion of sexual matters (e.g., attempts to discuss or comment on your sex life).

Offensive remarks about your appearance, body, or sexual activities.

Gestures or body language of a sexual nature that embarrassed or offended you ...

Bribes or some kind of reward for special treatment to engage in sexual behavior.

Threats of retaliation or revenge for not being sexually cooperative (such as by mentioning an upcoming review or evaluation)

Touching in a way that made you feel uncomfortable, such as attempts to stroke, fondle, or kiss you

Implications of better assignments or better treatment if you were sexually cooperative

Bad treatment for refusing to have sex .<smiles>C1CCC1</smiles> 
19. If you were sexually assaulted and could obtain medical and/or mental health care while (a) remaining anonymous and (b) being certain that there would not be an investigation, would you report the incident?

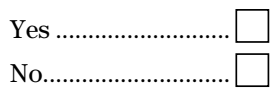

Not sure

20. Were you sexually assaulted during the past 12 months while in the military?

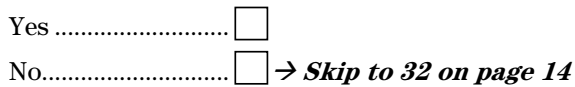

21. In which of the following locations did the incident occur?

At home installation inside the United States.

At home installation outside the United States

At a deployed location

While TDY or TAD

22. Did you report the incident in any of the following ways to any authorities, individuals, or organizations?

I used restricted (confidential) reporting..

I used unrestricted reporting...

I reported it, but I'm not sure whether I used restricted

(confidential) or unrestricted reporting.

I did not report the incident

$\rightarrow$ Skip to 24 on page 12 
23. To which authorities, individuals, or organizations did you report the incident?

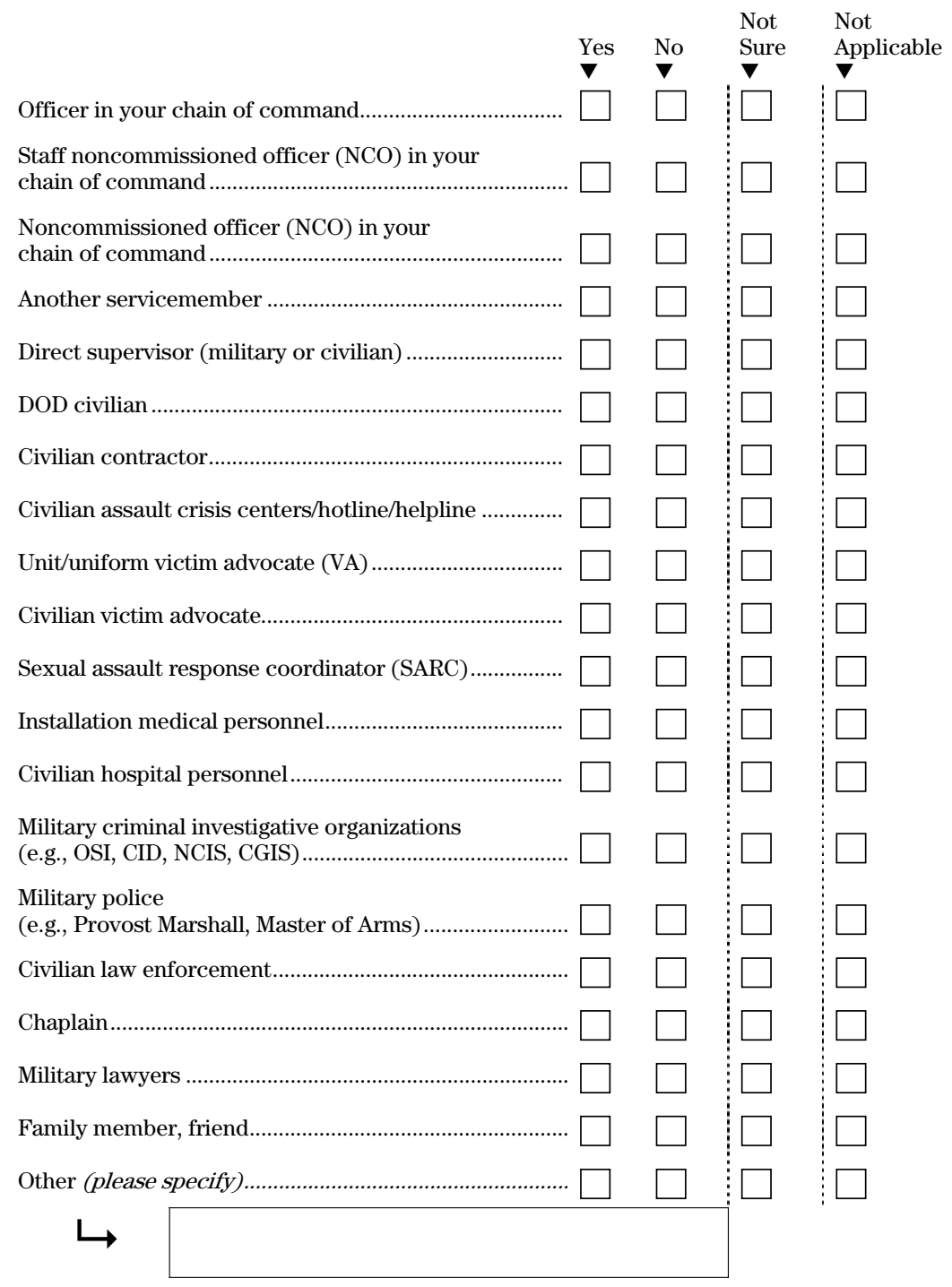

Please Skip to Question 25 on page 12 after completing Question 23 
24. For which of the following reason(s) did you not report the incident?

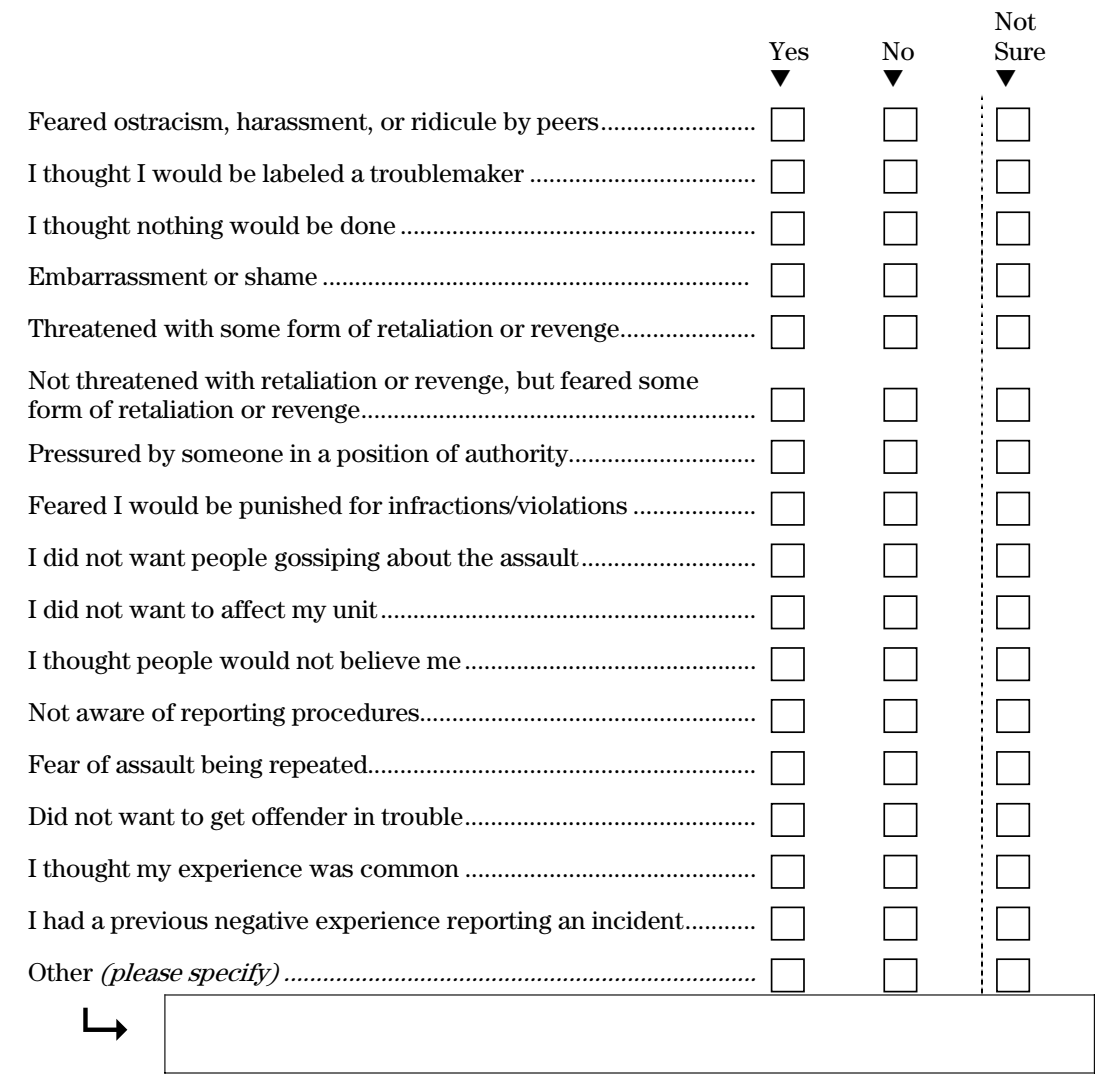

25. Did you receive medical care as a result of the incident?

I received medical care.......

I did not receive medical care because care was not available.

I did not seek medical care . 
Appendix VII: Survey Administered at

Installations Overseas

26. Where did you receive medical care for the incident?

Military treatment facility (MTF)......

Civilian hospital.

Other (please specify).

$\longrightarrow$

27. How satisfied or dissatisfied were you with the quality of medical care you received?

Very satisfied

Satisfied .

Neither satisfied nor dissatisfied

Dissatisfied.

Very dissatisfied

28. Why were you satisfied or dissatisfied with the quality of medical care you received?

29. Did you receive counseling or mental health care as a result of the incident?

I received counseling or mental health care.

I did not received counseling or mental health care

because assistance was not available

Skip to 32 on page 14

I did not seek counseling or mental health care 
30. How satisfied or dissatisfied were you with the quality of counseling or mental health care you received?

Very satisfied.

Satisfied

Neither satisfied nor dissatisfied

Dissatisfied.

Very dissatisfied.

31. Why were you satisfied or dissatisfied with the quality of mental health care or counseling you received?

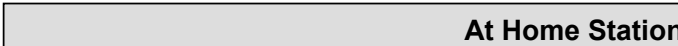

Home station-The permanent location of active duty units and Reserve Component units This location may be either inside or outside the Continental United States.

32. Have you served at your home station at any time during the past 12 months?

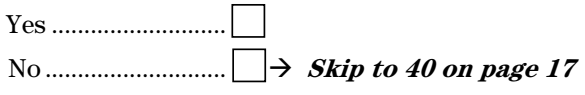

33. What is your home station?

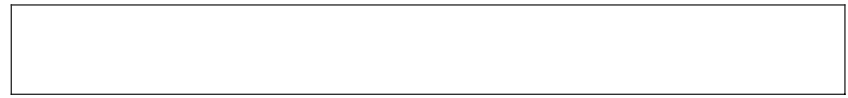




\section{Experiences At Your Current Location versus At Your Home Station}

Unit —Command or operational unit to which you are assigned.

Home station-The permanent location of active duty units and Reserve Component units. This location may be either inside or outside the Continental United States.

Deployed-Stationed at a location other than your home station.

PLEASE ANSWER THE FOLLOWING QUESTIONS FROM THE PERSPECTIVE OF THE LOCATION YOU INDICATED IN QUESTION 33.

34. Do you think sexual harassment incidents are taken more or less seriously at your current location or when at home station?

More seriously at current location

Equally seriously at current location as when at home station

Less seriously current location..

35. Do you think sexual assault incidents are taken more or less seriously at your current location or when at home station?

More seriously at current location

Equally seriously at current location as when at home station

Less seriously current location...

36. Do you think servicemembers in your unit would be more or less likely to report a sexual assault of another servicemember at your current location or when at home station?

More likely at current location.

Equally likely at current location as when at home station

Less likely at current location.

Not sure. 
37. How safe did you feel from being sexually assaulted at the following times and locations when at home station?

$\begin{array}{llllll} & \begin{array}{l}\text { Extremely } \\ \text { Safe }\end{array} & \begin{array}{l}\text { Very } \\ \text { safe }\end{array} & \begin{array}{l}\text { Moderately } \\ \text { safe }\end{array} & \begin{array}{l}\text { Somewhat } \\ \text { safe }\end{array} & \begin{array}{l}\text { Not at all } \\ \text { safe }\end{array}\end{array}$

On installation

grounds, $\underline{\text { in other }}$

areas

Off installation

grounds

38. Do you believe the risk for a sexual assault to occur is less or greater at your current location versus when at home station?

The risk is less at current location

The risk is the same at current location

as when at home station

The risk is greater at current location

39. Why do you believe the risk of a sexual assault occurring differs when at home station versus when deployed? 


\section{Experiences At Your Current Location versus Other Locations}

Unit-Command or operational unit to which you are assigned.

40. Not including your home station, have you served at another location at any time during the past 12 months?

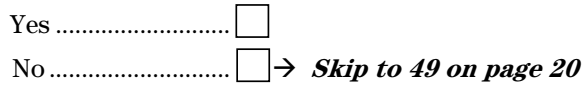

41. Excluding your current location, which of the following location(s) did you serve in during the past 12 months?

\section{On Land}

Afghanistan

\section{At Sea}

Persian/Arabian Gulf

(Arabian Sea North of 10 degrees north

latitude and west of 68 degrees east longitude,

Gulf of Aden, Gulf of Oman, Persian Gulf, or Red Sea ........

Kosovo Area

(Adriatic Sea or Ionian Sea North of the $39^{\text {th }}$ Parallel) 
42. Of the locations you indicated above, where did you serve the longest amount of time?

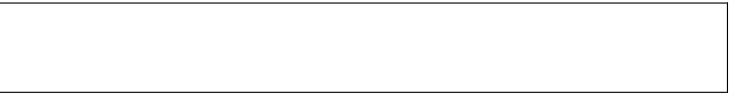

PLEASE ANSWER THE FOLLOWING QUESTIONS FROM THE PERSPECTIVE OF THE LOCATION YOU INDICATED IN QUESTION 42.

43. Do you think sexual harassment incidents are taken more or less seriously at your current location or the other location?

More seriously at current location

Equally seriously at current location as the other location .........

Less seriously current location.

44. Do you think sexual assault incidents are taken more or less seriously at your current location or the other location?

More seriously at current location

Equally seriously at current location as the other location .........

Less seriously at current location

45. Do you think servicemembers in your unit would be more or less likely to report a sexual assault of another servicemember at your current location or the other location?

More likely at current location

Equally likely at current location as the other location........

Less likely at current location

Not sure. 
46. How safe did you feel from being sexually assaulted at the following times and locations at the other location?

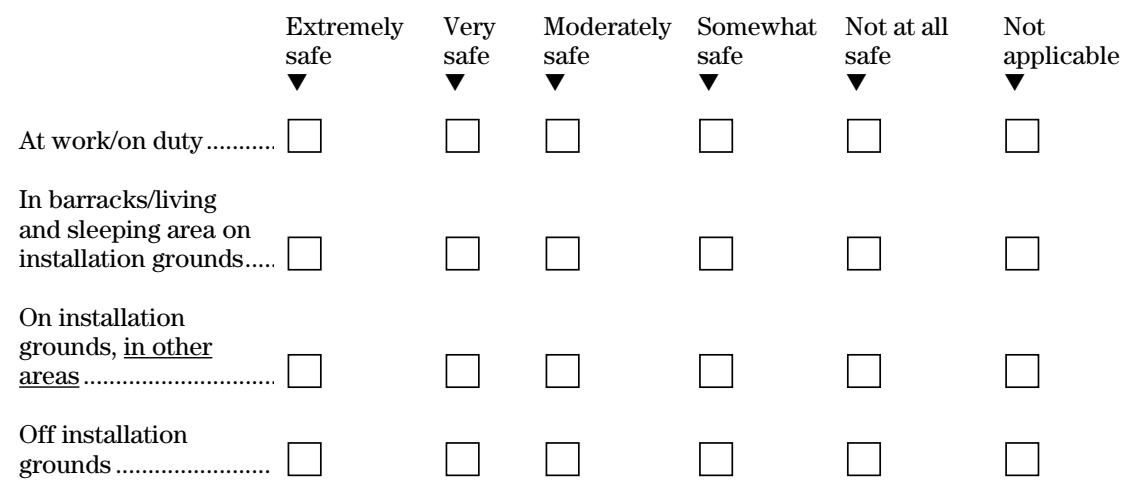

47. Do you believe the risk for a sexual assault to occur is less or greater at your current location versus the other location?

The risk is less at current location.

The risk is the same at current location as

as the other location

$\rightarrow$ Skip to 49 on page 20

The risk is greater at current location

48. Why do you believe the risk of a sexual assault occurring differs at your current location versus the other location? 
49. What is your current pay grade?

E5 to $\mathrm{E} 9$

50. What is your branch of service?

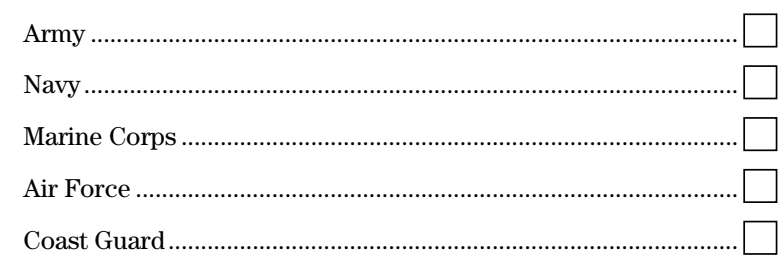

51. What is your component?

Active duty...

Reserve .

National Guard.

52. What is your age range?

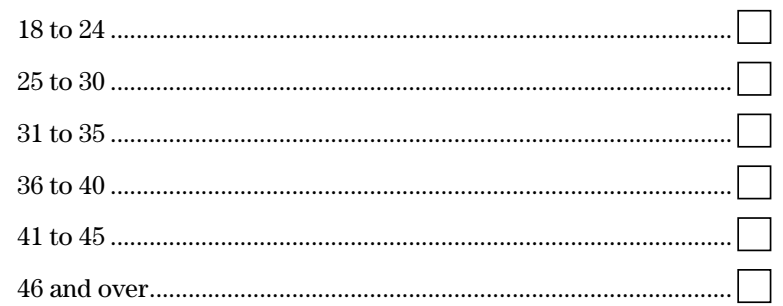

\section{What is your gender?}

Male.

Female 
Appendix VII: Survey Administered at

Installations Overseas

\section{General Comments}

54. With respect to the military services' sexual assault prevention and response programs, what message would you have us (GAO) take back to Congress? 


\section{Appendix VIII: GAO Contact and Staff Acknowledgments}

In addition to the contact named above, Marilyn K. Wasleski (Assistant Director), Krislin Bolling, Joanna Chan, Pawnee A. Davis, Konstantin Dubrovsky, K. Nicole Harms, Wesley A. Johnson, Ronald La Due Lake, Stephen V. Marchesani, Ayeke P. Messam, Amanda K. Miller, and Cheryl A. Weissman made significant contributions to the report. In addition, Sara G. Cradic, Kim Mayo, Sharon Reid, and Norris Smith III provided assistance during site visits. 
The Government Accountability Office, the audit, evaluation, and investigative arm of Congress, exists to support Congress in meeting its constitutional responsibilities and to help improve the performance and accountability of the federal government for the American people. GAO examines the use of public funds; evaluates federal programs and policies; and provides analyses, recommendations, and other assistance to help Congress make informed oversight, policy, and funding decisions. GAO's commitment to good government is reflected in its core values of accountability, integrity, and reliability.

Obtaining Copies of GAO Reports and Testimony

\section{Order by Mail or Phone}

The fastest and easiest way to obtain copies of GAO documents at no cost is through GAO's Web site (www.gao.gov). Each weekday, GAO posts newly released reports, testimony, and correspondence on its Web site. To have GAO e-mail you a list of newly posted products every afternoon, go to www.gao.gov and select "E-mail Updates."

The first copy of each printed report is free. Additional copies are $\$ 2$ each. A check or money order should be made out to the Superintendent of Documents. GAO also accepts VISA and Mastercard. Orders for 100 or more copies mailed to a single address are discounted 25 percent. Orders should be sent to:

U.S. Government Accountability Office

441 G Street NW, Room LM

Washington, DC 20548

To order by Phone: Voice: (202) 512-6000

TDD: (202) 512-2537

Fax: (202) 512-6061
To Report Fraud, Waste, and Abuse in Federal Programs

\section{Congressional} Relations

\section{Contact:}

Web site: www.gao.gov/fraudnet/fraudnet.htm

E-mail: fraudnet@gao.gov

Automated answering system: (800) 424-5454 or (202) 512-7470

Ralph Dawn, Managing Director, dawnr@gao.gov, (202) 512-4400 U.S. Government Accountability Office, 441 G Street NW, Room 7125 Washington, DC 20548

\section{Public Affairs}

Chuck Young, Managing Director, youngc1@gao.gov, (202) 512-4800 U.S. Government Accountability Office, 441 G Street NW, Room 7149 Washington, DC 20548 